\title{
III. Die Besatzungsmächte als „Interessen- vertreter" Westdeutschlands in der OEEC April 1948 bis Oktober 1949
}

Die Entscheidung über die aktive Beteiligung der Westzonen hatte zunächst noch keinen direkten Einfluß auf die Planung und Koordinierung der Wiederaufbaumaßnahmen. Diese Arbeit hatten sich erst einmal die drei Militärregierungen vorbehalten. Zumindest in der Anfangsphase der OEEC war dies, wie die Deutschen rasch begriffen, eher ein Vorteil. Ihre Außenseiterposition machte eine selbstbewußte Interessenpolitik in der von ehemaligen Kriegsgegnern dominierten Organisation praktisch unmöglich. Solche Rücksichten mußten die Amerikaner nicht nehmen, die überdies noch ihre Macht als „Geldgeber" ausspielen konnten. Die deutschen Experten, die an den Sitzungen in Paris teilnehmen durften, hatten somit anderthalb Jahre lang Gelegenheit, die Arbeitsweise einer internationalen Organisation kennenzulernen und sich auf den neuen Stil multilateraler Außenpolitik einzustellen. Daß dies relativ problemlos gelang, war sicherlich auch das Verdienst unverbrauchter und unbelasteter Kräfte, die für die größtenteils diskreditierten Diplomaten alter Prägung einspringen mußten. In die Formulierung handels- und außenpolitischer Strategien gingen dennoch Erfahrungen aus früheren Zeiten ein; insbesondere der Einsatz wirtschaftlicher Macht zur Überwindung der politischen Ohnmacht, wie er in der Weimarer Republik ansatzweise erprobt worden war, diente manchen deutschen Politikern, Spitzenbeamten und Unternehmern als Vorbild. Die Unterschiede zur damaligen Situation wurden jedoch bald deutlich: Die Entscheidungsgewalt lag bei den Besatzungsmächten, die alliierten Kontrollen waren wesentlich schärfer, die Eingriffe in die wirtschaftlichen und politischen Strukturen gingen tiefer. Ein neuer Aufstieg, so hatte es den Anschein, würde schwieriger und langwieriger werden.

\section{Die Kontroverse um die Teilnahme deutscher Repräsentanten an der Gründungsversammlung der OEEC}

Die Londoner Vereinbarung der drei Westmächte über die Einbeziehung der Westzonen in das European Recovery Program hatte die Frage der deutschen Mitarbeit recht eindeutig entschieden: Auf der „politischen“ Ebene der geplanten europäischen Organisation sollten Vertreter der Besatzungsbehörden die Interessen der Bizone und der französischen Zone wahrnehmen; lediglich auf der „technischen“ Ebene war es diesen freigestellt, deutsche Berater heranzuziehen. Im entsprechenden CEEC-Beschluß fehlte die- 
ser letzte Punkt sogar. ${ }^{1}$ Die Voraussetzungen für einen ersten „Auftritt“ bei der Vollversammlung der „Sechzehn“, die zugleich die vor allem von den Vereinigten Staaten geforderte „ständige Organisation“ aus der Taufe heben sollte, waren also eher ungünstig.

Der erwartungsvollen, bisweilen euphorischen Stimmung in den bizonalen Verwaltungsinstanzen, bei den Länderregierungen und in der Öffentlichkeit, hervorgerufen durch die Nachricht über die aktive Beteiligung an den Pariser Arbeiten, tat dies freilich keinen Abbruch. ${ }^{2}$ Beflügelt von der Aussicht auf ein baldiges internationales Comeback, wurden mancherorts bereits in der ersten Märzhälfte Auswahlkriterien und Personalvorschläge diskutiert. Dabei ging es freilich weniger um fachliche Kompetenz oder internationales Renommee möglicher Kandidaten, sondern in erster Linie um die Frage, welche deutschen Instanzen eine solche Aufgabe überhaupt wahrnehmen sollten - die Länderregierungen oder die im Aufbau begriffenen „zentralen“ Einrichtungen. Zu den eifrigsten Verfechtern der ersten Lösung zählte der bayerische Ministerpräsident Hans Ehard. Die Länderchefs als Verkörperung des föderalistischen Prinzips, so sein Kalkül, würden gerade in Paris eher akzeptiert werden als die Spitzen der „zentralisierten“ Behörden. Als amtierender Präsident des Länderrates rechnete er sich selbstverständlich gute Chancen aus, selbst nominiert zu werden. Um so größer war die Enttäuschung in Bayern, als sich die französische Regierung diesem Vorschlag verschloß und Amerikaner und Briten mit der Einrichtung einer Dienststelle in Frankfurt den „zentralisierten“ Weg beschritten. ${ }^{3}$ Die Frage, ob überhaupt Deutsche an der nächsten CEEC-Konferenz teilnehmen und wer diese Personen sein würden, war damit noch nicht beantwortet; eine gewisse Vorentscheidung über die Zuständigkeiten in ERP-Angelegenheiten bedeutete die „Frankfurter Lösung“ indessen schon: In der Bizone sollten nicht die Länderregierungen, sondern die überzonalen Organe die Planungs- und Koordinierungsaufgaben übernehmen. Lediglich in der französischen Zone war eine stärkere Mitsprache der Länder vorgesehen. Deutlich wurde aber vor allem, daß deutsche Hoffnungen, die alliierte Politik bereits in dieser ersten Phase des ERP beeinflussen zu können, verfrüht waren.

Dabei lehnten die Verantwortlichen auf amerikanischer und britischer Seite eine Einladung hochrangiger deutscher Politiker zur konstituierenden Sitzung der „ständigen Organisation" keineswegs von vornherein ab. Auf britische Initiative hin hatte sich das Bipartite Board am 24. März mit dem Problem befaßt und war übereingekommen, daß General Robertson die Bizone in Paris vertreten sollte. Neben Beratern aus beiden Ländern sollten ihn außerdem drei Deutsche begleiten: die Vorsitzenden des Exekutivrates, des Wirtschafts- und des Länderrates - freilich ohne selbst das Wort ergreifen zu dürfen. Die Entscheidung für den britischen Militärgouverneur begründete Clay mit dem Wunsch der Vereinigten Staaten, den Charakter des CEEC als rein europäische Organi-

\footnotetext{
' Entwurf eines CEEC-Beschlusses über die Teilnahme Deutschlands, o. D., BA, NL Pünder, 704.

2 Vgl. Vermerk für Makins v. 13. 3. 1948 u. Vermerk Stevens v. 6. 4. 1948, PRO, FO 371/70732. Grundsätzlich Werner Bührer, Auftakt in Paris. Der Marshallplan und die deutsche Rückkehr auf die internationale Bühne 1948/49, in: VfZ 36 (1988), S. 529-556, bes. S. 534 f.

${ }^{3}$ Telegramm Keller v. 16. 3. 1948 u. Keller an Tarbé de Saint Hardouin v. 24. 3. 1948, MAE, Y 1944-49, Vol. 131. Keller war franz. Generalkonsul in München. - Ein kleiner Trost für Ehard und seine Mitstreiter dürfte gewesen sein, daß als Leiter der ständigen Pariser Vertretung der geplanten Frankfurter Dienststelle, Keller zufolge, mit dem ehemaligen Wilhelmstraßen-Diplomaten und Pariser Botschaftssekretär (bis 1933) Baron von Brand ein Landsmann im Gespräch war.
} 
sation zu respektieren. ${ }^{4}$ Als das Vorhaben Ende März in Paris bekannt wurde ${ }^{5}$, antwortete das französische Außenministerium mit massiven Protesten: Die Anwesenheit deutscher Repräsentanten beim Gründungsakt der europäischen Organisation, so ließ man über die Botschafter in Washington und London mitteilen, erscheine gänzlich inopportun; lediglich „technische“ Experten waren die Franzosen bereit zu akzeptieren. ${ }^{6}$

Die Reaktionen fielen für den Quai d' Orsay eher enttäuschend aus: Sir Ivone Kirkpatrick vom Foreign Office wies Botschafter Massigli darauf hin, daß der französische Militärgouverneur Koenig offiziellen Verlautbarungen zufolge selbst beabsichtige, sich von den Ministerpräsidenten von Südbaden, Württemberg-Hohenzollern und RheinlandPfalz zur Gründungsversammlung begleiten zu lassen.' Noch weniger Erfolg hatte die französische Demarche in Washington. Der zuständige Abteilungsleiter im State Department verteidigte gegenüber Bonnet ausdrücklich das Motiv der beiden Militärgouverneure, nämlich der deutschen Öffentlichkeit die westliche Bereitschaft zu demonstrieren, das Land Schritt für Schritt in die internationale Gemeinschaft zurückzuführen. Zwar sicherte der Beamte eine Überprüfung der Entscheidung zu, doch deutete er gleichzeitig an, es werde nicht leicht sein, die beiden Generäle umzustimmen. ${ }^{8}$ Französische Befürchtungen, die deutschen Politiker könnten in Paris möglicherweise Opfer von „Zwischenfällen“ werden, hielten die Amerikaner für unbegründet. ${ }^{9}$ Mit diesen mageren Ergebnissen gab sich das Außenministerium in Paris verständlicherweise nicht zufrieden. Das Foreign Office wurde auf Veranlassung Alphands prompt davon unterrichtet, daß es sich bei dem Vorhaben General Koenigs um eine „initiative purement locale“ handle, „motivée par la croyance dans laquelle se trouvaient nos autorités en Allemagne que la décision d' envoyer à Paris des hommes politiques allemands au côté du Général Robertson avait déjà été prise“. Dieser Entschluß, daran ließ Alphand kaum einen Zweifel, würde rückgängig gemacht werden. Die ablehnende Haltung Frankreichs blieb unverändert. ${ }^{10} \mathrm{Da}$ Clay und Robertson zweifelsohne die „Hauptdrahtzieher“ des geplanten ersten Auftritts deutscher Politiker waren, bestanden gewisse Hoffnungen, die Regierungen in London und Washington doch noch zum Nachgeben veranlassen zu können, wenn es den Diplomaten des Quai d' Orsay gelang, die beiden zu isolieren. Die Chancen dafür standen nicht schlecht, denn auch der amerikanische Botschafter an der Seine, Caffery, machte sich den französischen Standpunkt zu eigen. Die Befürchtungen, die beabsichtigte Einladung sei Wasser auf die Mühlen der kommunistischen Propaganda, hielt er für vollauf gerechtfertigt, der mögliche Schaden in Frankreich erschien ihm größer als der Nutzen in Westdeutschland. „I understand and appreciate the propaganda benefits obtainable from the point of view of German public opinion in the precence of these German political figures at the CEEC signing, but it seems to me that

\footnotetext{
${ }^{4}$ Murphy an Sec State v. 4. 4. 1948, NA, RG 59, 840.50 Recovery/4-448.

${ }^{5}$ Eine entsprechende Mitteilung des amerikanischen Konsuls in Baden-Baden vom 30. März wurde umgehend nach Paris und Berlin gemeldet; Telegramm Klevanski v. 30. 3. 1948, MAE, Y 1944-49, Vol. 131.

6 Vermerk Klevanski v. 2. 4. 1948, AO, Eco I A 5c.

7 Massigli an Außenministerium v. 2. 4. 1948, Archives Nationales, Paris (künftig AN), 457 AP 22 (Papiers Georges Bidault).

8 Bonnet an Außenministerium v. 2. 4. 1948, AN, 457 AP 22.

${ }^{9}$ Brit. Botschaft Washington an Foreign Office v. 3. 4. 1948, PRO, FO 371/70732. Konkrete Beweise für diese wiederholt vorgebrachten Warnungen blieben die französischen Diplomaten allerdings schuldig.

10 Massigli an Außenministerium v. 3. 4. 1948, AN, 457 AP 22.
} 
bringing the Germans in on a working level in itself represents an important advance. To accelerate the pace still more would seriously jeopardize the progress already made." Antideutsche Gefühle, so warnte er nachdrücklich, seien keineswegs nur bei der extremen Rechten und den Kommunisten virulent: "If the government's policy is suddenly subjected to powerful opposition attacks, our progress toward an accelerated evolution of French thinking along the lines of our own policy may well suffer an abrupt check and a new start would have to be made under unfavourable conditions. " 11

Um die Hindernisse beiseite zu räumen, die einer deutschen Mitarbeit noch im Wege standen, trafen am 5. April 1948 Vertreter der drei Regierungen und Besatzungsbehörden unter Alphands Vorsitz in Paris zusammen. ${ }^{12}$ Außer der leidigen Frage der Anwesenheit Deutscher bei der Gründungszeremonie waren nämlich auch die Modalitäten des Beitritts und die Gültigkeit der Meistbegünstigungsklausel für den Handel der Westzonen mit den übrigen Teilnehmerländern umstritten. Und fast jedesmal kamen die gegensätzlichen Standpunkte zum Vorschein, die Frankreich auf der einen, Großbritannien und die Vereinigten Staaten auf der anderen Seite hinsichtlich der Eingliederung der Westzonen in den entstehenden westeuropäischen Verbund einnahmen. Während die Regierung in Paris darauf bedacht blieb, den besonderen, aus ihrer Sicht minderen Status der Besatzungszonen bereits auf der „protokollarischen“ Ebene deutlich werden zu lassen, bestanden die amerikanischen und britischen Verantwortlichen auf einer - zumindest formalen - Gleichbehandlung. Dieser Dissens zeigte sich bei der Festlegung der Aufnahmemodalitäten darin, daß Alphand aus „psychologischen“ Gründen dafür plädierte, das Gründungsdokument nur von den sechzehn Staaten unterzeichnen zu lassen; im Anschluß daran sollten die Bizone und die französische Zone durch die Unterzeichnung eines separaten Protokolls ihren Beitritt zum Abkommen vollziehen. Weil sie eine solche Vorgehensweise als diskriminierend empfanden, votierten die amerikanischen und britischen Unterhändler für einen „direkten“ Beitritt - ebenfalls aus „psychologischen" Gründen, in diesem Fall aber aus Rücksicht auf die Deutschen. Der Wirtschaftsexperte des Quai d' Orsay beugte sich schließlich dem Druck vor allem der Amerikaner, verlangte aber, eine Klausel in den Vertragstext aufzunehmen, welche die Militärgouverneure auf die bereits existierenden internationalen Vereinbarungen verpflichtete. "The French clearly feared“, so kommentierte einer der britischen Unterhändler, „that the signature on behalf of Germany of an agreement with no reservation maintaining present limitations imposed on the German economy, would mean that the Germans would at a later stage appeal to the European Recovery Agreement as justification for building up their industrial strength to a degree, and in ways inconsistent, with the policy of the Occupying Authorities." Da erneut keine Einigung erzielt werden konnte, schlug Berthoud vom Foreign Office vor, die Militärgouverneure sollten bei der Unterzeichnung eine entsprechende mündliche Erklärung abgeben, die zu Protokoll genommen werden sollte. Während sich in diesem Punkt also ein Kompromiß abzeichnete, war die Teilnahme deutscher Politiker nach wie vor umstritten. Alphand blieb hart: „It migth seem sentimental, but it was too early to invite Germans to come to a solemn ceremony of

1 Caffery an Sec State v. 5. 4. 1948, NA, RG 59, 840.50 Recovery/4-548.

12 Vgl. Caffery an Sec State v. 6. 4. 1948, FRUS 1948, III, S. 409-410; Telegramm an Foreign Office v. 6. 4. 1948, PRO, FO $371 / 70732$ (dort auch das Zitat); Außenministerium an Botschaften in London u. Washington, Telegramm-Kopie v. 7.4. 1948, AO, Eco I A 5a. 
signature in the Quai d' Orsay. German technical advice was not needed and German politicians were not wanted." Der amerikanische Einwand, gerade durch eine persönliche Anwesenheit könne die deutsche Zustimmung zum Abkommen am sinnfälligsten dokumentiert werden, vermochte die Franzosen ebensowenig umzustimmen wie der britische Kompromißvorschlag, wenigstens einen - in der zweiten Reihe postierten deutschen Berater als Begleiter des Bizonenvertreters zuzulassen; die Entscheidung wurde deshalb den drei Regierungen überlassen. Einzig in der Frage der Meistbegünstigung verliefen die Fronten anders: Sowohl die britischen als auch die französischen Unterhändler lehnten die Aufnahme einer entsprechenden Vorschrift in die multilaterale Vereinbarung ab; ein kleinerer Kreis von Experten wurde deshalb mit der Klärung beauftragt.

Die Verlagerung der Streitfragen auf die Regierungsebene erhöhte die Chancen, daß die französischen Verantwortlichen ihre harte Linie doch noch durschsetzen konnten. General Clay, der in Paris zu Recht als treibende Kraft hinter der umstrittenen Einladung galt, war sich dessen wohl bewußt und forderte seine Regierung zu einer unnachgiebigen Haltung auf: „Germany is too important in ERP not to make this fine gesture,

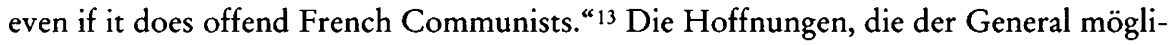
cherweise in Couve de Murville vom Quai d' Orsay gesetzt haben mochte, der - wohl als einziger prominenter französischer Diplomat - Clays Standpunkt teilte und bei Bidault in diesem Sinne intervenieren wollte, erfüllten sich nicht. ${ }^{14}$ Paris blieb unnachgiebig, und in London und Washington genossen die Interessen Frankreichs Vorrang. Als erster schwenkte Bevin, ungeachtet eventueller negativer Reaktionen in den Westzonen, auf die französische Linie ein. ${ }^{15}$ Mit diesem Teilerfolg in der Tasche unternahm Botschafter Bonnet einen erneuten Vorstoß, um die von Clay verteidigte Teilnahme deutscher Politiker zu Fall zu bringen: „J' ai ajouté que si le Général Clay parait y attacher une grande valeur nous ne pouvions que souligner combien il serait regrettable que le commandant en chef américan apparaisse comme patronnant la première visite d' hommes politiques allemands dans une France libre depuis celle de Ribbentrop à Georges Bonnet." 16 Das State Department gab dem französischen Drängen schließlich nach, nicht zuletzt, um unerwünschte antideutsche Proteste zu verhindern. Solche Demonstrationen, so die Befürchtung, könnten sich nachteilig auf die Wiederaufbauplanungen und möglicherweise auch auf das Klima in Westdeutschland auswirken. Eine gesonderte Deklaration der Militärgouverneure, daß durch den Beitritt bestehende internationale Abkommen nicht berührt würden, lehnten die Verantwortlichen in Washington jedoch weiterhin ab. ${ }^{17} \mathrm{Obwohl}$ die britische Regierung mittlerweile auch in diesem Punkt Konzessionsbereitschaft erkennen ließ, blieben die Amerikaner bei ihrem „Nein“, weil sie den Anschein vermeiden wollten, als seien die Westzonen „some sort of second-class member“; lediglich eine Willenserklärung zur aktiven Mitarbeit Westdeutschlands am

\footnotetext{
13 Clay an Noce v. 7. 4. 1948, Clay Papers II, S. 619.

${ }^{14}$ Murphy an Hickerson v. 8. 4. 1948, FRUS 1948, II, S. 169-170.

15 Douglas an Sec State v. 7. 4. 1948, MAE, Y 1944-49, Vol. 131; Foreign Office-Telegramm v. 8. 4. 1948, PRO, FO 371/70732.

16 Bonnet an Außenministerium v. 9. 4. 1948, MAE, Y 1944-49, Vol. 131. Vgl. auch Bonnet an Außenministerium v. 7. 4. 1948, ebenda; Aide-mémoire frz. Regierung v. 7. 4. 1948, NA, RG 59, 840.50 Recovery/4 748 .

17 Lovett an Botschaft Paris v. 10. 4. 1948, FRUS 1948, III, S. 418-419.
} 
Wiederaufbau erschien ihnen akzeptabel. ${ }^{18}$ Damit deutete sich eine Lösung an, die beide Seiten zufriedenstellen konnte. Die französische Regierung, Hauptgewinnerin bei diesem Verhandlungspoker, verhinderte den ersten internationalen Auftritt deutscher Politiker nach dem Kriege, das State Department, daß die ungleiche Behandlung Westdeutschlands durch eine besondere Erklärung der Militärgouverneure noch zusätzlich unterstrichen wurde. Mehr als einen Teilerfolg konnten die amerikanischen Unterhändler auch in der Kontroverse um die Meistbegünstigungsklausel nicht erzielen. Pierre Baraduc und Harry Lintott lehnten die Aufnahme eines entsprechenden Passus' in das Gründungsdokument mit dem Hinweis ab, dieses Problem sei Gegenstand der Verhandlungen über das „General Agreement on Tariffs and Trade“ (GATT). Es sei äußerst schwierig, wenn nicht unmöglich, berichtete Caffery ernüchtert nach Washington, die sechzehn Nationen dazu zu bewegen, das Prinzip der Meistbegünstigung zugunsten Westdeutschlands in den Vertragstext aufzunehmen. ${ }^{19}$ Die Experten einigten sich schließlich auf eine Formel, in welcher die Meistbegünstigung grundsätzlich bejaht, ihre Verwirklichung aber auf einen späteren Zeitpunkt verschoben wurde. ${ }^{20}$

Clay, der sich über die französische "Sentimentalität“ ereiferte und eine konsequente amerikanische Deutschlandpolitik forderte ${ }^{21}$, rückte aus Verärgerung über den französischen Vorschlag sogar von seinem ursprünglichen Plan ab, Angehörige der amerikanischen Militärregierung als Begleiter von Robertson nach Paris zu entsenden. ${ }^{22}$ Auf einer Sitzung im Zweimächtekontrollbüro am 14. April 1948 wurde der britische Militärgouverneur verbindlich beauftragt, die Bizone zwei Tage später in Paris zu vertreten. Man habe gehofft, „von einigen Ihrer Herren begleitet werden zu können“, erklärte der Brite Vertretern der bizonalen Organe und den Ministerpräsidenten während einer gemeinsamen Besprechung, durch „unvorhergesehene Einflüsse“ sei dieses Vorhaben jedoch mittlerweile zunichte gemacht worden. Mit der Verlesung der kurzen Ansprache, die er in Paris halten wollte, bot Robertson seinen Gesprächspartnern immerhin die Gelegenheit, eine im deutschen Namen abzugebende Erklärung wenigstens vorher zu hören ${ }^{23}$ eine Geste, zu der sich der französische Militärgouverneur nicht entschließen konnte. ${ }^{24}$ Wichtiger als auf deutsche Empfindlichkeiten Rücksicht zu nehmen, erschien es dem amerikanischen Botschafter in Paris freilich, den Text mit der französischen Regierung abzustimmen; jedenfalls riet er Robertson dringend zu diesem Schritt. ${ }^{25}$ Der lehnte die-

\footnotetext{
${ }^{18}$ Lovett an Botschaft London v. 12. 4. 1948, ebenda, S. 419-420; Bonnet an Außenministerium v. 12.4. 1948, AN, 457 AP 22.

${ }^{19}$ Caffery an Sec State v. 7. 4. 1948, FRUS 1948, III, S. 413-414.

${ }^{20}$ Caffery an Sec State v. 14. 4. 1948, ebenda, S. 423, Anm. 4.

21 Telefonkonferenz Bradley-Clay v. 10. 4. 1948, Clay Papers, II, S. 621-625, hier S. 624.

22 Clay an Draper v. 13. 4 1948, ebenda, S. 627. Vgl. auch Krieger, Clay, S. $360 f$.

${ }^{23}$ Bespr. Militärgouverneure - bizonale Vertreter v. 14. 4. 1948, AVBRD 4, Dok. 43, bes. S. 460-463.

${ }^{24}$ Koenig unterrichtete die beiden für die Pariser Verhandlungen vorgesehenen Sachverständigen und den badischen Wirtschaftsminister Lais erst am Tag nach der Unterzeichnung der OEEC-Konvention. Vgl. Pressekommuniqué (handschriftl. Datumsangabe: 19.4. 1948), AO, Eco I A 5c u. Vermerk v. 19. 4. 1948, AO, SGAAA, G 11, Plan Marshall 1947/50, Paquet 53.

${ }^{25}$ Caffery an Sec State v. 15. 4. 1948, NA, RG 59, 840.50 Recovery/4-1548.
} 
sen Vorschlag nach Rücksprache mit Clay zwar ab, doch scheint die Erklärung im Quai d' Orsay zuvor bereits zur Kenntnis genommen und gebilligt worden zu sein. ${ }^{26}$

Einem reibungslosen Ablauf der feierlichen Gründung der Organization for European Economic Cooperation (OEEC) am 16. April 1948 stand damit nichts mehr im Wege. Es hatte allerdings intensiver amerikanischer "Geburtshilfe“ bedurft, ehe die OEEC das Licht der Welt erblickte. Dennoch konnten die USA längst nicht alle ihre Ziele verwirklichen. Mit der Idee einer „continuing organization“ hatten die Amerikaner schon seit Beginn der ERP-Planungen geliebäugelt. Anders als die CEEC - und ganz anders als die Wirtschaftskonferenzen im Rahmen des Völkerbunds - sollte die neue Organisation nicht nur nominell eine ständige Regierungskonferenz auf Ministerebene sein; ein politisch einflußreicher Vorsitzender und ein vergleichsweise unabhängiges Sekretariat sollten ein Gegengewicht zu den einzelnen Regierungen bilden. Großbritannien und Frankreich hingegen waren bestrebt, das von ihnen dominierte Exekutivkomitee aus der CEEC zu übernehmen und den Generalsekretär nur mit geringen Kompetenzen auszustatten. ${ }^{26 a}$ Die am Ende beschlossene Organisationsstruktur stellte einen Kompromiß zwischen beiden Positionen dar. Oberstes Gremium war der Rat, der auf der Ebene der Fachminister normalerweise zweimal jährlich zusammentrat, auf der Ebene der Delegationsleiter in der Regel wöchentlich. Ihm gehörten alle Teilnehmerländer an. Der Exekutivausschuß setzte sich demgegenüber nur aus sieben Mitgliedern zusammen, die alljährlich vom Rat bestimmt werden mußten. Dessenungeachtet gab es mit Frankreich, Großbritannien, Italien, einem Beneluxland und später der Bundesrepublik faktisch fünf ständige Mitglieder. Der Rat ernannte überdies den Generalsekretär und seine Stellvertreter, der ebenso wie die verschiedenen technischen Komitees den Weisungen des Rats unterstand. Die Zahl dieser Komitees, bei denen zwischen horizontalen, übergreifenden Problemen gewidmeten und vertikalen, nach Branchen gegliederten Ausschüssen unterschieden wurde, schwankte. Daneben wurden für bestimmte vorrangige Aufgaben besondere Direktorien eingerichtet, beispielsweise für Handelsprobleme und für den Zahlungsverkehr. Eine Sonderstellung nahmen das Direktorium der 1950 gegründeten Europäischen Zahlungsunion und die Europäische Produktivitätszentrale ein. Beschlüsse wurden in der Regel einstimmig gefaßt, wie für internationale Organisationen „klassischer" Prägung üblich; für die Verfechter supranationaler Integrationskonzepte war dies sicherlich eine Enttäuschung. Die EZU kannte allerdings auch Mehrheitsentscheidungen - eine nicht unwichtige Ausnahme. Die Beschlüsse hatten unterschiedliche Qualität: Es gab verbindliche Entscheidungen, Empfehlungen und Resolutionen. Ferner konnten Abkommen mit Mitgliedsländern, dritten Staaten und anderen Organisationen abgeschlossen werden. ${ }^{26 \mathrm{~b}}$

26 Murphy an Sec State v. 16. 4. 1948, NA, RG 59, 840.50 Recovery/4-1648, läßt diesen Schluß zu.

${ }^{26 a}$ Vgl. Milward, Reconstruction, S. 168-175. Die Selbständigkeit hatte aus amerikanischer Sicht allerdings auch ihre Grenzen, wie Harriman deutlich machte: „We do not however desire to be confronted at a given moment with an irrevocable decision on your part concerning questions which require discussion, and we hope, my assistants and myself, to take part on the studies of all the questions which may arise in order to arrive at a joint conclusion and agreement." $\mathrm{C} / \mathrm{M}(48) 5$ v. 11. 5. 1948, S. 8, Historical Archives of European Communities, Florenz (künftig: HAEC), OEEC, 1.

$26 \mathrm{~b}$ Vgl. The Organisation for European Economic Co-operation. History and Structure, S. 13-19; OEEC-Handbuch 1959, S. 19; Weber, Geschichte, S. 104-105; zu Gemeinsamkeiten und Unterschieden im Vergleich mit anderen internationalen Zusammenschlüssen vgl. Armin Heinrichs, Die auswärtigen Beziehungen der Europäischen Gemeinschaft für Kohle und Stahl - insbesondere ihr Verhältnis zur OEEC, Bonn 1961, S. 27-31. - Laut George W. Ball, The past has another pattern. Memoirs, New 
Auf der Gründungsversammlung war von divergierenden organisatorischen Vorstellungen oder von einem Streit um die Einladung deutscher Politiker freilich nichts zu spüren. Wie von französischer Seite gewünscht, unterzeichneten Robertson und Koenig die OEEC-Konvention für die französische und die Bizone in Abwesenheit deutscher Repräsentanten. Da alle Delegationschefs das Wort ergriffen, stellten die Ansprachen der beiden Generäle keine Besonderheit dar; lediglich die Tatsache, daß sie als letzte unterschrieben, könnte als Indiz für den Sonderstatus der Besatzungszonen gedeutet werden, wenngleich sich für die Reihenfolge auch formale Argumente finden ließen. ${ }^{27}$ Die Euphorie über den Marshallplan, die in Westdeutschland nach den ersten Nachrichten über eine mögliche Beteiligung ausgebrochen war, mittlerweile aber merklich nachgelassen hatte, erhielt durch die als diskriminierend empfundene, erzwungene Abwesenheit westzonaler "Gäste" bei der Gründung der neuen Organisation jedenfalls einen weiteren Dämpfer. Resigniert stellte der amerikanische Generalkonsul in München nach Gesprächen mit bayerischen Politikern über die Unterzeichnung des OEEC-Abkommens fest: „Bavarian officials will give opinions about the plan when asked but seldom if ever mention it in political speeches or other public statements..."28

Der Start in der OEEC war für die Westdeutschen also eher enttäuschend verlaufen: Nicht einmal als Zaungäste des großen internationalen Ereignisses wurden sie geduldet. Frankreich hatte die erste Runde der Auseinandersetzung um die Integration des besiegten Landes in den westeuropäischen Verbund "gewonnen“. Entgegen amerikanischen Zusagen und Wünschen mußten sich die Westzonen vorerst mit einer Mitgliedschaft „Zweiter Klasse“ begnügen. Daran änderte auch die aus deutscher Sicht erfreuliche Tatsache nichts, daß wenig später, wie in London vereinbart, die ersten Sachverständigen nach Paris reisen durften und die von den Besatzungsregierungen hinterlegten Ratifikationsurkunden rechtlich denjenigen der übrigen Mitgliedsländer gleichgestellt wurden. ${ }^{29}$ Regierung und Öffentlichkeit in Frankreich waren gewiß die entschiedensten Gegner des geplanten Auftritts beim Gründungsakt gewesen - die immer wieder bemühten kommunistischen Proteste waren für Bidault insofern nur ein vorgeschobenes Argument -, doch brachten fast alle anderen Teilnehmerstaaten Verständnis für diese Haltung

York/London 1982, S. 81, zählte auch Jean Monnet zu den Enttäuschten: „But the OEEC’s nothing“, zitiert er ihn, ,it's only a watered-down British approach to Europe - talk, consultation, action only by unanimity. That's no way to make Europe."

${ }^{27}$ Vgl. zur OEEC-Gründung die Dokumentation in: Europa-Archiv 3 (1948), S. 1311-1315; Hugo J. Hahn/Albrecht Weber, Die OECD. Organisation für Wirtschaftliche Zusammenarbeit und Entwicklung, Baden-Baden 1976, S. 34-36. Die OEEC-Konvention ist abgedruckt u. a. in: Europa. Dokumente zur Frage der europäischen Einigung, Bd. I, München 1962, S. 214-229. - Die Unterzeichnung erfolgte in alphabetischer Reihenfolge; maßgeblich waren die französischen Bezeichnungen für die Teilnehmerländer.

${ }^{28}$ In einem Bericht des US-Generalkonsulats von Anfang April hieß es dazu: „With respect to the Marshall-Plan, the general tendency now is to be skeptical or at least reserved about all promises of the Occupying Powers. The conviction that their present misery is intentional and that the real object of the occupation is to destroy Germany as a future competitor, has now become almost a religious belief on the part of the vast majority of Germans. Therefore, they cannot be expected to be thrilled at the prospects of the Marshall Plan, although, of course, the more sensible people amongst them are convinced that without this plan there would be no hope at all of future recovery. "Generalkonsulat an Sec State v. 6. 4. 1948, NA, RG 59, 862.00/4-648 u. Generalkonsulat an Foreign Service v. 27. 4. 1948, NA RG 59, 840.50 Recovery/4-27748.

${ }^{29}$ Zunächst war umstritten, ob die Ratifikationen durch die Besatzungszonen auf die zur Inkraftsetzung der OEEC-Konvention erforderliche Mindestzahl von sechs Ratifikationsverfahren angerechnet werden sollte vgl. C/M (48) 16 v. 8. 7. 1948, HAEC, OEEC, 2. Auf der folgenden Ratssitzung wurde diese Frage positiv entschieden; vgl. C/M (48) 17 v. 9.7. 1948, ebenda. 
auf. Im Rückblick mag diese Art „symbolischer Politik“ wie ein letztes, sinnloses Aufbäumen Frankreichs gegen das vor allem von den USA betriebene wirtschaftliche und politische Comeback der Deutschen und die damit verbundene Rehabilitierung erscheinen; die deutschen Akteure konnten die demonstrative Zurücksetzung als Aufforderung und Chance zugleich begreifen, als "teilnehmende Beobachter" erst einmal Erfahrungen mit den neuen außenpolitischen Methoden und Gepflogenheiten zu sammeln und neue, der veränderten internationalen Lage und dem veränderten Status des Landes angepaßte Konzepte zu entwerfen. Wie gering die Spielräume für eine autonome „deutsche“ Politik im Rahmen des europäischen Wiederaufbauprogramms zunächt waren, sollte sich schon beim Aufbau und bei der inneren Austarierung der Marshallplanbürokratie in den Westzonen zeigen.

\section{Der Aufbau der alliierten und deutschen Marshallplan- bürokratie in den Westzonen}

Charakter und Struktur der Instanzen, denen die Planung und Abwicklung des Wiederaufbauprogramms auf amerikanischer Seite übertragen werden sollte, waren Gegenstand intensiver Diskussionen zwischen den betroffenen Ministerien und während der Anhörung vor Kongreß und Senat. Zwei grundsätzliche Alternativen boten sich an: ${ }^{30}$ eine selbständige Regierungsbehörde, zusammengesetzt aus Beamten der involvierten Ressorts und Persönlichkeiten aus der Privatwirtschaft, oder eine besondere Abteilung im State Department. Von der ersten Möglichkeit erhofften sich die Befürworter größere Flexibilität und „businesslike forms of management“, die zweite Lösung schien dagegen besser geeignet, die Gefahr eines Auseinanderdriftens von Rekonstruktions- und Außenpolitik zu bannen. Als nach anfänglichen Bedenken jedoch selbst die Verantwortlichen im State Department für eine „unabhängige“ Behörde votierten, war die Entscheidung praktisch gefallen.

Das Auslandshilfegesetz vom 3. April 1948, mit dem der rechtliche und finanzielle Rahmen der amerikanischen ERP-Politik abgesteckt wurde, sah die Errichtung einer Regierungsbehörde mit Sitz in Washington vor. ${ }^{31}$ Die Leitung dieser Economic Cooperation Administration (ECA) oblag einem dem Präsidenten verantwortlichen Administrator im Rang eines Ministers. Daß die Wahl auf den Studebaker-Chef Paul G. Hoffman fiel, der zuvor bereits dem Harriman-Komitee angehört hatte ${ }^{32}$, war ebenso ein Indiz für die Entschlossenheit, mit der das Ziel einer „businesslike administration“ verfolgt wurde, wie die Besetzung des Advisory Board mit Vertretern aus der Geschäftswelt, den Gewerkschaften und der Landwirtschaft. Den Posten des „Special Representative" in Paris vertraute die amerikanische Regierung dem damaligen Handelsminister und früheren Bankier W. Averell Harriman an, und auch die Leiter der „Special Missions" in den einzelnen Teilnehmerländern stammten in den meisten Fällen aus Indu-

30 Vgl. Hadley Arkes, Bureaucracy, the Marshall Plan and the National Interest, Princeton, N.J. 1972, bes. S. 59-131; Hogan, Marshall Plan, S. 101-109; dort S. 108, das folgende Zitat.

${ }^{31}$ Eine deutsche Übersetzung des Gesetzestextes findet sich in: Europa-Archiv 3 (1948), S. 1385-1394; zur ECA vgl. Hardach, Marshall-Plan, S. 95-98.

$32 \mathrm{Vgl}$. Arkes, Bureaucracy, S. $100 \mathrm{f}$. 
strie- oder Finanzkreisen..$^{33}$ Es war zu erwarten, daß die Vereinigten Staaten versuchen würden, dieser „Philosophie“ auch in den Empfängerländern Geltung zu verschaffen. Die Voraussetzungen hierfür waren in der Bizone zweifellos besonders günstig, hatten es die ECA-Vertreter doch hier zunächst nicht mit einer autonomen Regierung zu tun, sondern vor allem mit ihren eigenen Landsleuten in der Militärregierung. Der amerikanische Einfluß machte sich denn auch sehr viel stärker bemerkbar als in der französischen Zone.

\section{a) Der ERP-Apparat in der Bizone}

An der Spitze des amerikanisch-britischen Teils der bizonalen ERP-Organisation standen die beiden Militärgouverneure. ${ }^{34}$ Sie legten die Grundsätze der Wiederaufbaupolitik fest, prüften die bizonalen Programme vor der Übergabe an die OEEC und verhandelten mit der ECA-Sondermission über die Verwendung der "Gegenwertmittel“, des Fonds, der sich später aus den DM-Zahlungen der Abnehmer amerikanischer Waren speiste; außerdem hielten sie die Zentrale in Washington durch vierteljährliche Berichte über den Stand der Arbeiten auf dem laufenden. Über den konkreten Inhalt, eventuelle Änderungen und Ausführung der Programme entschieden die Wirtschaftsberater der beiden Militärgouverneure; im Frühjahr 1948 waren dies Lawrence Wilkinson für die amerikanische und Sir Cecil Weir für die britische Seite. Sie vertraten die Bizone auch bei der OEEC. Der „ERP Executive Board“, unterstützt vom „ERP Committee“ als Koordinierungsstelle spezieller Unterausschüsse, setzte die Entscheidungen der Militärgouverneure und die Vorgaben der Wirtschaftsberater in genaue Anweisungen um. Für den Schriftverkehr und die Abstimmung aller einschlägigen Aktivitäten war das ERP-Sekretariat des Zweimächtekontrollamtes in Frankfurt zuständig. Die Bizonale Delegation bei der OEEC schließlich leistete gemäß den Instruktionen der übergeordneten Instanzen die praktische "multilaterale Arbeit ". Sie sorgte für eine angemessene personelle und fachliche Repräsentation der Bizone, koordinierte den Einsatz der Sachverständigen in den einzelnen OEEC-Ausschüssen und übernahm die laufende Information der zuständigen Stellen in der anglo-amerikanischen Zone. Für die Posten des Delegationsleiters und des Statistikers waren Amerikaner vorgesehen, Großbritannien sollte den stellvertretenden Leiter, den Sekretär und den Verwaltungschef stellen; für Deutsche waren zunächst nur die Stellvertreterämter des Statistikers und des Sekretärs reserviert. Die restlichen Plätze sollten gleichmäßig aufgeteilt werden ${ }^{35}$. Den Geschäftsverkehr mit der ECA-Zentrale wickelte die „ERP Group“ in Washington ab, die aus Angehörigen des Department of the Army und der britischen Botschaft zusammengesetzt war; sie stellte, wenngleich mit einem deutlich kleineren Aufgabenbereich, eine Art Pendant zur OEEC-Delegation dar.

${ }^{33}$ Vgl. Hogan, Marshall Plan, bes. S. 136-142. Aus zeitgenössischer marxistischer Sicht Henri Claude, Der Marshallplan, Berlin (Ost) 1949, bes. S. 145-147.

${ }^{34}$ Vgl. zum folgenden Draft History of BICO: ERP, IfZ, MF 260, 3/409-1/22; „Bipartite Organisationen für das ERP“ (Stand: 30. 4. 1949), Parlamentarchiv, Bonn (künftig: PA), Bestand 2/603; Walter Vogel, Westdeutschland 1945-1950. Der Aufbau von Verfassungs- und Verwaltungseinrichtungen über den Ländern der drei westlichen Besatzungszonen, Teil II, Boppard a. Rh. 1964, S. 257-291.

35 "Composition of Bizonal Delegation“, Vermerk v. 21. 4. 1948, PRO, FO 371/70733. 
Mit dem Aufbau dieses Apparats hatten die zuständigen britisch-amerikanischen Stellen bereits im Februar 1948 begonnen - also noch vor der endgültigen Einigung mit Frankreich über die Beteiligung der Westzonen. Den Grundstein hatte das Zweimächtekontrollamt mit seinem Beschluß über die Bildung des Frankfurter ERP-Komitees vom 11. Februar gelegt; die Eile war dadurch bedingt, daß bis Mitte März der bizonale Aufbauplan für das erste Jahr vorliegen sollte. Diese Arbeit scheint jedoch zunächst von einem provisorischen Stab von Experten aus den verschiedenen involvierten BICO-Abteilungen und aus der Joint Export-Import Agency (JEIA), der gemeinsamen Außenhandelsbehörde für die Bizone, vorangetrieben worden zu sein, denn die erste Vollsitzung des Komitees fand erst am 22. März statt. ${ }^{36}$ Beteiligt waren u. a. Mitarbeiter der Ressorts Handel und Industrie, Verkehr, Ernährung und Landwirtschaft, der Finanzabteilung, der JEIA und des Büros des Politischen Beraters General Clays. Zum selben Zeitpunkt nahm auch das ERP-Sekretariat des Kontrollamtes mit dem Briten HandleyDerry und dem Amerikaner Harrelson an der Spitze seine Arbeit auf. Diese beiden Instanzen waren die wichtigsten Ansprechpartner für die deutschen Stellen, die etwa gleichzeitig entstanden.

Die Initiative zum Aufbau einer deutschen Marshallplanorganisation war vom Zweimächtekontrollamt ausgegangen. Mitte März 1948 hatten amerikanische und britische Offizielle Hermann Pünder, dem gerade gewählten Vorsitzenden des Verwaltungsrates und ehemaligen Leiter der Reichskanzlei in den Jahren 1926 bis 1932, die Errichtung einer besonderen Behörde vorgeschlagen: $\mathrm{Da}$ ihm als Oberdirektor die Koordinierung aller Arbeiten der fünf bizonalen Verwaltungen oblag, sollte in seinem Büro „eine kleine, aber sehr wichtige Stelle für die deutsche Mitarbeit am Marshallplan“ eingerichtet werden. Für diese „Sammelstelle“ sollte nach Möglichkeit kein Beamter aus einer der Verwaltungen ausgewählt werden, sondern „eine geeignete Persönlichkeit von außen“, kurz: ein Geschäftsmann. ${ }^{37}$ Amerikaner und Briten drängten auf eine rasche Erledigung dieses Auftrags, da ein "Partner“ für die alliierten ERP-Instanzen gebraucht wurde. ${ }^{38}$ Schon wenige Tage später konnte Pünder einen Kandidaten präsentieren - Otto Schniewind, einen Münchner Bankier und früheren Generalkonsul in Schweden. Schniewind, so informierte der Oberdirektor seine Kollegen und den Amerikaner Karl Bode vom ERP-Komitee, habe sich, nicht zuletzt aufgrund einer „alten Jugendfreundschaft“, bereit erklärt, „nicht im Beamtenverhältnis, sondern in loser Form und ohne zu große zeitliche Bindung diese Arbeit zu übernehmen." Bode zeigte sich mit dieser Wahl offensichtlich zufrieden. ${ }^{39}$ Als Bankier erfüllte Pünders "Jugendfreund“ ein wesentliches amerikanisches Kriterium, er war allerdings, entgegen dem offiziellen Spruchkammerbescheid, politisch keineswegs unbelastet. Alliierten Nachforschungen zufolge hatte Schniewind nicht nur seine Mitgliedschaft im Reichsbund der Deutschen Beamten und im Nationalsozialistischen Fliegerkorps verschwiegen, ihm wurde auch die Beteiligung an der „Arisierung “ einer Firma und das unerlaubte Führen des Titels eines Schwedischen Generalkonsuls in den Jahren 1945/46 vorgeworfen. Erstaunlicherweise schadeten

\footnotetext{
$36 \mathrm{Vgl}$. „Formation of Bipartite ERP Machinery“, In: Draft History of BICO: ERP, IfZA, MF 260, 3/409$1 / 22$.

37 Vermerk Pünder v. 13. 3. 1948, BA, NL Pünder, 704.

38 BICO-Stellungnahme (dt. Übers.) v. 18. 3. 1948, ebenda.

39 Vermerke Pünder v. 19. u. 24. 3. 1948, ebenda.
} 
ihm diese Enthüllungen nicht. ${ }^{40}$ Seine offizielle Ernennung zum „Berater für den Marshallplan bei dem Vorsitzer des Verwaltungsrates“, so der etwas umständliche Titel, erfolgte zwar erst am 9. Juni 1948, doch hatte er seine Tätigkeit bereits vorher aufgenommen.

Anders als in den übrigen Teilnehmerländern, die, wie Schniewind in einer ersten Zwischenbilanz anmerkte, ,in organisatorischer Hinsicht von ihren eigenen Erfahrungen" ausgehen konnten, kam der Anstoß in der Bizone also von außen; mehr noch, die Amerikaner insbesondere versuchten, den Aufbau der deutschen Apparatur entsprechend dem Muster der ECA zu beeinflussen. Mehr als einen Teilerfolg konnten sie allerdings nicht verbuchen, denn Pünder und Schniewind lehnten die „Errichtung eines besonderen Marshall-Plan-Amtes mit entsprechendem Beamtenkörper und Weisungsbefugnis gegenüber den anderen Ressorts" ab, weil sie die Entstehung eines zweiten Wirtschaftsressorts und die zu erwartenden „Reibungen“ mit der Verwaltung für Wirtschaft vermeiden wollten: Ein "neues zentrales Amt großen Ausmaßes“ erschien ihnen um so unnötiger, „als nach bewährtem deutschem Verwaltungsbrauch die hauptbeteiligte Verwaltung für Wirtschaft die Federführung in Marshall-Plan-Sachen übernommen hatte und die anderen Verwaltungen beteiligte, ohne daß es zu Schwierigkeiten gekommen" sei. Die gegenteiligen Wünsche vor allem amerikanischer Stellen erklärte Schniewind damit, daß dieses System in den angelsächsischen Ländern unbekannt sei; dies war für ihn jedoch kein ausreichender Grund, von der "bewährten deutschen Übung " abzugehen. ${ }^{41}$ Die zuständigen Abteilungen der fünf Verwaltungen erledigten also die fachlichen Aufgaben, Schniewinds kleine Dienststelle - Anfang 1949 bestand sie aus sechs Personen, Büroangestellte eingeschlossen - bearbeitete die allgemeineren, „politischen“ ERP-Angelegenheiten und hielt den Kontakt zur ECA-Mission und zu den ERP-Instanzen des Zweimächtekontrollamts in Frankfurt. Um die Aktivitäten auf deutscher Seite zu koordinieren, beschloß der Verwaltungsrat im August 1948, einen „ERP-Arbeitsausschuß“ $\mathrm{zu}$ installieren, der in der Regel in der Verwaltung für Wirtschaft tagte und auch nichtstaatlichen Institutionen wie der Bank deutscher Länder oder den Gewerkschaften offenstand. Der Ausschuß war dem Oberdirektor direkt unterstellt; er nahm am 23. September unter Leitung von Ministerialdirektor Eduard Schalfejew, der 1935 den Staatsdienst im Wirtschaftsministerium quittiert hatte, seine Geschäfte auf. Federführend bei der Aufstellung und Abstimmung der Programme der einzelnen Ressorts war jedoch die Verwaltung für Wirtschaft mit ihrer Marshallplanabteilung unter Ministerialdirigent Günter Keiser und dessen Stellvertreter Helmut Meinhold; beide hatten während des „Dritten Reiches“ Karriere gemacht - Keiser als Leiter der Statistischen Abteilung der Wirtschaftsgruppe Privates Bankgewerbe und Hauptschriftführer zweier angesehener geldwirtschaftlicher Fachzeitschriften, Meinhold als Wirtschaftsexperte des an der

\footnotetext{
40 „Der Genannte hat sich ... während des Dritten Reiches geradezu unglaublich gut gehalten, er ist weder formell noch tatbestandsmäßig belastet," heißt es im Bescheid der Spruchkammer München VI v. 17. 5. 1947, ebenda. Die alliierten Reports finden sich als Anlage zum Protokoll der 4. Sitzung des ZBR, Historisches Archiv der Deutschen Bundesbank (künftig: HADB), B 330/1.

${ }^{41}$ Vertraulicher Jahresbericht 1948 des Beraters für den Marshall-Plan v. 27. 1. 1949, S. 3, BA, Z 14,8. Vgl. auch Vogel, Westdeutschland II, S. $274 \mathrm{f}$.
} 
„Raumplanung“ in Osteuropa beteiligten "Instituts für deutsche Ostarbeit“.42 Die Hoffnungen auf ein eigenes Büro in Paris zur Betreuung der Sachverständigen aus der Bizone, die BICO-Beamte im März 1948 geweckt hatten, zerschlugen sich allerdings. ${ }^{43}$ Am 20. Mai wurden - als erste Deutsche - Hubert Frommel und Wilhelm Dörr als Stellvertreter des Statistikers und des Sekretärs zusammen mit zwei weiblichen Büroangestellten in die mit Amerikaner und Briten besetzte bizonale Delegation bei der OEEC aufgenommen; eine separate Dependance gab es nicht. ${ }^{44}$

Ein deutscher „Chefdelegierter" fehlte jedoch nach wie vor. Von Anfang an hatten amerikanische Besatzungsoffiziere, ganz im Sinne der Washingtoner Vorliebe für Geschäftsleute, „große Namen“ aus der Wirtschaft ins Gespräch gebracht, sei es als Mitglieder der Delegation, sei es wenigstens als Sachverständige für die einzelnen OEECAusschüsse: Die Bankiers Hermann J. Abs und Robert Pferdmenges, Richard Merton von der Metallgesellschaft in Frankfurt oder Otto Horatz von Felten \& Guilleaume in Köln etwa wurden genannt, Pünder und einzelne seiner Mitarbeiter schlugen zusätzlich Günter Henle von Klöckner, das ehemalige geschäftsführende Präsidialmitglied des Reichsverbandes der Deutschen Industrie, Ludwig Kastl, den Wuppertaler Textilfabrikanten und zeitweiligen Leiter des Deutschen Wirtschaftsrates für die britische Zone, Abraham Frowein, oder den Kölner Gewerkschaftsführer Hans Böckler vor. ${ }^{45}$ Im Juni 1948 regte der mittlerweile bestellte Leiter der Pariser Vertretung, der amerikanische Bankier Robert Trier, erneut die Nominierung einer prominenten Persönlichkeit an ihm schwebte der frühere Reichsbankdirektor Karl Blessing vor -, zumal eines der beiden deutschen Delegationsmitglieder von dem künftigen direkten Vorgesetzten abgelehnt wurde. ${ }^{46}$ Zur Enttäuschung des Amerikaners winkte Blessing jedoch ab, und auch andere ihm genehme Kandidaten wie der Düsseldorfer Industrielle Helmuth Wohltat, der in der Zwischenkriegszeit gelegentlich als Wirtschaftsdiplomat von sich Reden gemacht hatte, der Abteilungsleiter für Außen- und Interzonenhandel in der Verwaltung für Wirtschaft, Vollrath von Maltzan, und der Frankfurter Rechtsanwalt Rudolf Mueller kamen nicht zum Zuge. ${ }^{47}$ Unterschiedliche Gründe waren dafür verantwortlich, daß sich keiner dieser Vorschläge realisieren ließ: Gegen Abs regte sich in Frankreich noch 1950, im Zusammenhang mit der Suche nach einem Delegationsleiter für die Schumanplanverhandlungen, massiver Widerstand; Blessing und Mueller verzichteten von sich aus. Generell war in der obersten Etage der Wirtschaft die Bereitschaft, auf der internationalen politischen Bühne westdeutsche Interessen zu vertreten, nicht sonderlich groß. Offenbar waren die Erfolgsaussichten zu ungewiß, die Position zu unattraktiv und der Handlungsspielraum zu gering, um einen Einsatz lohnend erscheinen zu lassen. Personen aus der „zweiten Reihe“, die sich während des „Dritten Reiches“ nicht exponiert hatten, waren für solche repräsentativen Aufgaben im Ausland am ehesten geeignet.

\footnotetext{
42 Vgl. Vertraulicher Jahresbericht, S. 4 (wie Anm. 41) und Vogel, Westdeutschland II, S. 281 f.; zu Schalfejew vgl. Boelcke, Wirtschaft, S. 86, zu Keiser Brackmann, Krieg, bes. S. 299, zu Meinhold vgl. Götz Aly/ Susanne Heim, Ein Berater der Macht. Helmut Meinhold oder der Zusammenhang zwischen Sozialpolitik und Judenvernichtung, Hamburg 1986.

${ }^{43}$ Vgl. Bührer, Auftakt, S. $536 \mathrm{f}$.

${ }^{44}$ Vgl. "German Members of Permanent OEEC Delegation in Paris“, in: Draft History of BICO: ERP, IfZA, MF 260, 3/409-1/22.

t5 Vgl. Vermerk Pünder v. 13. 3. 1948, „Vorschläge Dr. Kaufmann“, o. D., und „Vorschlagsliste deutscher Sachverständiger", o. D., alle BA, NL Pünder, 704.

t6 Vermerk Pünder v. 16. 6. 1948, BA, Z 14, 75.

t7 Vermerk Schniewind v. 18.6. 1948, ebenda.
} 
Wiederum fiel die Wahl auf einen Münchner Bankier, Hans Karl von Mangoldt, ein Neuling auf dem diplomatischen Parkett, der sich aber rasch Ansehen erwarb. ${ }^{48} \mathrm{Daß}$ damit zwei der wichtigsten Posten in der deutschen Marshallplanorganisation Persönlichkeiten anvertraut wurden, die zuletzt in Bayern tätig gewesen waren, dürfte vermutlich kein Zufall gewesen sein, argwöhnte doch schon ein Zeitgenosse, der Generalsekretär des Länderrats, Heinrich Troeger, die Direktorialkanzlei Pünders werde „bajuvarisiert“ ${ }^{49}$ Von noch größerer Bedeutung war freilich das „richtige“ Parteibuch. Nachdem mit Günter Keiser von der Verwaltung für Wirtschaft und Kurt Häfner von der Verwaltung für Ernährung, Landwirtschaft und Forsten zwei SPD-Mitglieder den „Ruhm“ für sich in Anspruch nehmen konnten, als erste deutsche Sachverständige in Paris dabeigewesen zu sein, legte die CDU/CSU-Fraktion im Wirtschaftsrat „um so entscheidenderen Wert ... auf eine starke Besetzung der Marshall-Plan-Abteilung beim Vorsitzenden des Verwaltungsrates mit CDU-Vertretern". ${ }^{50}$ Einschlägige Erfahrungen auf dem Gebiet multilateraler Wirtschaftskooperation, ein wohl nicht völlig abwegiges Qualifikationsmerkmal, hatte hingegen keiner derjenigen aufzuweisen, die nun an den Schalthebeln der deutschen ERP-Apparatur saßen. Einzig Oberdirektor Pünder war aufgrund seiner Teilnahme an den Völkerbundstagungen mit dieser Form des internationalen Verkehrs einigermaßen vertraut; ${ }^{51}$ freilich ging es nach dem Zweiten Weltkrieg doch sehr viel stärker um wirtschaftliche Fragen, und überdies war Pünder in die Marshallplanarbeiten nicht unmittelbar involviert. Dies war zunächst freilich kein Nachteil, denn die von alliierter Seite verordnete Passivität gestattet es den Deutschen, sich mit der ungewohnten Materie und den neuen diplomatischen Gepflogenheiten ohne unmittelbaren äußeren Druck vertraut zu machen. Der Einfluß Pünders oder Schniewinds war anfangs äußerst gering. Sie konnten zwar die deutschen Vorschläge in den bizonalen, amerikanisch dominierten Entscheidungsprozeß einspeisen, aber im Grunde waren sie in diesen Prozeß nicht wirklich integriert: Die deutschen Stellen rangierten in der hierarchischen Struktur der bizonalen Marshallplanverwaltung nämlich nicht auf einer der unteren Stufen, sie agierten faktisch erst einmal außerhalb dieser Hierarchie (Vgl. Schaubild 1). Die Klage Pünders vor dem ERP-Ausschuß des Wirtschaftsrates im September 1948, man habe weder ein Weisungsrecht gegenüber den deutschen Vertretern in Paris noch Anspruch auf Berichterstattung, mag dies illustrieren. ${ }^{52}$ Die Mitsprachemöglichkeiten deutscher Experten verbesserten sich in der Bizone allerdings zusehends, während die Entwicklung in der französischen Zone kaum vorankam.

${ }^{48}$ Vgl. Vogel, Westdeutschland II, S. 287, Anm. 6; Bizonale OEEC-Delegation, Report Nr. 43, PRO, FO $371 / 76938$.

${ }^{49}$ Heinrich Troeger, Interregnum. Tagebuch des Generalsekretärs des Länderrats der Bizone 1947-1949, hg. v. Wolfgang Benz und Constantin Goschler, München 1985, S. 80. Als „Drahtzieher“ dieser „Bajuvarisierung “ vermutete Troeger den Ministerialrat Johannes von Elmenau, der aus der bayerischen Bürokratie in die Direktorialkanzlei übergewechselt war.

so Die CDU/CSU im Frankfurter Wirtschaftsrat. Protokolle der Unionsfraktion 1947-1949, bearb. v. Rainer Salzmann, Düsseldorf 1988, Protokoll v. 22. 4. 1948, S. 188. Nachdem nicht vier, wie ursprünglich geplant, sondern nur zwei Sachverständige nach Paris reisen durften und keine kompetenteren CDU/ CSU-Angehörigen ausfindig gemacht werden konnten, blieben nur die beiden Sozialdemokraten übrig. Vgl. Aktenvermerk Holzapfel v. 24. 4. 1948, zit. n. ebenda, Anm. 2.

51 Vgl. Hermann Pünder, Von Preußen nach Europa. Lebenserinnerungen, Stuttgart 1968, bes. S. 83-88.

52 Rede-Entwurf Pünder v. 6. 9. 1948, BA, Z 14,8. 
Schaubild 1: ERP-Apparat in der Bizone (Stand Ende 1948)

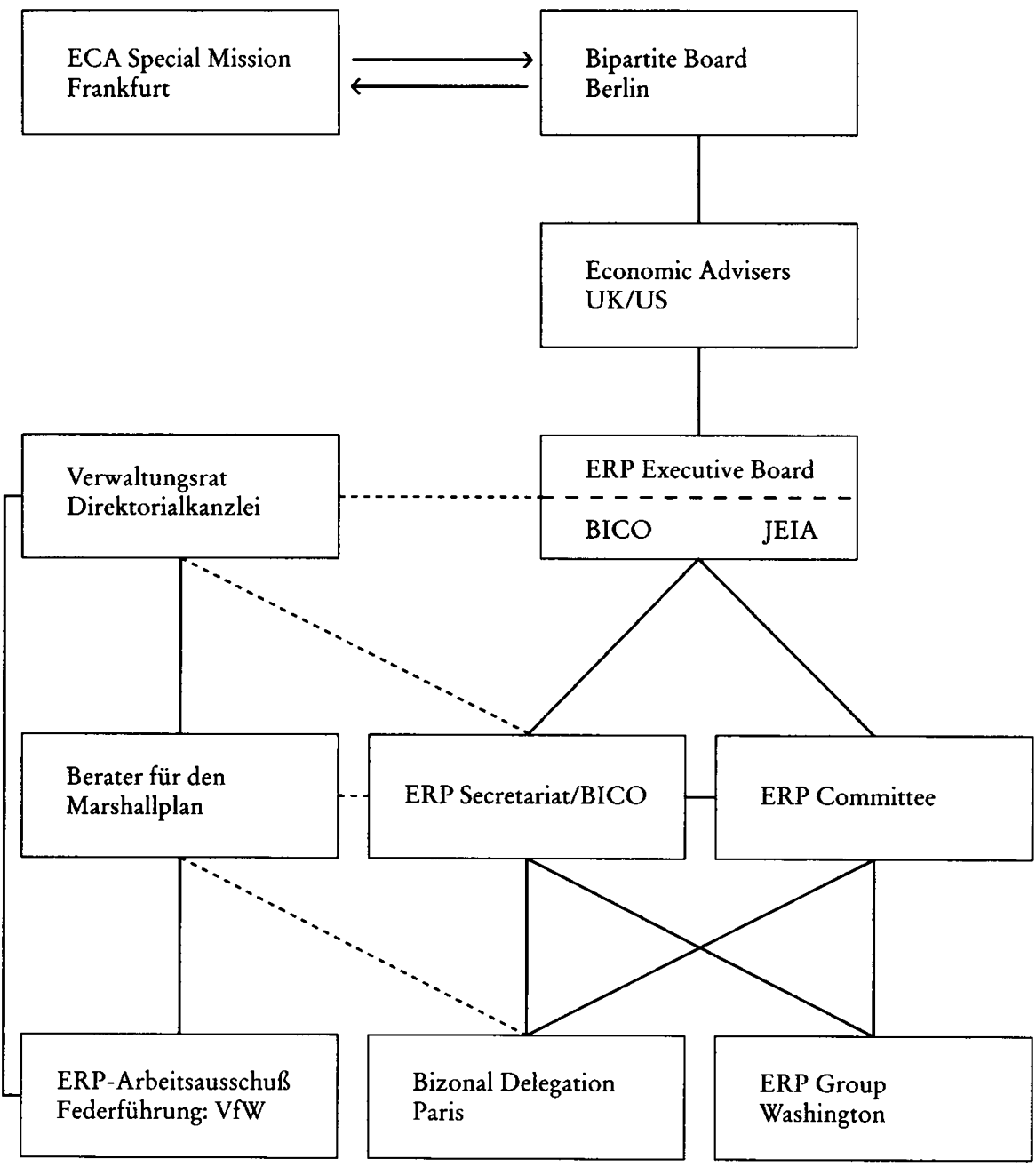

\section{b) Der ERP-Apparat in der französischen Zone}

Anders als in der Bizone war der Aufbau einer Marshallplanbürokratie in der französischen Zone nicht nur ein organisatorisches, sondern auch ein politisches Problem. ${ }^{53}$ Zum einen war die Neigung der französischen Militärregierung, Deutsche an den Entscheidungen über die ERP-Programme teilhaben zu lassen, nicht gerade groß; schon aus arbeitsökonomischen Gründen war jedoch eine verstärkte deutsche Mitarbeit geboten. Zum anderen erforderte ein effizienter Einsatz der Marshallplanhilfe eine intensivere

${ }^{33}$ Vgl. dazu und grundsätzlich Vogel, Westdeutschland II, S. 276f., 291-297; Karl Albrecht, Das Menschliche hinter dem Wunder. 25 Jahre Mitwirkung am deutschen Wirtschaftsaufbau, Düsseldorf-Wien 1970 , bes. S. $57-75$. 
Zusammenarbeit der drei Länder der französischen Zone, als bis dahin üblich und erlaubt war. Diese grundsätzlichen Fragen spielten also in die Aufteilung der Kompetenzen zwischen den einzelnen ERP-Instanzen hinein.

Die formalen Strukturen ähnelten denen in der Bizone. An der Spitze stand der Marshallplanausschuß der Militärregierung unter Leitung des Chefs des Zivilkabinetts, Roger Gromand. Die Planung oblag der „Direction Statistique, de la Documentation et du Plan Marshall" mit Oberst Maurice Halff an der Spitze, er hielt den Kontakt mit der Special Mission in Baden-Baden und war der Hauptansprechpartner der deutschen Verantwortlichen. Die praktische Arbeit, etwa die Aufstellung von Jahres- oder Quartalsprogrammen, erledigte - als Pendant zum ERP-Sekretariat des Zweimächtekontrollamtes - das Marshallplanbüro, assistiert von den Fachreferenten der Militärregierung. Für die kaufmännische Abwicklung der Marshallplanimporte war das Office du Commerce Extérieur (OFICOMEX) zuständig. Die Delegation der Besatzungszone leistete die konkrete Arbeit in Paris. Eine "Einkaufsmission“ in Washington wurde erst später etabliert.

Den Aufgabenbereich des „Beraters für den Marshallplan“ übernahm in der französischen Zone die "Deutsche Geschäftsstelle des Europäischen Wiederaufbauprogramms" in Baden-Baden mit Hilfe eines personell sehr sparsam ausgestatteten Büros. Zum Leiter dieser mit Beschluß der drei Wirtschaftsminister vom 11. Juni 1948 errichteten Verbindungsstelle zwischen der Militärregierung, der Special Mission und den deutschen Instanzen wurde Hans-Georg Sachs bestellt, der von 1940 bis 1945 als Legationssekretär im Auswärtigen Amt tätig gewesen war. Um die Aktivitäten in den drei Ländern aufeinander abzustimmen, wurde bereits im Mai 1948 ein Koordinierungsausschuß eingerichtet, dem der frühere Abteilungsleiter bei der Reichsgruppe Industrie, Karl Albrecht, zugleich Chef der Forschungsstelle für Wirtschaftsaufbau in Tübingen, vorstand. Dieser Ausschuß setzte sich zusammen aus Vertretern der drei Wirtschaftsministerien und der Eisenbahnverwaltung; je nach Bedarf wurden andere Ressorts und Persönlichkeiten aus der Privatwirtschaft hinzugezogen. Das ständige deutsche Mitglied der Delegation der französischen Zone in Paris und die Sachverständigen standen zwar in engem Kontakt mit diesen Stellen, waren aber den Weisungen der französischen Instanzen unterworfen.

Die Suche nach geeigneten Kandidaten für Paris hatte, wie bereits erwähnt, noch vor der OEEC-Gründungsversammlung begonnen. Als am 17. März 1948 ein erster „offizieller" Vorschlag der drei Regierungen vorlag, war die Diskussion um die Teilnahme deutscher Repräsentanten an der konstituierenden Sitzung der OEEC noch in vollem Gange, der Auftrag dieser Kandidaten also ungewiß. Unabhängig davon bewiesen die Regierungschefs freilich wenig Gespür, da die französischen Behörden zwei der vier Nominierten ablehnten..$^{54}$ Als Sachverständige wurden schließlich der Mainzer Professor der Nationalökonomie, Hubert Armbruster, der 1940/41 bei der Bank für Internationalen Zahlungsausgleich beschäftigt gewesen war, und der Präsident der Industrieund Handelskammer Ravensburg, Eugen Dörtenbach, ernannt; den personalpolitischen

\footnotetext{
54 Vgl. Bespr. Königs mit den Länderchefs der frz. Zone v. 17. 3. 1948, AVBRD 4, Dok. 36, S. 400-401; Mayer an Sec State v. 20. 3. 1948, NA, RG 84, Box 462, File 858. (Ich danke Hellmuth Auerbach für die Überlassung einer Kopie dieses Dokuments sowie weiterer einschlägiger Aktenkopien aus dem Staatsarchiv Sigmaringen, die ich im folgenden zitiere.)
} 
Schaubild 2: ERP-Apparat in der französischen Zone (Stand Ende 1948)

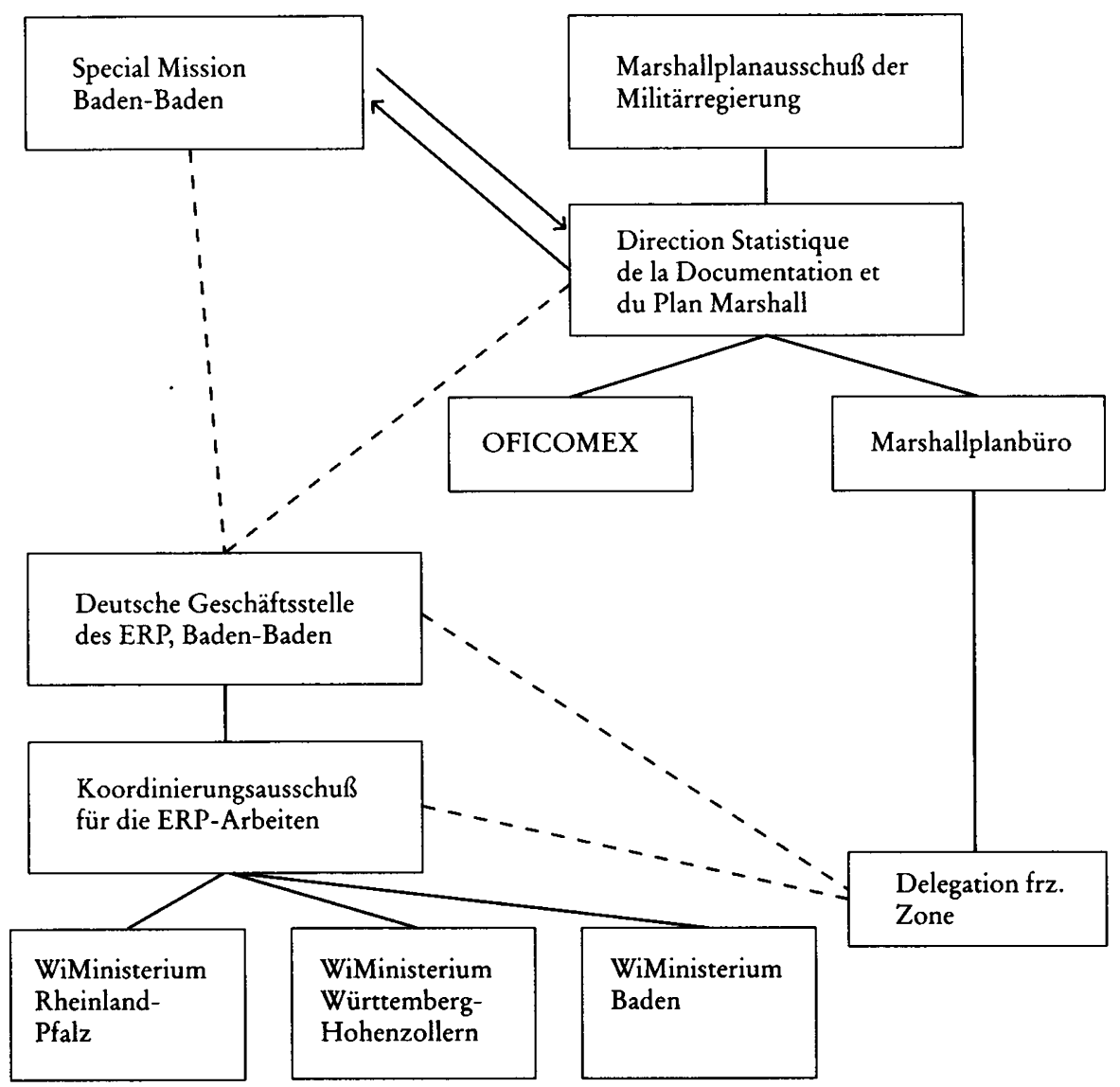

Wünschen der Amerikaner leisteten somit auch die zuständigen Stellen in der französischen Zone Folge. Übertriebene Erwartungen hinsichtlich deutscher Mitsprachemöglichkeiten dämpfte der Wirtschaftsminister von Württemberg-Hohenzollern nach einem ersten Treffen der beiden Sachverständigen mit Oberst Halff jedoch sofort wieder: Die beiden „hätten einige, wenn auch flüchtige Einblicke in die französischen Pläne nehmen können“, doch sei ihr Aufgabenkreis in Paris „offenbar sehr beschränkt“.55 Anfänglichen Unsicherheiten der beiden Experten über ihren Status und ihre Zuständigkeit begegneten die Verantwortlichen der Länderregierungen mit der Order, sie sollten „die deutschen wirtschaftlichen Interessen als Mandatare der deutschen Bevölkerung der französischen Zone verantwortlich“ vertreten, sich aber „jeder politischen Stellungnahme“ enthalten. ${ }^{56}$

\footnotetext{
55 Niederschrift 43. Ministerbesprechung v. 9. 4. 1948, StASigm, Film S IV/Wü 2/778, S. 292 ff.

56 Niederschrift 51. Ministerbesprechung v. 10.6. 1948, ebenda, S. $362 \mathrm{ff}$.
} 
Diese "Stellenbeschreibung" war indes zu Beginn der Marshallplanarbeiten in der französischen Zone von der Wirklichkeit ein gutes Stück entfernt. Aus der Sicht Halffs und anderer handelte es sich zunächst eher um eine Art „Probezeit“ für die Handvoll deutscher Fachleute und Koordinatoren. Die Einrichtung eines mit deutschem Personal besetzten kleinen Büros, welches die Delegationsarbeiten in Paris unterstützen sollte, erschien Halff verfrüht; er wollte erst die Erfahrungen mit der Baden-Badener Dienststelle abwarten und „eventuellement plus tard, utiliser les meilleurs de ses élements à $\mathrm{Pa}$ ris“" ${ }^{57}$ Theodor Axenfeld, der zunächst in Baden-Baden tätig gewesen war, schien diese "Probezeit" offensichtlich erfolgreich bestanden zu haben, denn er durfte Anfang Oktober 1948 in die ständige Vertretung bei der OEEC wechseln. Daß der involvierte Personenkreis und der gesamte Apparat in Baden-Baden klein blieb, entsprach indessen ganz den deutschen Wünschen. Wie Albrecht rückblickend schrieb, war man sich in der französischen Zone wohl bewußt, daß eine eigene ERP-Bürokratie nur störend wirken würde, wo es doch vor allem auf eine "möglichst sinnvolle und intensive Kooperation" mit der Bizone ankam - auch wenn diese Kooperation, wie auch schon die engere $\mathrm{Zu}$ sammenarbeit zwischen den zuständigen Ressorts der drei Landesregierungen, von den Militärbehörden erst nach einigem Zögern toleriert wurde. ${ }^{58}$ Es waren aber nicht allein die geringen Mitsprachemöglichkeiten der Deutschen - auch in der Bizone -, welche den Sonderstatus der Westzonen im Rahmen des ERP ausmachten; schon die beiden Verträge mit den Vereinigten Staaten über die Marshallhilfe unterschieden sich in einem wichtigen Punkt grundlegend von den bilateralen Abkommen der übrigen OEEC-Länder.

\section{Die bilateralen ERP-Abkommen mit den Vereinigten Staaten}

Um in den Genuß der amerikanischen Wirtschaftshilfe zu kommen, mußten die Empfängerländer zwei Voraussetzungen erfüllen. Die erste war die Unterzeichnung der OEEC-Konvention. Wenngleich manche der Ziele, auf die sich die Regierungen damit verpflichteten, aus eigenem Antrieb wohl kaum als verbindlich anerkannt worden wären, galt die Konvention doch keineswegs als amerikanisches Oktroi, eher als eine selbstauferlegte, auf Gegenseitigkeit beruhende Übereinkunft souveräner Staaten. Anders verhielt es sich mit der zweiten Bedingung, den vom amerikanischen Auslandshilfegesetz vorgeschriebenen bilateralen Abkommen mit den einzelnen OEEC-Mitgliedern, in denen die Konditionen der Hilfeleistung festgeschrieben wurden. So ganz trauten die Amerikaner ihrem multilateralen Ansatz offenbar selbst nicht, deshalb bestanden sie auf einer vertraglichen Absicherung mit dem jeweiligen Empfängerland. Zumindest tendenziell räumten die projektierten Verträge der ECA-Administration und damit letztlich den USA einen nicht unbeträchtlichen Einfluß auf die Wirtschafts- und Strukturpolitik souveräner Staaten ein. Die Furcht vor einem Verlust der Unabhängigkeit auch auf wirtschaftlichem Gebiet war deshalb weit verbreitet: „... there was no country in Western Europe where the charge was not levelled at the government that it was selling vital na-

57 Vermerk Halff v. 24. 5. 1948, AO, Aff EcoFin, Carton 2, Dossier 3000 A, Plan Marshall.

${ }^{58}$ Albrecht, Wunder, S. $58 \mathrm{f}$. 
tional interests for dollars. " 59 In Frankreich und Großbritannien fielen die Beschwerden verständlicherweise besonders heftig aus.

Die Kritik richtete sich vor allem gegen den Ton des Vertragsentwurfs, die Vorschriften für den Wechselkurs zwischen Landeswährung und Dollar, die Ausdehnung des Meistbegünstigungsprinzips auf Westdeutschland, Japan und Südkorea sowie den einseitigen Charakter des Schiedsgerichtsverfahrens. ${ }^{60}$ Noch am 21. Juni 1948 berichtete Botschafter Caffery nach Washington, in der französischen Öffentlichkeit mehrten sich die kritischen Stimmen: „... it is time to let our American friends know that as precious as is their aid, and as much as we appreciate it, there are conditions attached (in the original draft) which no free country could accept. "61 Hoffnungen in Paris und London, mit Italien ein weiteres wichtiges Land als Verbündeten zu gewinnen, zerschlugen sich jedoch, als die Regierung in Rom das Abkommen am 28. Juni 1948 unterzeichnete. ${ }^{62}$ Immerhin veranlaßten die Proteste das State Department, in dessen Zuständigkeit die bilateralen Verträge fielen, in allen wesentlichen Punkten zu Konzessionen, auch wenn sich diese manchmal in abgemilderten Formulierungen erschöpften. Die endgültigen Vertragstexte enthielten jedenfalls deutliche Korrekturen gegenüber den ursprünglichen Entwürfen. ${ }^{63}$

Für die französische Zone und die Bizone unterzeichneten erneut die Militärgouverneure, deutsche Stellen hatten keinerlei Einfluß auf die Verhandlungen, den bizonalen Instanzen wurde das Dokument sogar erst vierzehn Tage nach Unterzeichnung zugänglich gemacht. ${ }^{64}$ Verglichen mit den massiven Protesten der französischen Öffentlichkeit gegen den ursprünglichen Text des bilateralen Vertrages zwischen den USA und Frankreich fiel General Koenigs Kommentar zum Entwurf des Abkommens mit „seiner" Besatzungszone erstaunlich moderat aus. Er formulierte zwar einen generellen Vorbehalt gegen solche Artikel, die seinen Spielraum als Zonenbefehlshaber einzuengen drohten, und wandte sich dezidiert dagegen, den Vertrag auf gültige Vereinbarungen anzuwenden, schien aber grundsätzlich zur Unterschrift entschlossen zu sein. ${ }^{65} \mathrm{Ob}$ der verspätete Abschluß des bizonalen Abkommens als Indiz dafür zu werten ist, daß die beiden Militärgouverneure ernstere Bedenken gehabt hatten als ihr französischer Kollege, muß offenbleiben. Robertson deutete zwar Schwierigkeiten bei den Verhandlungen an, ging aber nicht näher darauf ein. Zugleich versicherte er Pünder, daß alle Punkte unter Berücksichtigung bizonaler Interessen eingehend geprüft worden seien. ${ }^{66}$ Wie bei den an-

\footnotetext{
${ }^{59}$ Vgl. hierzu und zum folgenden Milward, Reconstruction, S. 113-118, das Zitat S. 113; Brähler, Marshallplan, S. 217-226.

${ }^{60}$ Harriman an Sec State v. 4. 6. 1948 u. Aide-Mémoire der brit. Regierung v. 11. 6. 1948, beide in FRUS 1948, III, S. 446-450.

${ }^{61}$ Caffery an Sec State v. 1.6. 1948, ebenda, S. 454-455.

62 Vgl. zu den Daten der übrigen Vertragsabschlüsse ebenda, S. 463.

${ }^{63}$ Vgl. „Current Economic Developments“, Bericht v. 28. 6. 1948, ebenda, S. 459-462; „Planung und Aktion in der westeuropäischen Zusammenarbeit“, in: Europa-Archiv 3 (1948), S. 1529-1538, bes. S. 1534.

${ }^{64}$ Vgl. Vertraulicher Jahresbericht 1948 des Beraters für den Marshallplan v. 27. 1. 1948, S. 8, BA Z 14, 8. Pünder hatte am 15. 7. 1948 um Informationen gebeten, anläßlich einer Besprechung mit den Militärgouverneuren erhieiten die Deutschen eine Kopie des Textes. Clay führte zeitliche Gründe dafür an, daß die geplante Konsultation vor der Unterzeichnung nicht mehr zustande gekommen war. Bespr. Militärgouverneure - bizonale Offizielle v. 30. 7. 1948, IfZ, Mf 260, 11/100-2/20. Das deutsche Protokoll findet sich in: AVBRD, Bd. 4, Dok. 74, S. 703-708.

${ }^{65}$ Koenig an Larre v. 24. 6. 1948, AO, Eco IA 5a; der ECA-Vertragsentwurf v. 25. 5. 1948 in französischer Übersetzung in der Anlage des Schreibens.

${ }^{66}$ Bespr. Militärgouverneure - bizonale Offizielle v. 30. 7. 1948, IfZA, MF 260, 11/100-2/20.
} 
deren Abkommen fehlten in den überarbeiteten Versionen für die Westzonen jene Paragraphen, welche die Vertragspartner auf das Meistbegünstigungsprinzip verpflichteten und - auf amerikanischen Wunsch - Konsultationen über eine Anpassung des Wechselkurses vorschrieben. ${ }^{67}$ Andere Zugeständnisse lassen sich nicht feststellen. Im Gegensatz $\mathrm{zu}$ den Beteuerungen Robertsons und Clays, der Vertragstext weiche nur unwesentlich vom Standardwortlaut ab, ${ }^{68}$ enthielten die beiden "westdeutschen" Abkommen sogar einen Passus, der zumindest de jure eine eindeutige Benachteiligung darstellte. Im Entwurf hatte es noch recht vage geheißen, alle Hilfsleistungen der Vereinigten Staaten begründeten „a claim against the German economy“, in der endgültigen Fassung wurde daraus schließlich „a claim against Germany.“ Eine weitere wichtige Besonderheit der beiden Verträge bestand darin, daß die künftigen Exporterlöse der Besatzungszonen dazu verwandt werden sollten, die ERP-,,Schulden“ zurückzuzahlen -, at the earliest practicable time consistent with the rebuilding of the German economy on healthy, nonaggressive lines".

Diese Klauseln verursachten auf deutscher Seite gewisse Irritationen. Pünder sorgte sich mit Blick auf künftige Exporterlöse um die deutsche „Bewegungsfreiheit“, glaubte aber nicht, daß die Vereinigten Staaten tatsächlich die Absicht hätten, diese Vorschrift „in ihrer wörtlichen Form praktisch durchzuführen“. Er vermutete hinter diesen Formulierungen politische Motive: Im Falle eventueller Differenzen mit der Sowjetunion über Reparationsforderungen könne die amerikanische Regierung nämlich „ihre Ansprüche aus den Marshallplan-Lieferungen in die Waagschale werfen". In dieser Ansicht fühlte sich Pünder, wohl zu Recht, dadurch bestätigt, daß im Vertragstext durchgängig von den "US/UK Zones“ die Rede war, nur an dieser einen Stelle ausdrücklich von "Germany" ${ }^{69}$ Auch der Berater für den Marshallplan, Schniewind, schloß sich dieser Interpretation in seinem vertraulichen Jahresbericht für 1948 unter Berufung auf Norman Collisson von der Frankfurter ECA-Mission an. Die Rückzahlungspflicht sei aus politischen Gründen vereinbart worden, der Bizone würden daraus „keine wirtschaftlichen Nachteile erwachsen". 70

In diesen beiden Punkten kam es also offensichtlich rasch zu einem informellen amerikanisch-deutschen Konsens über die "richtige“ Auslegung der strittigen Vertragsparagraphen, der auch in die offizielle Stellungnahme der bizonalen Verwaltungen zum ERP-Abkommen Eingang fand: Man nehme an, hieß es dazu lapidar, daß es nicht die Absicht der USA sei, „die Bizone als das wirtschaftlich schwächste Gebiet Westeuropas schlechter zu stellen als andere Teilnehmerländer“. Die Kritik der deutschen Experten entzündete sich stattdessen an anderen, zum Teil ebenfalls nur in den beiden deutschen Abkommen enthaltenen Artikeln. So monierten sie beispielsweise, daß die Notwendigkeit, die Stahlproduktion zu steigern, nicht besonders erwähnt sei, obwohl gerade Erfolge auf diesem Gebiet entscheidend zum wirtschaftlichen Aufschwung in Westeuropa beitragen würden. Eine Besonderheit war auch die Vorschrift, für jede Art von Hilfe -

67 Vgl. Economic Cooperation Agreement (Draft) für die Bizone v. 25. 5. 1948 u. Economic Cooperation Agreement (endgültige Fassung), beide in: IfZA, MF 260, 11/100-1/15; die endgültige Fassung des Abkommens mit der französischen Zone ebenda, 11/100-1/16. Eine deutsche Übersetzung der bizonalen Vereinbarung in: Europa-Archiv 3 (1948), S. 1561-1565.

${ }^{68} \mathrm{Vgl}$. Bespr. Militärgouverneure - bizonale Offizielle v. 30. 7. 1948, IfZA, MF 260, 11/100-2/20.

${ }^{69}$ Rede-Entwurf v. 6. 9. 1948, BA, Z 14, 8. Pünder hielt die Rede einen Tag später vor dem interfraktionellen ERP-Ausschuß.

70 Vertraulicher Jahresbericht 1948, ebenda. 
also nicht allein auf "grants“ - DM-Beträge auf ein Sonderkonto einzuzahlen; die bizonalen Fachleute sahen darin sogar einen Verstoß gegen das Auslandshilfegesetz. Unzufrieden waren sie ferner mit dem für eine Anlaufzeit vereinbarten Umrechnungskurs von $0,50 \$=1,00 \mathrm{DM}$ und mit der alliierten Kontrolle über das Sonderkonto; eine Mitsprache deutscher Stellen erschien ihnen, nicht zuletzt wegen der „außerordentliche(n) kreditpolitische(n) Bedeutung " des Sonderfonds, unabdingbar.71

Dies waren, alles in allem, nun doch "Sonderkonditionen“, die über den Rahmen dessen hinausgingen, was die Vereinigten Staaten gegenüber den anderen ERP-Partnern an potentiellen Druckmitteln parat hatten. Die Gleichbehandlung Westdeutschlands, bei den europäischen Regierungen sonst häufig angemahnt, war also für die amerikanischen Verantwortlichen ebenfalls noch keineswegs selbstverständlich. Dies bedeutete nicht, daß sie entschlossen waren, diese „Daumenschrauben“ auch wirklich anzuziehen - aber für den Notfall waren, um im Bild zu bleiben, bei den Deutschen ein paar Umdrehungen mehr möglich. Den zuständigen Politikern und Beamten in den Westzonen war das bewußt. Um so mehr kam ihnen das Reparationsargument zupaß, das die Chance bot, die wahren Machtverhältnisse zu kaschieren, wollte man doch mit den übrigen OEECPartnern auf gleicher Stufe stehen. Um das Manko, am Abschluß des Vertrages überhaupt nicht beteiligt worden zu sein, wenigstens teilweise auszugleichen, versuchten die bizonalen Verantwortlichen die Amerikaner nachträglich auf ihre Lesart der problematischen Artikel einzuschwören. Ein „Ausverkauf“ deutscher Souveränitätsrechte konnte Pünder und seinen Mitarbeitern zwar schwerlich zum Vorwurf gemacht werden; gleichwohl waren sie darauf bedacht, daß der Handlungsspielraum einer künftigen deutschen Regierung nicht unnötig eingeengt wurde. Die beiden bilateralen Abkommen über wirtschaftliche Zusammenarbeit, die ersten internationalen Verträge, die „im deutschen $\mathrm{Na}$ men“ nach dem Zweiten Weltkrieg abgeschlosssen wurden, standen freilich noch ganz im Zeichen der Kontrolle. Vertrauen mußten sich die Repräsentanten des neuen „Deutschland“ noch erwerben, die Mitarbeit beim europäischen Wiederaufbau war ein erster großer Test. Mißglückte dieser Test, boten die ERP-Abkommen zumindest eine gewisse Handhabe, den Schaden für die Vereinigten Staaten in Grenzen zu halten.

\section{Der Marshallplan und die Suche nach neuen außenpolitischen Strategien}

„The ECA has a big stick - which can mean either life or disaster to many European countries and their people“, schrieb Harriman im November 1948 an seinen Chef, den ECA-Administrator Paul Hoffman, fügte aber einschränkend hinzu: „It is a fundamental principle of American foreign policy that the more power we have, the more considerate we should be of the sovereignty of other nations."72 Im Rückblick mag diese Feststellung gar zu dramatisch - oder zu optimistisch - erscheinen; für die damaligen Akteure war der Marshallplan jedoch zweifelsohne ein Faktor, welcher die Außenwirtschafts- und Außenpolitik entscheidend beeinflußte.

\footnotetext{
71 Pünder an BICO/ERP-Secretariat v. 23. 12. 1948 inkl. Anlage betr. ERP-Abkommen USA/Bizone, IfZA, MF 260, 11/100-1/15.

72 Harriman an Hoffman v. 6. 11. 1948, NA, RG 469, ECA, SRE, Confidential Records, 1948-49, Box 1.
} 
Dies galt in besonderem Maße für Westdeutschland. Zwar setzten sich Clay und andere amerikanische Deutschlandpolitiker dafür ein, das Ansehen der deutschen Verwaltungs- und Regierungschefs durch eine allmähliche Erweiterung der Kompetenzen zu stärken, aber von einer Rücksichtnahme, wie sie beispielsweise gegenüber Frankreich oder Großbritannien praktiziert wurde, waren diese Konzessionen noch weit entfernt. Über eine Instrumentalisierung der Bizone im Sinne der globalen handelspolitischen Strategie der USA dachten die zuständigen Beamten bei der Militärregierung und in der ECA deshalb auch recht ungeniert nach: „Unless the Bizonal Area participates to the full, and participates even as the spearhead of the US insistence that European trade once again go onto a multilateral system, we will face the failure of ERP“, befand F. Taylor Ostrander von der Wirtschaftsabteilung der amerikanischen Militärregierung schon im April 1948. ${ }^{73}$ Noch in einer Direktive an den künftigen ECA-Repräsentanten und amerikanischen Hohen Kommissar in Westdeutschland, John J. McCloy, bekräftigte ECAChef Hoffman diesen Standpunkt: „Germany's inherent position in European trade is very strong and it is of the utmost importance that this strength be used in a manner consistent with the broadest objectives of American policy. “74 Der Glaube, in Westdeutschland einen steuerbaren Vorreiter beim Aufbau des anvisierten liberalen Welthandelssystems zu haben, war also in den USA weit verbreitet. ${ }^{75}$

Deutsche Politiker und Industrielle mußten dieses amerikanische Interesse in ihre außenwirtschafts- und außenpolitischen Planungen einbauen, wollten sie nicht von vornherein deren Scheitern riskieren. Die zweite Maxime ergab sich angesichts der politischen Machtlosigkeit fast von selbst: Das zweifelsohne noch vorhandene und für den europäischen Wiederaufbau dringend benötigte westdeutsche Wirtschaftspotential mußte als Hebel benutzt werden, um die außenpolitische Isolation zu überwinden und Schritt für Schritt auch politischen Einfluß zu erlangen. Auf den ersten Blick bot sich hier eine Wiederaufnahme jener "Wirtschaftsaußenpolitik“ an, wie sie zeitweise von Stresemann propagiert worden war. Sein Wort von der Wirtschaft als der "einzigen großen Waffe“ der deutschen Außenpolitik schien nach 1945 erneut Gültigkeit zu besitzen. ${ }^{76}$ Es zeigte sich freilich bald, daß die Kräftekonstellation nach dem Zweiten Weltkrieg mit jener der zwanziger Jahre wenig gemein hatte.

Bereits in seiner Antrittsrede vor dem Wirtschaftsrat im März 1948 skizzierte Oberdirektor Pünder die Umrisse einer außenpolitischen Strategie. Er bekannte sich zu einer „engen Verflechtung der Wirtschaften“ und zur "schicksalhaften Mitarbeit" der Westdeutschen am europäischen Wiederaufbau mit dem Ziel einer allmählichen „Wiedereingliederung Deutschlands in die Wirtschaft Europas". Diese durch den Marshallplan in Gang gesetzte Entwicklung war für ihn nicht nur Voraussetzung des Aufstiegs der eige-

\footnotetext{
${ }^{73}$ Ostrander an Humphrey v. 16. 4. 1948, ebenda.

${ }^{74}$ Hoffman an McCloy, Briefentwurf v. 13. 7. 1949, NA, RG 469, Assistant Administrator for Programs, Subject Files, 1948-50, Box 18. Vgl. auch, mit einer weiteren einschlägigen Stellungnahme Hoffmans vom Mai 1950, Volker Berghahn, Unternehmer und Politik in der Bundesrepublik, Frankfurt a. M. 1985, S. $135-136$.

${ }^{75}$ Knapp, Anfänge, S. 51. Vgl. auch Abelshauser, Wirtschaftsgeschichte, S. 152.

${ }^{76}$ Vgl. dazu Hans-Jürgen Schröder, Zur politischen Bedeutung der deutschen Handelspolitik nach dem Ersten Weltkrieg, in: Gerald D. Feldman u. a. (Hrsg.), Die deutsche Inflation. Eine Zwischenbilanz, Berlin/New York 1982, S. 235-251; Karl-Heinrich Pohl, Deutsche „Wirtschaftsaußenpolitik“ 1925/26. In einigen Aspekten der Stresemannschen Europa-Politik, in: Wolfgang Michalka/Marshall M. Lee (Hrsg.), Gustav Stresemann, Darmstadt 1982, S. 426-440. Das Zitat stammt aus der bereits zitierten Rede Stresemanns vom 14. 12. 1925, in: ADAP, Serie B, Bd. I, 1, S. 727-753, hier S. 729.
} 
nen Wirtschaft, sondern auch „die beste Sicherung eines echten und dauerhaften Friedens“. Ganz postnational-europäisch klang schließlich seine an die westlichen Nachbarn gerichtete Feststellung, in Europa dürften „Staatsgrenzen in diesem Stadium der Menschheitsgeschichte nicht mehr verschoben“, vielmehr müßten sie "durch immer stärkere Verflechtung allmählich uninteressant" werden. ${ }^{77}$ Gut einen Monat später apostrophierte Pünder den Marshallplan als die „erste wirklich große Hoffnung nach dem Zusammenbruch des Naziregimes“, zugleich aber auch als „letzte Chance“. Er zeigte sich zuversichtlich, daß „ein sehr großer Teil von Deutschland“ wieder „ein ehrliches und vollberechtigtes Mitglied der europäischen Gemeinschaft" werden könne. ${ }^{78}$ Ludwig Erhard, der Direktor der Verwaltung für Wirtschaft, präsentierte vor dem Wirtschaftsrat ebenfalls Vorschläge zur Neugestaltung der Außenbeziehungen. Die Geschichte war ihm Beweis genug - ,im Guten und im Bösen“ -, daß das deutsche "Schicksal von der Befriedung der Welt“ abhänge: Die Deutschen wüßten deshalb um ihre „Verpflichtung und Verantwortung“, sich „nur als Teil eines größeren Ganzen zu fühlen und entsprechend zu handeln“. Mit seinem Hinweis, daß der Marshallplan nicht auf einen „sich selbst genügenden, sogenannten Großraum“ abziele, weil njede künstliche oder bewußte räumliche Beschränkung auch den materiellen Erfolg begrenzen würde", entsprach er nicht nur amerikanischen Erwartungen; der künftige Wirtschaftsminister der Bundesrepublik formulierte damit zugleich eine der Maximen seines handelspolitischen Programms, ja seiner Integrationspolitik überhaupt. Etwas paradox mutet dagegen vor dem Hintergrund der damaligen Verhältnisse und wegen der späteren, in erster Linie wirtschaftlich fundierten Erfolgsgeschichte der Bundesrepublik seine Warnung an, die Wirtschaft drohe "wieder einmal zum Schicksal zu werden“ - schließlich konnte sich die „Staatspolitik“, deren Vorrang Erhard so entschieden verteidigte, für geraume Zeit kaum anderer als ökonomischer Mittel bedienen. Überdies war er sich, ebenso wie Pünder, der Bedeutung des heimischen Wirtschaftspotentials für den Wiederaufbau in Westeuropa sehr wohl bewußt. ${ }^{79}$ In der anschließenden ersten „parlamentarischen “ Aussprache über die deutsche Mitwirkung am Marshallplan bekannten sich fast alle Redner zur europäischen Zusammenarbeit und zu einem positiven Beitrag der Deutschen zum Wiederaufbau Europas. Auf die deutschlandpolitischen Konsequenzen der Westintegration machte jedoch nur der Zentrumsabgeordnete Fritz Stricker aufmerksam. Einzig die KPD verweigerte sich dem europapolitischen Konsens der anderen Parteien und attakkierte den Marshallplan - zum Teil übrigens mit den gleichen Argumenten, die hinter vorgehaltener Hand auch in CDU-Kreisen und in der Industrie, von Kritikern wie Fritz Baade sogar öffentlich vertreten wurden..$^{80}$

Unbeeindruckt von den mittlerweile unterzeichneten, aus deutscher Sicht eher enttäuschenden bilateralen Abkommen ging Pünder Anfang September vor dem ERP-Ausschuß noch einmal auf die außenpolitische Seite des Marshallplans ein, die für ihn auf lange Sicht gesehen „vielleicht von größerer Bedeutung" war als der unmittelbare wirtschaftliche Effekt. Er bezeichnete den Plan als „das Instrument, nach langen Jahren der Abriegelung gegenüber dem Ausland wieder den Anschluß an die Welt draußen zu finden“. Die Hoffnung, mit Hilfe des ERP in den „Kreis der Nationen“ zurückkehren zu

\footnotetext{
77 Vgl. Wörtliche Berichte des Wirtschaftsrates, Bd. 2, 13. Vollversammlung v. 16./17. 3. 1948, S. 361-366.

${ }^{78}$ Ebenda, 14. Vollversammlung v. 21./22. 4. 1948, S. 433-436.

79 Die Ansprache Erhards, ebenda, S. 436-445, die Zitate S. 443-444.

${ }^{80} \mathrm{Vgl}$. dazu ebenda, S. 481-490.
} 
können, stützte er auf die bei allen Beteiligten gewachsene Einsicht in die „wichtige Rolle" der deutschen Wirtschaft im europäischen Handelsaustausch. Ohne eine "gesunde westdeutsche Wirtschaft", versicherte der Vorsitzende des Verwaltungsrats seinen Zuhörern unter Berufung auf die Berichte der verschiedenen amerikanischen Untersuchungskommissionen, könne das Ziel des Marshallplans nicht erreicht werden. Zudem schaffe „die wirtschaftliche Interessierung“ auch ein Interesse am „allgemeinen Wohlergehen" Westdeutschlands, mithin eine "politische Interessierung" der Vereinigten Staaten am deutschen „Schicksal“. In der festen Überzeugung, mit den USA den Geldgeber zum Verbündeten zu haben, verteilte Pünder bereits Zensuren an die übrigen OEECPartner, die von einer wirklichen Zusammenarbeit "noch weit entfernt" seien. Zwar konstatierte er generös „erfreuliche Zeichen des Verständnisses für Deutschland“ - für ihn offenbar das wichtigste Kriterium europäischer Gesinnung -, doch alles in allem zeige sich "auch in Paris immer noch das unerfreuliche Bild einer Vernachlässigung der gesamteuropäischen Gesichtspunkte zugunsten einer Kirchturmspolitik, die nur auf einen möglichst großen Anteil des eigenen Landes an dem zu verteilenden Kuchen" ausgehe. ${ }^{81} \mathrm{Wie}$ sein Vorgesetzter unterstrich Schniewind die Vehikel-Funktion des Marshallplans und würdigte ihn als ein "besonders geeignetes Instrument“, Westdeutschland den Weg zu normalen internationalen Beziehungen zu ebnen. Als Argument gegen die alliierte Demontagepolitik und für die Revision der Potsdamer Beschlüsse erschien ihm das European Recovery Program ebenfalls gut geeignet. Möglichkeiten und Perspektiven einer „echten europäischen Zusammenarbeit" versuchte er vor allem mit dem Hinweis auf die positiven Folgen des deutschen Zollvereins im 19. Jahrhundert zu illustrieren. Die deutschen Politiker und Spitzenbeamten, daran ließ auch Schniewind keinen Zweifel, fühlten sich bereits als gute Europäer, während die meisten anderen OEECLänder verdächtigt wurden, „ihren eigenen Interessen in möglichst großem Umfang Geltung zu verschaffen" .82

Den zuständigen deutschen Stellen in der französischen Zone war die politische Bedeutung des Marshallplans und seine Instrumentalisierbarkeit im Sinne eigener Interessen und Ziele gewiß ebenfalls bewußt, wenngleich in den einschlägigen Stellungnahmen und Rechenschaftsberichten die wirtschaftlichen Aspekte und Auswirkungen des Plans eindeutig dominierten. ${ }^{83}$ Von außenpolitischen Gedankenspielereien - um sehr viel mehr handelte es sich zunächst ja nicht - hielten sich Albrecht, Sachs, Axenfeld und ihre Mitarbeiter wohl schon deshalb fern, weil ihre französischen Vorgesetzten alles taten, um entsprechende Ambitionen zu dämpfen; außerdem mußte es für die drei südwestdeutschen Länder zuallererst darum gehen, den Anschluß an die Bizone zu vollziehen, ehe an weitergesteckte Ziele zu denken war. In wirtschaftlicher Hinsicht waren die Erwartungen freilich ähnlich hoch wie auf bizonaler Seite. Aus diesem Grund hatte sich der spätere ECA-Missionschef in Baden-Baden, Hector Prud'homme, sogar schon im April 1948 veranlaßt gesehen, Averell Harriman auf die Risiken dieser Marshallplan-Eu-

81 Rede-Entwurf Pünder v. 6. 9. 1948, BA, Z 14, 8.

82 Vertraulicher Jahresbericht 1948 , bes. S. 2, 11 f. u. 23, BA, Z 14, 8.

${ }^{83} \mathrm{Vgl}$. Vertraulicher Abschlußbericht über die deutschen ERP-Arbeiten in der französischen Besatzungszone v. 24. 10. 1949, verf. v. Karl Albrecht, Institut für Weltwirtschaft, Kiel/Wirtschaftsarchiv (künftig IWW/WA), NL Baade, III ERP; Albrecht, Wunder, bes. S. 61-71. 
phorie hinzuweisen, die im Falle ausbleibender Erfolge rasch in ihr Gegenteil umschlagen konnte. ${ }^{84}$

Aus amerikanischer Sicht kam es deshalb darauf an, nicht nur die akuten wirtschaftlichen Probleme lösen zu helfen, sondern den Westdeutschen ein neues Ideal zu vermitteln - „the ideal that only as part of a Western European Union would they have any chance of surviving and that the desire of reacquiring complete national independence is antiquated and no longer responds to the present situation " $.85 \mathrm{Ob}$ die ersten "Außenpolitiker" Westdeutschlands diese Lektion wirklich begriffen hatten, oder ob sie lediglich, wie es von ihnen erwartet wurde, wohlfeile Bekenntnisse zur europäischen Zusammenarbeit abgaben, läßt sich nur schwer beurteilen: Eine realistische Alternative gab es nicht, sollte der Wiederaufbau zügig und mit Aussicht auf baldige Erfolge in Angriff genommen werden. Westdeutschland war keine Großmacht im Wartestand mehr, wie noch das Deutsche Reich nach dem Ersten Weltkrieg. Es gab vorerst keine Regierung, die deutsche Interessen - mit wie geringem Nachdruck auch immer - in internationalen Verhandlungen hätte vertreten können, ja nicht einmal über die inneren Verhältnisse konnten deutsche Stellen allein entscheiden. Zu einer offensiven Instrumentalisierung der heimischen Wirtschaft nach Weimarer Muster waren deutsche Politiker zunächst gar nicht in der Lage, da wichtige Industriezweige und vor allem der Außenhandel alliierter Kontrolle unterstanden. Die maßgeblichen Beamten und Planer auf deutscher Seite taten also gut daran, von vornherein auf Kooperation zu setzen und jeden Anschein eigener, "nationaler" Ambitionen zu vermeiden. Bei Pünder, Schniewind, von Mangoldt, Albrecht und den meisten übrigen, hauptsächlich mit ERP-Angelegenheiten befaßten deutschen Experten war die Bereitschaft dazu offenbar vorhanden. Andere, wie der Direktor der Verwaltung für Wirtschaft, Erhard, waren trotz gegenteiliger öffentlicher Äußerungen eher skeptisch, was Effizienz und Nutzen internationaler Zusammenarbeit anbelangte. ${ }^{86}$ Für diese Gruppe war eine Einstellung charakteristisch, die ein Mitarbeiter der Information Control Division der hessischen Militärregierung bei einer wachsenden Zahl deutscher Intellektueller und Politiker bemerkt haben wollte: „We will recover despite the Marshall Plan. ${ }^{17}$ Diese Kreise, zu denen auch mehrere Industrielle zu rechnen waren, begrüßten zwar die in Aussicht gestellten Warenlieferungen und Kredite, kritisierten aber den vermeintlichen Widerspruch zwischen dem Ziel und den "planwirtschaftlichen" Wegen dahin und warnten vor "Zwangswirtschaft" und "nationalistischer Wirtschaftspolitik". Herbert Gross, ein der Industrie nahestehender Wirtschaftsjournalist, bemängelte in einer internen Analyse sogar ein „Aufleben der britischen und französischen Empire-Autarkie, eine gegen Deutschland sich richtende intereuropäische Autarkie und ein unkoordiniertes, durch die planenden Staaten aber willkürlich verschärftes

84 Prud'homme an Harriman v. 23. 4. 1948, NA, RG 469, SRE, Confidential Records, 1948-49, Box 1.

${ }^{85}$ American Consul, Hamburg, an Sec State v. 23. 11. 1948, NA, RG 59, 862.50/11-2348.

${ }^{86}$ Die Ergänzung, die der Generalsekretär des Länderrats, Troeger, seinen Tagebuchnotizen nachträglich hinzufügte - Erhard sei "gegen die Ziele und Maßnahmen des Marshallplans" eingestellt gewesen und habe die Auffassung vertreten, „man solle uns das Geld geben, dann werden wir es besser anzuwenden verstehen“ - ist zwar nicht ohne quellenkritische Vorbehalte zu lesen; ganz aus der Luft gegriffen scheint die Erhard zugeschriebene Außerung freilich nicht zu sein; Troeger, Interregnum, S. 124. Vgl. auch Volker Hentschel, Ludwig Erhard. Ein Politikerleben, München u. Landsberg am Lech 1996, S. 58.

${ }^{87}$ Moll an OMGUS v. 6. 8. 1948, IfZA, MF 260, 5/268-3/1. 
Kämpfen um die Dollarmärkte. "88 Die Zustimmung zu der amerikanischen Initiative war also keineswegs einhellig. Mehr oder weniger offen artikuliert, hielt sich recht hartnäckig die Überzeugung, Westdeutschland käme auch alleine ganz gut zurecht, wenn nur die alliierten Eingriffe und Kontrollen endlich aufhörten. Die Probe auf den Realitätsgehalt sowohl der außenpolitischen Entwürfe der Optimisten wie der Befürchtungen der Skeptiker mußte die praktische Umsetzung des Wiederaufbauprogramms bringen. Allzu hochfliegende Pläne erhielten dabei zwar einen Dämpfer, aber zu größerem Pessimismus, dies wurde rasch deutlich, bestand dennoch kein Anlaß.

\section{Die Westzonen in der OEEC}

Die bizonale Ständige Vertretung bei der OEEC nahm im Mai 1948 mit einer Kernbesetzung ihre Arbeit auf. Zum Leiter wurde wenig später der Amerikaner Robert Trier, ein Bankier, ernannt, zu seinem Stellvertreter der Engländer Eric S. Jackson. Anfang Juni stießen, wie erwähnt, mit Frommel, Dörr und den beiden Sekretärinnen Irene Meyer und Ingeborg Coleman die ersten vier Deutschen dazu. Der deutsche "Chefdelegierte“ Hans-Karl von Mangoldt folge Ende Juli. Die Finanzierung des technischen Apparats und der deutschen Mitglieder der Delegation erfolgte durch die Joint Export-Import Agency: Sie stellte die erforderlichen Beträge aus den Exporterlösen der Bizone bereit und enthielt den entsprechenden DM-Gegenwert aus einem Globaltitel des bizonalen Haushalts. Die amerikanischen und britischen Bediensteten wurden aus den Etats der beiden Militärregierungen bezahlt. ${ }^{89}$

Die Delegation der französischen Zone stand unter der Leitung von René Larre vom Pariser Finanzministerium, als sein Stellvertreter fungierte Comte de Pierredon; Anfang Oktober $1948 \mathrm{kam}$ als ständiges deutsches Mitglied Theodor Axenfeld hinzu. Sein Spielraum scheint erstaunlicherweise recht groß gewesen zu sein, denn er durfte, zum Teil sogar schon vor seinem Wechsel in die französische Hauptstadt, an Sitzungen der technischen Komitees der OEEC als einziger Vertreter der französischen Zone teilnehmen. Das war gewiß ein Vertrauensbeweis für ihn, doch profitierte er offensichtlich mindestens ebensosehr von der häufigen Abwesenheit seiner Vorgesetzten. ${ }^{90} \mathrm{Im}$ allgemeinen scheint das Verhältnis zwischen französischen und deutschen Delegierten und Sachverständigen allerdings nicht so vertrauensvoll gewesen zu sein, klagte doch Albrecht noch im Februar 1949 über eine ,unzureichende deutsche Vertretung in den technischen Unterausschüssen " und über mangelhafte oder gänzlich vorenthaltene Informationen seitens französischer ERP-Verantwortlicher. ${ }^{91}$

Wie groß der deutsche Spielraum, abgesehen von den gerade in der Anlaufphase nicht unbeträchtlichen bürokratischen Erschwernissen, ${ }^{92}$ letztlich war, mußte sich nun bei der

${ }^{88}$ „Kritische Gedanken zum Marshall-Plan“, Ausarbeitung Gross v. 16. 1. 1949, Haniel-Archiv, Oberhausen (künftig HAO. - Mittlerweile werden die Akten im Rheinisch-Westfälischen Wirtschaftsarchiv zu Köln aufbewahrt), NL H. Reusch, 4001290/4.

${ }^{89} \mathrm{Vgl}$. Draft History of BICO: ERP, bes. S. 54-59, IfZA, MF 260, 3/409-1/22; Rieck an Paulssen v. 13. 5. 1949, BA, Z 14, 76; Vogel, Westdeutschland, bes. S. 286-288.

90 Vgl. Protokoll 19. Sitzung Handelsausschuß v. 23. 8. 1948, MAE, Y 1944-1949, Vol. 131; Vogel, Westdeutschland, bes. S. $295 \mathrm{f}$.

91 Vermerk Albrecht v. 22. 2. 1949, BA, Z 14, 156.

92 Vgl. Bührer, Auftakt, bes. S. $542 \mathrm{f}$. 
Inangriffnahme der kurz- und langfristigen Aufgaben im Rahmen der OEEC sowie in den Verhandlungen mit den Militärregierungen und den ECA-Missionen herausstellen. Die erste Bewährungsprobe für die Deutschen vor Ort und in den ERP-Stäben zu Hause kam schneller, als ihnen vermutlich lieb war: Bei der Ausarbeitung der Wiederaufbaupläne, zunächst des Plans für das Jahr 1948/49, mußten sie ihre Kompetenz unter Beweis stellen. Zugleich war dies die erste Gelegenheit, die Tragfähigkeit der zumindest ansatzweise entwickelten außenwirtschaftlichen und außenpolitischen Konzeptionen des Wiedererstarkens via Kooperation zu testen. Hinter dürren Produktionsziffern, Ein- und Ausfuhrschätzungen oder Prognosen zur Zahlungsbilanz verbargen sich also jeweils unterschiedliche Konzepte für die zukünftige Rolle Westdeutschlands.

\section{a) Wiederaufbauprogramme}

Um das Ziel der „viability“ - der wirtschaftlichen Lebensfähigkeit der OEEC-Länder, unabhängig von fremder Unterstützung - innerhalb der vom Marshallplan gesetzten Vierjahresfrist zu erreichen, mußten die amerikanische Hilfe und die in Westeuropa vorhandenen Ressourcen möglichst effektiv zum Einsatz gebracht werden. Die dafür notwendigen Koordinierungsarbeiten sollten, auf Wunsch der ECA, hauptsächlich von der OEEC übernommen werden. Wie schon zur Vorbereitung des CEEC-Schlußberichts im Herbst 1947 sollten die Teilnehmerländer erneut Produktions- und Bedarfspläne aufstellen, die in Paris zu einem koordinierten und integrierten Gesamtprogramm umformuliert werden sollten, das zugleich als Richtschnur für die Verteilung der ERP-Mittel gedacht war. Benötigt wurden zwei Arten von Programmen: Neben Plänen, welche an die vom US-Kongreß durchgesetzten jährlichen Bewilligungszeiträume angeglichen waren, forderte die OEEC von ihren Mitgliedern ein "Long-Term-Program“ an, das den gesamten Zeitraum abdecken und eine Auflistung jener Schritte und Maßnahmen enthalten sollte, dank derer die Regierungen eine ausgeglichene Handels- und Zahlungsbilanz zu erreichen hofften. Die langfristigen Programme waren also stärker wirtschaftspolitisch akzentuiert, während die Jahrespläne einen eher technischen Charakter aufwiesen; letztere dienten auch als Grundlage für die Aufstellung konkreter Vierteljahrespläne, die in standardisierter Form „Einzelheiten über Art und Menge der benötigten Waren, Preise und Lieferländer" enthielten und den Anteil der ECA-finanzierten Einfuhren bestimmten. ${ }^{93}$ Anders als beim CEEC-Report sollten die nationalen Pläne dieses Mal jedoch tatsächlich auf ihre innere Stimmigkeit und ihre Kompatibilität miteinander sowie mit den allgemeinen Zielen des Marshallplans untersucht werden.

Die bei der Formulierung der Pläne anzuwendenden Verfahren und die Auswahl der Daten waren im zuständigen OEEC-Ausschuß nicht unumstritten. Insbesondere der Vorschlag der ECA, Planziffern für Produktion, Verbrauch, Ein- und Ausfuhr sowie den Lagerbestand aller Güter anzugeben, deren Ex- und Importvolumen den Wert von 100000 Dollar überschritt, erregte Anstoß. Die britische Delegation bezweifelte sogar, ob derart detaillierte Angaben überhaupt notwendig seien. Sie befürchtete nicht nur, daß Arbeitskraft vergeudet und die Aufmerksamkeit von politischen auf statistische Pro-

\footnotetext{
${ }^{93}$ Helmut Meinhold, Dic wirtschaftlichen Gründe des Marshall Plans, in: Wirtschaftsverwaltung 2 (1949), Sonderdruck aus H. 6. u. 7, das Zitat S. 7. Vgl. auch van der Beugel, Marshall Aid, S. 139-172; Wexler, Marshall Plan, S. 57-70, 208-217; Brähler, Marshallplan, S. 229-233.
} 
bleme abgelenkt werden würde; sie war auch überzeugt, daß das erforderliche planerische Instrumentarium in den Mitgliedsländern gar nicht vorhanden sei. Überdies stellten die Briten die Verläßlichkeit der Daten in Frage: „It would be extremely difficult to distinguish, within such a mass of detail, those figures which represent serious planning or realistic forecasts from those which represent no more than exercises in imaginative statistics." 94

Wichtiger als solche gewiß triftigen Einwände war aus der Sicht Pünders und seiner Kollegen jedoch, daß deutsche Stellen und Experten damit erstmals die Chance erhielten, auf die Programme für die Bizone und die französische Zone Einfluß zu nehmen, mag dieser Einfluß zunächst auch noch so gering gewesen sein. Außerdem gestatteten die Pläne erste Eindrücke von den Vorstellungen der Partnerländer über die Rolle Westdeutschlands im westeuropäischen Verbund. Der Dirigismusvorwurf, der später gegen die „Planwirtschaftler" der ECA und der OEEC erhoben wurde, spielte zu diesem Zeitpunkt noch keine Rolle. Die wirtschafts- und ordnungspolitische Wende stand noch bevor.

\section{Aufbauplan 1948/49}

Der offizielle Anstoß zu den Planungsarbeiten für das erste Marshallplanjahr war in der Bizone, wie erwähnt, am 17. Februar 1948 vom Zweimächtekontrollamt gekommen. Zur Begründung hatte es damals allerdings noch geheißen, daß der US-Kongreß zur Beschlußfassung über das ERP diese Daten benötige. Im Grunde war es zunächst eher darum gegangen, die aus Washington übermittelten Daten zu kommentieren, als selbständig einen Produktions- und Bedarfsplan aufzustellen. ${ }^{95}$ Entsprechende "inoffizielle" Gespräche mit deutschen Stellen waren aber offensichtlich schon vorher aufgenommen worden: Anfang Februar hatte das Zweimächteamt eine Ex- und Importliste überreicht, und am 16. Februar lag eine erste deutsche Stellungnahme zum Außenhandel vor. ${ }^{96}$ Unabhängig vom Marshallplan hatte die bizonale Wirtschaftsverwaltung jedoch bereits damit begonnen, sich wie im Vorjahr eine Übersicht zu verschaffen, „welche wirtschaftlichen Ziele bei Anspannung aller Kräfte im Verlauf des Wirtschaftsjahres erreichbar sein würden ". ${ }^{77}$ Die Aufforderung, einen ERP-Aufbauplan auszuarbeiten, traf die deutschen Experten also nicht unvorbereitet.

Schon der Außenhandelsplan vom 16. Februar und der Kommentar des VfW-Beamten Strauss zur Ex- und Importliste ließen erkennen, daß Amerikaner und Deutsche in ihren Prognosen zu ähnlichen absoluten Größenordnungen gelangten, ${ }^{98}$ die Auffassungen über die Zusammensetzung der Ein- und Ausfuhren jedoch teilweise stark divergierten. Aber selbst nach dem Exportvorschlag der Verwaltung für Wirtschaft, der ein breitgefächertes Warenangebot enthielt, sollte etwa die Hälfte des geplanten Devisener-

94 „Programme for the Year 1948-49“, Comments by U. K. Delegation v. 21. 5. 1948, IfZA, MF 260, 11/ 90-2/9. Vgl. auch die - nicht so kritische - französische Stellungnahme gleichen Datums, ebenda, und die Debatte im OEEC-Rat C/M (48) 4 v. 10. 5. 48, HAEC, OEEC, 1.

${ }^{95} \mathrm{BICO}$ an Vors. bizonales Exekutivkommitee v. 17. 2. 1948, BA, NL Pünder, 704.

96 Vgl. Verwaltung für Wirtschaft an BICO v. 24. 2. 1948 u. Aufbauplan 1948, Teilplan Außenhandel v. 16. 2. 1948 , beide in IfZA, MF $260,1 / 178-1 / 18$.

97 Helmut Meinhold, Erläuterungen zum Aufbauplan 1948/49 für die Wirtschaft der Vereinigten Wirtschaftsgebiete, in: Wirtschaftsverwaltung 1 (1948), H. 3, S. 28-38, hier S. 28.

98 Vgl. „Der Anteil der Bizone am ERP über die Unterlagen der Pariser Verhandlungen“, ungez. Artikel in: Wirtschaftsverwaltung 1 (1948), H. 8, S. 19-21, hier S. 19. 
löses von mindestens 600 Mio. Dollar durch die Ausfuhr der Rohstoffe Kohle im Wert von 240 und Holz im Wert von 60 Mio. erzielt werden. Die Ziffern für jene Branchen, die aus deutscher Sicht besonders wichtig waren, lagen mit 40 Mio. Dollar für den Maschinenbau, 30 Mio. für die Sparte Eisen-, Blech- und Metallwaren, 30 Mio. für Feinmechanik und Optik, 20 Mio. für Chemie und 12,5 Mio. für die Stahlindustrie noch immer mehr oder weniger deutlich unter den für notwendig erachteten Mengen. Es war jedenfalls nicht zu übersehen, daß die BICO-Liste größeres Gewicht auf Roh- und Halbwaren legte, während die Exportplanung der VfW im Interesse höherer Erlöse und der Rückgewinnung des früheren Kundenstammes hauptsächlich auf Fertigerzeugnisse, vor allem Maschinen, abgestellt war. ${ }^{99}$ Die ersten amerikanisch-britischen Vorschläge waren also noch stark vom Denken der Zeit vor dem Marshallplan geprägt; die deutschen Instanzen zeigten sich indes entschlossen, die eigene Konzeption offensiv dagegenzusetzen.

Termingerecht, am 12. März 1948, reichte der Oberdirektor den bizonalen Aufbauplan beim Zweimächtekontrollamt ein. ${ }^{100}$ Die Reaktion fiel negativ aus: „Ohne unsere Vorlage ... irgendwie kritisieren zu wollen“, notierte Pünder nach einer Unterredung mit Vertretern des Kontrollamts, hätten seine Gesprächspartner moniert, daß „zu wenig berücksichtigt scheine, daß dies der erste offizielle deutsche Schritt in internationalen Angelegenheiten sei, der insbesondere von den in Paris gesammelten 16 Nationen eingehend und zweifellos sehr kritisch überprüft" werden würde. Außerdem sei der Plan in seinen Zahlenangaben "teilweise zu knapp und teilweise wohl auch ungenau“.101 Eine Stellungnahme des $Z$ weimächteamts vom 18 . März bekräftigte diese mündlich vorgetragenen Einwände unter Hinweis auf die außenpolitische Bedeutung des deutschen Vorschlags, der deshalb „das Bewußtsein der Verantwortung widerspiegeln sollte, welche die Bizone gemeinsam mit anderen beteiligten Nationen zu übernehmen bereit sein" müsse. Wo die Defizite im einzelnen gesehen wurden, verdeutlichte die Forderung, die Bizone müsse den höchstmöglichen Beitrag bei so wichtigen einheimischen Rohstoffen wie Kohle, Stahlschrott und Holz einplanen. Kurzum: Eine Revision und Erweiterung des Aufbauplans waren unumgänglich. ${ }^{102}$

Am 25. März, wiederum fristgerecht, präsentierte Pünder den zuständigen alliierten Stellen die überarbeitete Fassung. Zunächst als offizieller Vorschlag gedacht, wurde der Plan doch nur als „Diskussionsgrundlage" behandelt, nachdem die bizonalen Repräsentanten in Paris, Sir Cecil Weir und Lawrence Wilkinson, signalisiert hatten, daß er ,in der vorgesehenen Form unter keinen Umständen" vorgelegt werden könne. Die Haupteinwände des Z $\mathrm{Z}$ weimächtekontrollamtes richteten sich dieses $\mathrm{Mal}$ gegen die immer noch zu geringe Schrottausfuhr, die vorgesehene Einfuhr von 5,5 Mio. Tonnen Kohlen sowie den geplanten Importüberschuß in Höhe von 1,58 Mrd. Dollar - also im wesentlichen nach wie vor gegen die vermeintlich fehlende deutsche Bereitschaft, die eigenen Ressourcen und Produktionsmöglichkeiten zugunsten des europäischen Wiederaufbaus op-

${ }^{99}$ Aufbauplan 1948 u. VfW an BICO v. 24. 2. 1948 (dort auch die Zitate), beide in IfZA, MF 260, 1/178-1/ 18.

100 Vgl. dazu AVBRD 3, Dok. 38, S. 413-414. Ein Exemplar des Plans findet sich u. a. in BA, NL Pünder, 704. Vgl. auch Gerd Hardach, The Marshall Plan in Germany, 1948-1952, in: Journal of European Economic History, 16 (1987), S. 433-485, bes. S. 442-454.

101 Vermerk Pünder v. 19. 3. 1948, BA, NL Pünder, 704.

102 "Bemerkungen zu der Vorbereitung des deutschen Wiederaufbauplanes und dessen Vorlegung bei der Pariser Konferenz" v. 18. 3. 1948, ebenda. 
timal auszuschöpfen. Während sich die alliierten und deutschen Experten rasch auf eine Verdoppelung des Schrottexports auf 1,2 Mio. Tonnen einigen konnten, scheiterte eine Verständigung über die Kohlenbilanz. Obwohl die Vertreter der Militärregierung die Bedarfszahl von 64 Mio. Tonnen - bei einer nach Abzug der Ausfuhren gemäß dem sogenannten Moskauer Kohlenverteilungsplan und anderen Verpflichtungen noch verfügbaren Menge von 59 Mio. Tonnen - als berechtigt anerkannten, rieten sie von Kohlenimporten zur Deckung dieser Lücke dringend ab. In der Frage der Waren- und Dienstleistungsbilanz schließlich stellten sie kategorisch fest, daß höchstens ein Defizit von etwa 1,2 Mrd. Dollar tragbar sei. Nach dieser neuerlichen alliierten Kritik machte sich auf deutscher Seite Ernüchterung breit. Angesichts der „offensichtlichen Schwächen und Risiken des jetzigen gekürzten Planes", faßte der bayerische Wirtschaftsminister Hanns Seidel die Debatten in den zuständigen Gremien des Länderrats zusammen, sei allen Beteiligten klar, daß „wirklich fühlbare Verbesserungen in der Versorgungsgrundlage bestenfalls nach einer relativ langen Anlaufzeit eintreten“ würden und „ein sachlich nicht gerechtfertigter Optimismus die wachsende Ungeduld des Volkes nur noch verschärfen" könne. 103

Der am 9. April 1948 fertiggestellte, nun bereits zweimal überarbeitete Aufbauplan 1948/49 für die bizonale Wirtschaft versuchte die Einwände des Zweimächtekontrollamtes weitgehend zu berücksichtigen. ${ }^{104}$ In einem auf den 13. April datierten Begleitschreiben bat Pünder um Verständnis dafür, daß das Vereinigte Wirtschaftsgebiet infolge der Kriegsschäden noch nicht imstande sei, „den Beitrag zum europäischen Wiederaufbau zu leisten, der seinen Wünschen und Erwartungen der europäischen Nationen und der Vereinigten Staaten" entspreche. Wie sehr ihm daran lag, mögliche Vorwürfe wegen unzureichender deutscher Leistungen von vornherein zu entkräften, erhellt nicht zuletzt daraus, daß er wenigstens für die Zukunft den "größtmöglichen Beitrag“, die „stärkstmögliche Beteiligung " in Aussicht stellte. ${ }^{105}$ Auch der Aufbauplan war von dem Bemühen gekennzeichnet, den Partnern plausibel zu machen, warum die westdeutsche Wirtschaft den erwarteten und angestrebten Beitrag vorerst nicht erbringen konnte, oder, anders formuliert, warum die Bizone zunächst die Rolle des Hilfsempfängers beanspruchte: Erst nach einer grundlegenden wirtschaftlichen Gesundung könne sie „an frühere Leistungen zum Nutzen des westeuropäischen Wiederaufbaus" anknüpfen; dazu bedürfe die Bizone jedoch einer „kräftigen Bluttransfusion in Gestalt von Nahrungsmitteln, Rohstoffen und Produktionshilfsmitteln“. Das Gegenangebot fiel merklich bescheidener aus. Heimische Rohstoffe wie Kohle, Schrott und Holz wollte das Vereinigte Wirtschaftsgebiet lediglich „unter Berücksichtigung des eigenen Bedarfes... zum gesamteuropäischen Wiederaufbau beisteuern".

${ }^{103}$ Bericht des bayerischen Wirtschaftsministers Seidel über die Sitzung des Wirtschafts- und des Landwirtschaftsausschusses des Länderrats am 7. 4. 1948, Anlage zum Protokoll der Länderratssitzung v. 14./15. 4. 1948, PA, Bestand 2/605; auch Bespr. Militärgouverneure - bizonale Vcrtreter v. 14. 4. 1948, AVBRD 3, Dok. 43, S. 416, Anm. 32.

104 Vgl. Direktorialsitzung v. 9. 4. 1948, AVBRD 3, Dok. 42, S. 448-449. Die Langfassung des Plans findet sich u. a. in BA, Z 8, 198; die Kurzfassung ebenda, NL Pünder, 704 sowie in Wirtschaftsverwaltung 1 (1948), H. 1, S. 15-19.

105 Pünder an BICO v. 13. 4. 1948. Der Text war gegenüber dem Schreiben, mit dem Pünder die Fassung vom 25. März übersandt hatte, kaum geändert. Allerdings war nun nicht mehr von dem „gerechten Verlangen“, sondern nur noch von den "Erwartungen der anderen Nationen" die Rede, und aus der "stärksten“" war die „stärkstmögliche“ Beteiligung des Vereinigten Wirtschaftsgebietes geworden. Vgl. Abdruck des früheren Schreibens in AVBRD 3, Dok. 43, Anm. 12. 
Die Angaben zur Zahlungsbilanz spiegelten dieses Mißverhältnis eindrucksvoll wider: Einfuhren in Höhe von 1,96 Mrd. Dollar - davon entfielen 45 Prozent auf Nahrungsmittel, 16 Prozent auf Rohstoffe und Halbfabrikate, ebenfalls 16 Prozent auf Konsumgüter und 7 Prozent auf Investitionsgüter - standen Ausfuhren im Wert von 695 Mio. Dollar gegenüber: Kohle, Holz und Schrott, aber auch hochwertige industrielle Fertigwaren im Wert von etwa 300 Mio. Dollar - Waren, welche die „darniederliegende Wirtschaft und die seit vielen Jahren notleidende Bevölkerung selbst auf das dringendste“ benötigte. Damit demonstrierte die Bizone, wie es im Plan ausdrücklich hieß, ihr „starkes Interesse an einer möglichst engen Verflechtung mit der übrigen Welt“. Daß sogar die Steigerung des Fertigwarenexports, erklärtes Ziel der deutschen Wirtschaftspolitik, noch als „Opfer“ verbrämt wurde, dürfte weniger Ausdruck propagandistischer Skrupellosigkeit als ernster Beweisnöte in puncto deutscher Kooperationsbereitschaft gewesen sein. Erst zu einem späteren Zeitpunkt, lautete, auf einen Nenner gebracht, die „Botschaft“ des Aufbauplans, werde die westdeutsche Wirtschaft „ihrer materiellen und sittlichen Verpflichtung zur Förderung der Ziele des Marshallplans“ nachkommen können. ${ }^{106}$ Helmut Meinhold, in der Verwaltung für Wirtschaft mit ERP-Angelegenheiten befaßt, beeilte sich denn auch, den Plan nicht als eine „politische Anforderungsliste“, sondern als eine "rein sachliche Feststellung“ der allernotwendigsten Importe zu charakterisieren, nachdem in der ausländischen Presse, beispielsweise im „Economist“, Kritik an der Höhe des vorgesehenen Zahlungsbilanzdefizits laut geworden war. ${ }^{107}$

Der Aufbauplan sorgte aber auch in der innerdeutschen Diskussion für einigen Wirbel. Zum einen wünschten die beiden Militärregierungen, um den Eindruck zu vermeiden, es handle sich um einen ausgesprochenen CDU-Vorschlag, positive Erklärungen der maßgeblichen politischen Instanzen und Parteien. Als Vertreter des Länder- und des Wirtschaftsrates dieses Ansinnen zunächst ablehnten, weil sie den deutschen Vorschlag noch gar nicht kannten, verärgerten sie die Besatzungsoffiziere; außerdem entstanden zwischen den verschiedenen "staatlichen“ und "parlamentarischen“ Instanzen der Bizone beträchtliche Spannungen. Insbesondere der Länderrat kritisierte den Alleingang der Verwaltungsbürokratie und forderte für die Zukunft größere Mitspracherechte. Daß sich die SPD dieser Forderung anschloß, war aus innenpolitischen Gründen zwar verständlich, letztlich aber nicht ganz fair, denn in Gestalt des VfW-Beamten Günter Keiser spielte ein Sozialdemokrat eine, wenn nicht die maßgebliche Rolle bei der Formulierung des Aufbauplans. ${ }^{108}$ Zum anderen attackierte die SPD den deutschen Vorschlag, offensichtlich unter Rückgriff auf die Thesen Baades, auch inhaltlich als unzureichend und allzu bescheiden: Westdeutschland, so stand in einem Informationsdienst der Partei im April $1948 \mathrm{zu}$ lesen, dürfe nicht als „Ausräuberungsgebiet für Rohstoffe“ mißbraucht werden. ${ }^{109}$

Wie sich bald herausstellte, war diese ganze Aufregung jedoch ziemlich überflüssig. Selbst die dritte und vorerst letzte Version des Jahresprogramms 1948/49 fand am Ende keine Billigung als offizieller Vorschlag der Bizone und wurde „in Paris praktisch nicht

\footnotetext{
106 Aufbauplan 1948/49, I. Gesamtplan, BA, NL Pünder, 704; vgl. auch Hardach, Marshall-Plan, S. 213 215.

107 Meinhold, Aufbauplan, S. 38.

108 Vgl. dazu Bespr. Militärgouverneure - bizonale Vertreter v. 14. 4. 1948, AVBRD 3, Dok. 43, S. 460-463, bes. Anm. 34; Troeger, Interregnum, S. 75-76.

${ }^{109}$ Sopade - Sonderdienst Nr. 154 v. April 1948, zit. n. Troeger, Interregnum, S. 76.
} 
verwertet". ${ }^{110}$ Was sich schon während der inneramerikanischen Debatten über das Auslandshilfegesetz angekündigt hatte, erfuhr nun, in den Verhandlungen innerhalb der OEEC und mit der ECA im Sommer 1948, seine Bestätigung: Ausschlaggebend für die Zuteilung der ERP-Mittel waren weniger die jeweiligen nationalen Pläne, als vielmehr die amerikanischen Kalkulationen. Und diese addierten sich bekanntlich zu einem kleineren Gesamtbetrag als von der OEEC vorgesehen - mit der Konsequenz, daß die Länderanteile ebenfalls gekürzt werden mußten. ${ }^{111}$

Die Bizonenvertretung legte in Paris Ende Juli 1948 schließlich zwei Pläne mit entsprechenden Erläuterungen vor, von denen sich einer, „X-Plan“ bzw. „Budgetplan“ genannt, exakt an den ECA-Vorschlag von 445 Mio. Dollar hielt. Die Autoren des beigefügten Memorandums folgten allerdings insofern der deutschen Kritik an dieser - zu knapp bemessenen - Quote, als sie betonten, daß die Bizone bei Bewilligung eines höheren Betrages zu einem früheren Zeitpunkt als wichtige „europäische Hilfsquelle“ für Investitionsgüter und andere Produkte, die sonst aus dem Dollar-Raum bezogen werden müßten, dienen könnte. Überhaupt war in dem Memorandum deutlich weniger die Rede von Rohstoffexporten, wie noch in der Reaktion des Zweimächteamts auf den ersten Aufbauplan angemahnt, sondern vielmehr von der künftigen Rolle der Bizone als „recht bedeutende Bezugsquelle“ für Investitionsgüter. ${ }^{112}$ Der „Y“- oder „Bedarfsplan“ orientierte sich hingegen stärker an den tatsächlichen Erfordernissen und Möglichkeiten der Zweizonenwirtschaft. Er hob vor allem darauf ab, daß zunächst einmal die Versorgung der Bevölkerung mit Lebensmitteln, Bekleidung und anderen Verbrauchsgütern verbessert werden müsse, ehe an eine nennenswerte Steigerung der Produktion und damit des bizonalen Beitrags zum europäischen Wiederaufbau zu denken sei. ${ }^{113}$ Auffallend ist das Bemühen, das eher enttäuschende „Angebot“ des Vereinigten Wirtschaftsgebietes aufzuwerten: „In spite of the low level of economic activity, the programme includes a considerable contribution to the programmes of other countries in an effort to further a joint European programme", hieß es beispielsweise in den Erläuterungen zum Bedarfsplan; vorsorglich wurde zugleich an das Verständnis der übrigen OEEC-Partner appelliert: "The extremely low level of activity from which the Bizone starts must be taken into consideration when assessing this contribution. " ${ }^{114}$ Bei aller - teilweise recht massiven - internen Kritik an den Entwürfen deutscher Experten verhielten sich die amerikanischen und britischen Repräsentanten der Bizone in Paris also ausgesprochen fair gegenüber ihren Schützlingen.

Die OEEC ließ sich von diesen Argumenten allerdings nicht beeindrucken. Der Aufgabe, die von amerikanischer Seite durchgesetzten Kürzungen auszugleichen, versuchte sie nämlich dadurch gerecht zu werden, daß sie Dollar-Einfuhren in entsprechendem

$110 \mathrm{Vgl}$. „Der Anteil der Bizone am ERP“, ungez. Artikel in: Wirtschaftsverwaltung 1 (1948), H. 8, S. 1921, hier S. 20.

111 Vgl. Wexler, Marshall Plan, S. 59-65.

112 „Jahresprogramm 1948/49. Die Wirkungen des ersten ,Budget Programme' auf das wirtschaftliche Leben der Bizone (X-Plan)“ v. 27. 7. 1948, Anlage zum Rundschreiben Nr. 3 des ERP-Arbeitsausschusses, PA, Bestand 2/608; die englische Fassung in IfZA, MF 260, 11/122-1/13. Vgl. hierzu und zum folgenden insgesamt Vermerk Martini über die Sitzung des interfraktionellen ERP-Ausschusses v. 7.9. 1948, BA, Z 14,8; 14. Direktorialsitzung v. 15. 6. 1948, AVBRD 3, Dok. 42, S. 619-620, bes. Anm. 4.

113 „ERP für die Bizone, Wirtschaftsjahr 1948/49. Detaillierte Erklärung des Requirements Program für das erste Jahr (Y-Plan)", o. D., Anlage zum Rundschreiben Nr. 3 des ERP-Arbeitsausschusses, PA, Bestand $2 / 608$.

${ }^{114}$ „ERP for Bizonal Area of Germany. Fiscal Year 1948/49“ v. 27. 7. 1948, IfZA, MF 260, 11/122-1/13. 
Umfang durch Lieferungen aus den Mitgliedsländern ersetzte; dieser Warenverkehr sollte über ein Clearingsystem von den potentiellen Überschußländern in der OEEC finanziert und die auf diese Weise eingesparten Dollarbeträge von den ERP-Zuteilungen abgezogen werden. Für die Bizone ergaben sich aus dieser Operation, einem Vorgriff auf das weiter unten ausführlicher behandelte Abkommen über den innereuropäischen Zahlungs- und Verrechnungsverkehr, eine Marshallhilfe in Höhe von 364 Mio. Dollar und Kredite in europäischer Währung im Wert von 6 Mio. Dollar. Als die OEEC dann noch, um des Problems Herr zu werden, daß alle Teilnehmer aus dem Clearing Kredite erwarteten, für die Bizone kurzerhand einen europäischen Ausfuhrüberschuß von 91 Mio. Dollar festlegte, ${ }^{115}$ der von den verbliebenen ERP-Mitteln abzuziehen gewesen wäre, drohte der Hilfsbetrag gar auf 273 Mio. Dollar zu schrumpfen. Nach massiven Protesten der bizonalen Delegation, des ECA-Sonderbeauftragten Harriman und nicht zuletzt Clays setzte der OEEC-Rat am 11. September 1948 die Wirtschaftshilfe schließlich auf 414 Mio., den - davon abzuziehenden - europäischen Überschuß auf 10 Mio. Dollar fest. ${ }^{116}$ Allem Anschein nach hatte die kompromißlose Haltung des amerikanischen Militärgouverneurs letztlich den Ausschlag gegeben; mit dem Vorwurf an die Adresse der britischen OEEC-Delegation, sie betreibe aus Angst vor Kürzungen des eigenen Anteils Obstruktionspolitik gegenüber der Bizone, hatte er sogar eine Konfrontation mit dem britischen Partner riskiert. ${ }^{117}$ Und für den Fall einer zu niedrigen Quote hatte Clay mit Stimmenthaltung in der OEEC gedroht, um zu demonstrieren, daß eine wirtschaftliche Gesundung der Bizone und damit ein Beitrag zum europäischen Wiederaufbau auf dieser Basis ausgeschlossen sei. ${ }^{118}$ Der amerikanische Militärgouverneur war jedenfalls fest entschlossen gewesen, eine ungerechte ERP-Zuteilung zu verhindern - und hatte sich damit am Ende gegen die zunächst "gesamteuropäisch“ argumentierende ECA durchgesetzt. ${ }^{119}$ Pünder, Schniewind und andere deutsche ERP-Verantwortliche lobten zwar ausdrücklich den amerikanischen Einsatz, die Enttäuschung über das Ergebnis der Beratungen in Paris und Washington war dennoch nicht zu überhören: „Mit diesen Beträgen wirtschaftlich so schnell vorwärtszukommen, wie es im deutschen und im europäischen Interesse erforderlich wäre“, hieß es beispielsweise in einem resümierenden Beitrag in der offiziellen Zeitschrift der Verwaltung für Wirtschaft, sei „unmöglich“.120

Verglichen mit der Bizone schnitt die französische Zone, relativ gesehen, etwas besser ab. Die Mitsprachemöglichkeiten deutscher Experten bei der Aufstellung des Planes

115 Vgl. Bizonal Delegation, Wochenbericht v. 23.-28. 8. 1948, Anlage "Conditional Aid“ v. 31. 8. 1948, BA, Z 14, 47.

116 Vgl. Bizonal Delegation, Wochenbericht v. 6.-11. 9. 1948, ebenda. Vgl. auch „Der Anteil der Bizone am ERP“, in: Wirtschaftsverwaltung 1 (1948), H. 8, S. 19-21; Werner Abelshauser, Der Kleine Marshallplan. Handelsintegration durch innereuropäische Wirtschaftshilfe 1948-1950, in: Helmut Berding (Hrsg.), Wirtschaftliche und politische Integration in Europa im 19. und 20. Jahrhundert, Göttingen 1984, S. 212-224.

117 Telegramm an Foreign Office v. 31. 8. 1948, PRO, FO 317/70736; vgl. auch Telefonkonferenz v. 30. 8. 1948, Clay Papers I, S. 790-796, bes. S. 791.

118 Robertson an Foreign Office v. 1. 9. 1948, ebenda.

119 Vgl. Telefonkonferenz Clay-Draper v. 30. 8. 1948, Clay Papers II, S. 790-792. Zum Verhältnis Clay/ Department of Army - ECA vgl. Hoffmann an Harriman v. 30. 8. 1948, NA, RG 469, ECA, Deputy Administrator, Country Files 1948-49, Box 1. Vgl. insgesamt auch van der Beugel, Marshall Aid, S. 153-155; Werner Abelshauser, Hilfe und Selbsthilfe. Zur Funktion des Marshallplans beim westdeutschen Wiederaufbau, in: VfZ 37 (1989), S. 85-113, bes. S. $93 \mathrm{f}$.

120 „Der Anteil der Bizone am ERP“, in: Wirtschaftsverwaltung 1 (1948), H. 8, S. 21. 
waren allerdings noch geringer als in der Bizone. Die Überlegungen, die im Koordinierungsausschuß und in der ERP-Geschäftsstelle in Baden-Baden angestellt wurden, dienten mehr dem Zweck, Argumente für den Fall parat zu haben, daß die Vorschläge der französischen Militärregierung zu sehr von den eigenen abwichen.

Im Vordergrund des Aufbauplans 1948/49 der französischen Zone stand die Verbesserung der Ernährungssituation. Ziel war es, durch höhere Lebensmitteleinfuhren die Mindestversorgung auf etwa 2000 Kalorien anzuheben; daneben sollte aber auch die Erzeugung der heimischen Landwirtschaft zumindest auf das Niveau von 80 Prozent der durchschnittlichen Erträge der Jahre 1935 bis 1938 gesteigert werden. Ein besonders heikler Punkt waren die Holzanforderungen, da die französischen Ziffern für Einschlag und Export den von deutscher Seite errechneten Zuwachs im Jahr 1948 um 286 Prozent übertrafen. Einen spürbar geringeren Einschlag vermochten die deutschen Sachverständigen erst für das Jahr 1949 durchzusetzen. Ein weiterer wichtiger Teil des Programms galt dem Energie- und Rohstoffbedarf; während die Abhängigkeit von Rohstoffimporten struktureller Natur war, hielten die deutschen Experten auf dem Energiesektor eine Befriedigung des Bedarfs aus heimischen Ressourcen für möglich, wenn die französischen Stromentnahmen, noch dazu zu Preisen unter dem üblichen Niveau, aufhörten. Der Aufbauplan war also „in erster Linie auf verbesserte Deckung des Nahrungsmittelund Konsumgüterbedarfs abgestellt", wie Karl Albrecht, der Leiter des Koordinierungsausschusses rückblickend einräumte, „während sowohl das Investitionsprogramm wie die sonstigen Möglichkeiten für einen langfristigen Wiederaufbau infolge des allgemeinen Tiefstandes der Wirtschaft der Zone zunächst zurückgestellt werden mußten". ${ }^{121}$ Der Plan war, wie die ECA-Mission monierte, eher ein Hilfsgesuch als ein Wiederaufbauprogramm.

Albrecht und seine Kollegen errechneten ein Importvolumen von etwa 370 Mio. Dollar; aus dem Marshallplan erhofften sie sich einen Betrag von 100 bis 110 Mio. Dollar. Die ursprünglichen amerikanischen Kalkulationen vom Februar 1948 hatten jedoch lediglich 65 Mio. Dollar für die ersten fünfzehn Monate vorgesehen, und selbst die im weiteren Verlauf der inneramerikanischen Debatten vorgeschlagenen 85 Mio. Dollar stellten die französischen Verantwortlichen und ihre deutschen „Schützlinge“ keineswegs zufrieden. ${ }^{122}$ Der OEEC-Rat setzte die Quote schließlich auf 100 Mio. Dollar fest und entsprach damit in etwa den deutschen Erwartungen. Zufrieden waren wohl auch die zuständigen französischen Beamten in Baden-Baden, verzichteten sie doch auf Proteste. Allerdings hatte Frankreich, anders als die Vereinigten Staaten, auf die Höhe des Hilfsbetrages für "seine“ Zone bereits im Verhandlungsstadium Einfluß nehmen können: In beiden maßgeblichen OEEC-Sonderausschüssen - der "Group of Four", welche die einzelnen Aufbaupläne prüfte und einen Vorschlag zur Vergabe der Mittel für das erste

121 „Abschlußbericht über die deutschen ERP-Arbeiten in der französischen Besatzungszone“, Verf. Karl Albrecht, v. 24. 10. 1949, IWW/WA, NL Baade, III ERP. Vgl. auch hierzu und zum folgenden Albrecht, Wunder, S. 61-69; „Elements d'Information pour les delegués generaux et superiéurs concernant l'application du Plan Marshall en Z.F.O.A.", v. 19.6. 1948, AO, Eco I A 5d; Hardach, Marshall-Plan, S. $217 \mathrm{f}$.

${ }^{122}$ Die Darstellung bei Albrecht, Wunder, S. 68, die Deutschen hätten die zuständigen französischen Stellen erst davon überzeugen müssen, daß ein höherer Betrag notwendig sei, erscheint aufgrund des $\mathrm{Be}-$ strebens jedes Teilnehmers, einen möglichst hohen Anteil zu erhalten, wenig plausibel. 
Marshallplanjahr ausarbeitete, und der „Group of Five“, die sich mit dem Ausgleich der innereuropäischen Zahlungsbilanzen befaßte - saßen nämlich Vertreter Frankreichs. ${ }^{123}$

Obwohl die Aufbauprogramme im Grunde schon durch die amerikanischen Kürzungsbeschlüsse ihrer ursprünglichen Funktion größtenteils beraubt worden waren, ging die Arbeit daran unterdessen weiter. Ihr Zweck verkehrte sich allerdings ins Gegenteil: Anstatt den Experten in Paris und Washington als Basis für die ERP-Zuteilungen zu dienen, mußten die Pläne nun auf die finanziellen Vorgaben aus den Vereinigten Staaten zugeschnitten werden. Die dergestalt revidierten Jahresprogramme wurden im Laufe der zweiten Septemberhälfte bei der OEEC eingereicht. ${ }^{124}$ Sie lieferten jedoch nurmehr die Daten für den Gesamtbericht der OEEC, den Harriman auf der Ratssitzung am 16. Oktober 1948 in Empfang nahm. Damit war der erste Abschnitt der Planungsarbeiten abgeschlossen, und die Vorbereitungen für den zweiten Jahresplan und das „LongTerm-Program“ konnten beginnen. ${ }^{125}$

Die wirtschaftliche Bilanz dieser ersten Planungsversuche war für die Westzonen keineswegs so ungünstig, wie die Klagen der bizonalen Wirtschaftspolitiker und -fachleute vermuten lassen könnten. Legt man die direkte Dollarhilfe zugrunde, rangierte Westdeutschland hinter Großbritannien, Frankreich und Italien an vierter Stelle; der Betrag von insgesamt 574 Mio. Dollar entsprach einem Anteil von 10,5 Prozent an der Gesamtsumme von 4,875 Mrd. Dollar für alle fünfzehn Empfängerländer. ${ }^{126}$ Mit diesem Ergebnis konnten die Deutschen, knapp dreieinhalb Jahre nach Kriegsende, durchaus zufrieden sein. Auch wenn von den Regierungen und der Öffentlichkeit in den übrigen westeuropäischen Ländern ebenfalls kein unvoreingenommenes Urteil zu erwarten war - in diesem Punkt urteilten sie "gerechter", weil sie die Erinnerung an Krieg und Nationalsozialismus nicht aussparten. Damit ist freilich auch schon die Frage nach der politischen Bilanz aufgeworfen.

Eine Antwort darauf fällt nicht leicht, denn die Deutschen agierten ja zunächst nicht autonom, sondern im Windschatten vor allem der amerikanischen Militärregierung. Die Erhöhung der bizonalen Quote, dessen waren sich auch Pünder und seine Mitarbeiter bewußt, war allein das Verdienst Clays und anderer Vertreter der Militärbehörden gewesen. ${ }^{127}$ Dieser Erfolg schadete den deutschen Verantwortlichen politisch indessen mehr, als er ihnen nützte. Der „Economist“ beispielsweise warnte die Amerikaner davor, die Bizone als eine Art Lieblingskind zu behandeln und die Deutschen von der ihren Nachbarn auferlegten Pflicht zur gegenseitigen Hilfe zu befreien. ${ }^{128}$ Und mit Blick auf den Streit um die Höhe der bizonalen Quote mokierte sich John L. B. Titchener vom For-

123 Dies dürfte, auch wenn van der Beugel den "nichtnationalen“ Charakter dieser Gremien hervorhebt, nicht ganz unwichtig gewesen sein. Vgl. zur Zusammensetzung und Tätigkeit der beiden Ausschüsse van der Beugel, Marshall Aid, S. 147-153.

124 Vgl. Bizonal Delegation, Wochenbericht v. 13.-18. 9. 1948, BA, Z 14, 47.

125 Vgl. Bizonal Delegation, Wochenbericht v. 11.-16.10. 1948, ebenda; van der Beugel, Marshall Aid, S. $155-157$.

126 Die Schweiz und Portugal beantragten für 1948/49 keine Mittel. - Die ECA revidierte die OEECEmpfehlungen noch einmal nach unten, so daß am Ende ein Gesamtvolumen von 4,756 Mrd. Dollar übrig blieb. In den meisten Fällen kam es nur zu geringfügigen Kürzungen der Länderanteile: 3,4 Mio. Dollar waren es bei der Bizone, 800000 Dollar bei der französischen Zone.

127 Pünder z. B. erkannte in einer Rede vor dem ERP-Ausschuß ausdrücklich an, daß sich „die Vertreter der Militärregierung sowohl in Frankfurt wie in Paris in einer Weise für die Belange der Bizone bei der Durchführung des Marshallplans einsetzen, wie dies deutsche Vertreter gar nicht besser tun könnten“; Rede Pünders v. 7. 9. 1948, BA, Z 14, 8.

128 „Economist“ v. 11. 9. 1948, zit. n. van der Beugel, Marshall Aid, S. 155. 
eign Office darüber, "that the eyes of the Bizone were probably bigger than their stomach". ${ }^{129}$ Das Ansehen Westdeutschlands war, mit anderen Worten, bei den übrigen OEEC-Partnern anfangs nicht besonders hoch. Befürchtungen, die Vereinigten Staaten könnten dem Wiederaufbau in Westdeutschland Priorität einräumen, erschwerten einen unverkrampften Umgang noch zusätzlich. Die deutschen Sachverständigen in Paris und die mit ERP-Fragen befaßten Politiker und Beamten in Frankfurt können für dieses eher negative Image allerdings kaum verantwortlich gemacht werden, da sie nach außen selten in Erscheinung traten. Die Hauptverantwortung trugen also die Repräsentanten der amerikanischen Militärregierung, deren bisweilen rabiater Einsatz für die Interessen der Bizone in Paris, London, Den Haag und anderen Hauptstädten auf wenig oder gar kein Verständnis stieß.

Ganz so harmonisch, wie es aufgrund dieses amerikanischen Engagements zu vermuten gewesen wäre, war das Verhältnis zwischen der Militärregierung und ihren deutschen Schützlingen freilich nicht. Während der Arbeiten am Aufbauplan hatten Angehörige des Zweimächtekontrollamtes wiederholt inhaltliche und formale Kritik an den deutschen Entwürfen geübt. Die Militärgouverneure seien nicht willens, hieß es beispielsweise in einem Schreiben an Pünder vom 23. Juli 1948, „von den USA Hilfe für eine Sache zu erbitten, die durch harte Arbeit und vermehrte Anstrengungen durch die Doppelzone selbst bewerkstelligt werden" könne. Aber nicht nur die Neigung der bizonalen Instanzen, stärker auf Hilfe als auf Selbsthilfe zu setzen - ein Vorwurf, den der „Economist" ebenfalls erhob - wurde bemängelt, sondern auch die Verläßlichkeit der deutschen Berechnungen: Die Pläne der Verwaltung für Wirtschaft seien „keineswegs sorgfältig durchgearbeitet" gewesen und ließen „einen großen Mangel an Zusammenarbeit zwischen den zentralen Planungsstellen und den ausführenden Stellen erkennen“. Das Fazit, daß trotzdem ein "brauchbarer" Plan entwickelt worden sei, war wohl mehr als Ermunterung für die frustrierten deutschen ERP-Experten gedacht, die in drei Anläufen kein Jahresprogramm zustande gebracht hatten, dem das Zweimächteamt zustimmen konnte. ${ }^{130}$ Die politische Bilanz fiel also eher zwiespältig aus: Von einer gleichberechtigten Partnerschaft in der OEEC oder gar mit den Militärregierungen waren die Westzonen noch weit entfernt, die überall anerkannte Bedeutung des westdeutschen Wirtschaftspotentials schlug sich noch nicht in einem vergleichbar hohen Ansehen deutscher Sachverständiger und Politiker nieder. Immerhin gab es aber Anzeichen für eine Wende: Zum einen wuchs die Bereitschaft der Besatzungsbehörden, insbesondere der amerikanischen Stellen, die Deutschen stärker am Planungsprozeß zu beteiligen, ungeachtet der zum Teil unbefriedigenden Erfahrungen während der Arbeit am Programm 1948/49; zum anderen wurden alle Angehörigen der Bizonalen Delegation, auch die Deutschen, Ende Oktober 1948 den Mitgliedern einer herkömmlichen diplomatischen Mission gleichgestellt. ${ }^{131}$ Vor allem dieses letztere Ereignis bedeutete für die Westzonen einen wichtigen Schritt auf dem Weg zu internationaler Anerkennung. Und Gelegenheiten, die Schwächen und Ungeschicklichkeiten der ersten Entwürfe auszubügeln und vergessen zu machen, boten sich bereits unmittelbar nach der Verabschiedung des OEEC-Programms für das Jahr 1948/49.

129 Vermerk Titchener v. 9. 9. 1948, PRO, FO $371 / 70736$.

${ }^{130} \mathrm{BICO}$ an Vors. Verwaltungsrat v. 23. 7. 1948, BA, Z 13, 6.

131 Vgl. Bizonal Delegation, Wochenbericht v. 25.-30.10. 1948, BA, Z 14, 47. 


\section{Programm 1949/50}

Ungeachtet der keineswegs ermutigenden Erfahrungen beim ersten Versuch erbat die OEEC von den Teilnehmerländern auch für das zweite Marshallplanjahr Programme als Grundlage für die Vergabe der ERP-Mittel. Diese Programme sollten über die allgemeinen wirtschaftspolitischen Ziele, die konkreten Vorhaben für einzelne Bereiche, die erhofften Effekte auf das Wirtschaftsleben, die Entwicklung der Zahlungsbilanz und die Höhe der ERP-Anforderungen Auskunft geben. Im Unterschied zum Vorjahr sollten die neuen Pläne allerdings stärker als Teil des auf vier Jahre angelegten Gesamtprogramms konzipiert, d. h. auf die gleichzeitig anlaufenden Planungen für den Zeitraum bis 1952/53 abgestimmt werden. ${ }^{132}$

In der Bizone wurden die Arbeiten bereits im Sommer 1948 in die Wege geleitet, noch ehe die endgültige Entscheidung über die Verteilung der Mittel für das erste Marshallplanjahr gefallen war. Ende Juli forderte das Zweimächteamt die Verwaltung für Wirtschaft auf, trotz der Ungewißheit über die künftige Quote mit den Vorbereitungen für das zweite Jahresprogramm zu beginnen. ${ }^{133} \mathrm{Im}$ September lag ein erster Entwurf vor. Er veranschlagte Exporte im Wert von 1110 und Importe im Wert von 2540 Mio. Dollar, mithin ein Defizit von 1430 Mio. Diese Lücke sollte durch Kapitaleinfuhren in Höhe von 250, GARIOA-Mittel in Höhe von 730 und ERP-Hilfe in Höhe von 450 Mio. Dollar gedeckt werden. Ein mit ERP-Experten des Zweimächtekontrollamtes ausgehandelter Kompromißvorschlag sah eine durch höhere Exporte und geringere Importe erzielte Senkung des Defizits um 310 Mio. Dollar vor. Zum Entsetzen der deutschen Planer nahmen Berliner Stellen der Militärregierungen jedoch weitere Korrekturen vor, die im Endeffekt auf eine drastische Kürzung des ERP-Betrages hinausliefen: ${ }^{134}$

Tabelle 4: Ansätze für bizonale Ex- und Importe, Planjahr 1949/50 (in Mio. Dollar)

$\begin{array}{lccc} & \begin{array}{c}\text { ursprünglicher } \\ \text { deutscher } \\ \text { Vorschlag }\end{array} & \begin{array}{c}\text { BICO- } \\ \text { Revision }\end{array} & \begin{array}{c}\text { Vorschlag } \\ \text { der Militär- } \\ \text { regierung }\end{array} \\ \text { Exporte } & 1113 & 1230 & 1136 \\ \text { Importe } & 2543 & 2350 & 2093 \\ \text { (davon Nahrungs- und Düngemittel) } & (1100) & (1050) & (900) \\ \text { Defizit } & 1430 & 1120 & 957 \\ \text { gedeckt durch: Kapitaleinfuhr } & 250 & 80 & 46 \\ \text { GARIOA } & 730 & 555 & 728 \\ \text { ERP } & 450 & 485 & 183\end{array}$

Quellen: Haraldson an Murphy v. 24. 9. 1948, IfZA, MF 260, POLAD 461/26; „Gegenüberstellung der Vorschläge zum ERP-Jahr 1949/50“, ebenda, 11/110-1/7.

\footnotetext{
132 Vgl. van der Beugel, Marshall Aid; S. 157-158; Principal Features of the Bizonal E.R.P. Program 19491950, in: Draft History of BICO: ERP, IfZA, MF 260, 3/409-1/22.

${ }^{133} \mathrm{BICO}$ an VfW v. 29. 7. 1948, IfZA, MF 260, 11/94-1/10-11.

${ }^{134}$ Haraldson an Murphy v. 24. 9. 1948, IfZA, MF 260, POLAD 461/26 (= RG 84). Vgl. auch E.R.P. Annual 1949/50 Programme. Estimate of Foreign Aid Required, o. D., ebenda, 11/133-1/6; Hardach, Marshall-Plan, S. 222-226.
} 
Aufs höchste alarmiert, bat Pünder den BICO-Vorsitzenden, General Adcock, um eine Unterredung. In seinem Schreiben wies er unter anderem darauf hin, daß die vorgesehene Kürzung nicht nur die kommunistische Propaganda anspornen, sondern auch die ersten Schritte einer künftigen westdeutschen Regierung hemmen werde. Außerdem hinke die Entwicklung in der Bizone so weit hinter dem Stand in den übrigen OEECLändern her, daß - entgegen der mit Blick auf den amerikanischen Kongreß notwendigen jährlichen Reduktion der Marshallhilfe - eine ähnlich hohe oder sogar höhere Summe erforderlich sei: „We feel that such a low planning figure would ... hamper our tactical situation at the later Paris negotiations ... since the other countries will, without any doubt, apply for the highest possible amount of ERP funds. " Eine Erhöhung der ursprünglichen Summe hielt Pünder nach den bisherigen Erfahrungen nämlich für nahezu unmöglich. ${ }^{135}$ Das Zweimächteamt rechtfertigte in seiner Antwort den niedrigeren Betrag mit dem Argument, daß im Grunde eine jährliche Kürzung der Auslandshilfe um mindestens 370 Mio. Dollar unerläßlich sei, um bis 1952/53 das Ziel der „viability“ zu erreichen, während der Vorschlag der Militärregierungen nur eine Reduzierung um 200 Mio. Dollar vorsehe, stimmte aber dem gewünschten Gespräch zu. ${ }^{136}$

Bei dem Treffen am 24. September 1948 bekräftigten die beiden Vorsitzenden des Kontrollamtes, Adcock und Macready, diesen Standpunkt. GARIOA- und ERP-Mittel in Höhe von 911 Mio. Dollar hielten sie angesichts des restriktiven Kurses in Washington gerade noch für vertretbar. Im übrigen versicherten sie ihren deutschen Gesprächspartnern, daß sich die alliierten Vertreter in Paris mit aller Kraft für die bizonale Wirtschaft einsetzen würden, ganz gleich ob in der bevorstehenden oder einer späteren OEEC-Verhandlungsrunde. ${ }^{137}$ Oberdirektor Pünder überließ es weitgehend Günter Keiser, die deutschen Gegenargumente vorzutragen. Der VfW-Beamte hatte ein Memorandum vorbereitet, das vor allem auf die besondere Lage des Vereinigten Wirtschaftsgebietes abhob: Der Weg zur Lebensfähigkeit im Jahre 1952/53 sei „wohl für kein europäisches Land so schwierig wie für die Bizone", und dementsprechend seien die in den nächsten drei Jahren erforderlichen Anstrengungen und Aufwendungen in der Bizone „ungleich größer als in anderen Ländern“. Keiser leitete daraus die Notwendigkeit hoher Importe und damit eines vergleichsweise hohen Defizits ab, dementsprechend auch ERP-Hilfe "mindestens in der Größenordnung von wiederum 414 Mio. Dollar “. Die von der Militärregierung eingeplanten 183 Mio. Dollar reichten seiner Ansicht nach für die Bizonen-Einfuhr aus Dollarländern bei weitem nicht aus, konnten doch die GARIOA-Mittel nur für landwirtschaftliche Importe verwandt werden. ${ }^{138}$ Das in diesem Zusammenhang auch von Keiser vorgebrachte taktische Argument, ein bei der OEEC erst einmal „offiziell“ angeforderter Betrag könne nachträglich kaum noch erhöht werden, stieß übrigens bei manchen Angehörigen der amerikanischen Militärregierung durchaus auf Zustimmung. Wenn sich beispielsweise Wesley C. Haraldson, ein Mitarbeiter Robert Murphys, fragte, warum die Bizone, nachdem sie im ersten Jahr über 400 Millionen Dollar benötigt habe - „and needed it so badly as to warrant a great deal of ill will in OEEC and bad press throughout Europe" -, im zweiten Jahr mit weniger als der

135 Pünder an Adcock v. 22. 9. 1948, ebenda, 11/94-1/10-11. Vgl. auch Direktorialsitzung v. 21. 9. 1948, AVBRD 4, Dok. 86, S. 806.

136 BICO an Pünder v. 23. 9 1948, IfZA, MF 260, 11/94-1/10-11.

137 Bespr. BICO-Pünder u. a. v. 24. 9. 1948, ebenda, 11/110-1/7.

138 Vermerk Keiser zum Jahresprogramm 1949/50 der Militärregierung v. 24. 9. 1948, ebenda. 
Hälfte dieser Summe auskomme, so implizierte diese Verwunderung wohl auch eine Kritik an den maßgeblichen Persönlichkeiten der Militärregierung. ${ }^{139}$

Die beiden Vorsitzenden des Zweimächtekontrollamtes ließen sich jedoch von solchen Argumenten nicht beeindrucken. Macready berief sich insbesondere auf die Stimmung im US-Kongreß und gab sich überzeugt, daß Westdeutschland ohne irgendwelche Nachweise, allmählich „auf eigenen Füßen“ stehen zu können, überhaupt kein Geld bekommen werde. ${ }^{140}$ Und die Einwände gegen die ERP-Quote von 183 Mio. Dollar wurden damit beantwortet, daß es sich bei dieser Summe um einen Nettobetrag handle, der durch einen OEEC-internen Zuschuß noch aufgestockt werden könne. ${ }^{141}$ Erstaunlicherweise erhob jedoch auch die Pariser ECA-Vertretung Bedenken gegen die 55prozentige Kürzung des ERP-Anteils: Nach Meinung eines Mitarbeiters Harrimans sollte eher der Anteil der im Rahmen des "Government Aid and Relief in Occupied Areas“ (GARIOA)-Programms nach Westdeutschland fließenden Mittel gesenkt werden. Auf jeden Fall, und darin stimmte er mit dem Chef der bizonalen Delegation, Trier, überein, sollte die Angelegenheit von den zuständigen amerikanischen Stellen intern geregelt werden, bevor ein offizieller Vorschlag bei der OEEC eingereicht wurde. ${ }^{142}$

Allem Anschein nach einigten sich ECA und Militärregierung auf einen Kompromiß, denn der erste ausformulierte Entwurf für das Programm 1949/50 vom Oktober 1948 sah eine Reduzierung des GARIOA-Betrages auf 610 Mio. Dollar und dementsprechend eine Steigerung der ECA-Quote auf 327,1 Mio. Dollar vor. Hinzu kam noch, resultierend aus einem prognostizierten Netto-Überschuß aus dem OEEC-Clearing, eine Summe von 45,3 Mio. Dollar als „conditional aid“. Somit erreichte die eingeplante ERPHilfe mit insgesamt 372,4 Mio. Dollar fast das Niveau des Vorjahres. ${ }^{143}$ Das erwartete Gesamtdefizit lag mit 981 Mio. Dollar geringfügig über dem ursprünglichen Vorschlag der Militärregierung, aber nach wie vor deutlich unter der Kalkulation der Verwaltung für Wirtschaft. In der Kontroverse um die Finanzierung des Defizits behielt also die ECA die Oberhand, während sich in der Frage der Höhe des Defizits die Militärregierung mit ihrem Standpunkt, durch eine deutliche Senkung des Fehlbetrages zumindest auf dem Papier erste Erfolge beim Wiederaufbau zu demonstrieren, offensichtlich durchsetzen konnte. Diese erklärte Absicht der Militärregierung kam in einer Reihe von Planziffern zum Ausdruck. Eine der bemerkenswertesten Änderungen gegenüber dem Plan für 1948/49 bestand in der Erhöhung der Exporte um 50 Prozent. Noch erfreulicher war aus deutscher Sicht, daß auch die Tendenz stimmte: Geplant war nämlich, die Fertigwarenexporte zu steigern und gleichzeitig die Ausfuhr von Kohle, Koks und Holz zu drosseln. Mit anderen Worten, die Warenstruktur der westdeutschen Ausfuhr sollte allmählich wieder den Vorkriegsverhältnissen angeglichen werden.

\footnotetext{
${ }^{139}$ Haraldson an Murphy v. 24. 9. 1948, ebenda, POLAD 461/26.

140 Bespr. BICO-Pünder u. a. v. 24. 9. 1948, ebenda, 11/110-1/7.

141 Schumacher an ERP Secretariat v. 24. 9. 1948, ebenda, 11/94-1/10-11.

142 Arthur an Harriman u. Foster an Bruce, beide v. 8. 10. 1948, NA, RG 469, Deputy Administrator, Country Files 1948-49, Box 1

143 Vgl. hierzu und zum folgenden "The 1949/50 Programme submitted to the OEEC by the Bizone“, o. D., IfZA, MF 260, 11/133-1/6. Die Datierung ergibt sich aus der Laufzeit des Aktenbandes. - „Bedingte Hilfe“ gewährten die USA den europäischen Gläubigerländern in Höhe der jeweiligen den Schuldnerländern eingeräumten Ziehungsrechte. Vgl. dazu Abelshauser, Der Kleine Marshallplan, bes. S. 215-216.
} 
Tabelle 5: Tatsächliche bzw. geplante Warenstruktur der bizonalen Ausfuhr (in Prozent der Gesamtausfuhr)

Warengruppe

Metalle u. Metallwaren

Maschinen u. optische Erzeugnisse

Chemikalien

Bergbau

Textilien

alle übrigen

$\begin{array}{rr}1936^{1} & 1947 \\ 32 & 4 \\ 21 & 5 \\ 15 & 3 \\ 13 & 55 \\ 8 & 2 \\ 11 & 31\end{array}$

$1948 / 49$

$1949 / 50$

$1952 / 53$

13

14

34

$55 \quad 45$

28

$31 \quad 16$

$\begin{array}{rr}16 & 14 \\ 20 & 35 \\ 6 & 14 \\ 34 & 15 \\ 9 & 7 \\ 15 & 15\end{array}$

Quelle: 1949/50 Programme, IfZA, MF 260, 11/133-1/6. Die letzten drei Spalten enthalten die Planziffern.

1 Deutsches Reich.

Eine Anpassung an frühere Gegebenheiten strebten die alliierten Planer auch bei der regionalen Verteilung der Exporte an. Die Schwierigkeiten waren allerdings beträchtlich: Aufgrund der politischen Verhältnisse im Nachkriegseuropa nahmen die OEECPartner einen deutlich höheren Anteil auf als vor dem Krieg, während die osteuropäischen Länder ihre einstige Bedeutung fast vollständig eingebüßt hatten. Wegen der Möglichkeit, Dollars zu verdienen, war die Steigerung der Ausfuhr nach Nord- und Südamerika besonders wichtig, obwohl die Aussichten nicht gerade günstig waren und Deutschland in dieser Region früher meist eine eher untergeordnete Rolle gespielt hatte. Bedeutsamer war der indirekte Beitrag zur Verminderung des Dollarmangels in Westeuropa, den sich die Experten der Militärregierungen von ihrem Exportprogramm in dem Maße erhofften, in dem es der Bizone gelang, Güter zu liefern, die andernfalls aus den Vereinigten Staaten und anderen „Dollarländern“ hätten importiert werden müssen. Um all diese Ziele zu erreichen, bedurfte es freilich, wie die Autoren des Jahresprogramms hervorhoben, einiger Voraussetzungen, auf die das Vereinigte Wirtschaftsgebiet keinen Einfluß besaß: zunächst einmal der Bereitschaft und Fähigkeit der anderen Länder, deutsche Waren zu kaufen, darüber hinaus aber auch normaler Handelsbeziehungen, die Anerkennung deutscher Warenzeichen und Patente eingeschlossen. Solche dezidierten Hinweise auf die Pflichten anderer blieben indessen die Ausnahme. Vielmehr war dem Jahresprogramm 1949/50 - vor allem in der im allgemeinen Teil stark überarbeiteten zweiten Fassung - deutlich anzumerken, daß seine Verfasser bemüht waren, den aktiven Beitrag der bizonalen Wirtschaft zum europäischen Wiederaufbau herauszustreichen. ${ }^{144}$

Mit dieser Akzentuierung waren die zuständigen Beamten des Marshallplanbüros und der Verwaltung für Wirtschaft vermutlich einverstanden, mit der Höhe der vorgesehenen Mittel für die Bizone sicherlich nicht. Wie schon bei ihren Planungen für das erste Marshallplanjahr hatten die deutschen Fachleute einen besonderen Nachholbedarf unterstellt, d. h., sie erhofften sich mehr Hilfe, als sie zu geben bereit waren. Erneut setzte sich jedoch die Militärregierung am Ende durch. Lediglich in der Frage des Anteils der ERP-Mittel am Gesamtbetrag mußte sie zurückstecken - allerdings wohl hauptsächlich aufgrund des Widerstands der ECA. Die Deutschen behielten also keineswegs, wie es in

144 „The Bizonal Area of Germany 1949/50 Program“, o. D. (vermutlich Ende Oktober, Anfang November 1948), Paragraph 4, IfZA, MF 260, 11/94-1/10-11. 
der offiziösen Geschichte des Zweimächtekontrollamtes hieß, immer dann die Oberhand, wenn die jeweiligen Standpunkte trotz größter Bemühungen nicht auf einen Nenner zu bringen waren. ${ }^{145}$ Sie fühlten sich, im Gegenteil, benachteiligt, und Erhard brachte diese Unzufriedenheit anläßlich eines Besuchs des ECA-Chefs Ende Oktober 1948 auch zum Ausdruck. Mit dieser Beschwerde holte er sich bei Hoffman allerdings eine Abfuhr: „... the attitude of the Military Governments is so far from trying to handicap Western Germany in the accomplishment of what the Germans want that sometimes the ECA thinks the Military Governments are presenting a program more for the interest of Germany than of Europe as a whole. "146 Der Standpunkt Erhards, Keisers und der übrigen mit Marshallplanfragen befaßten Beamten, dem Wiederaufbau in Westeuropa sei am besten gedient, wenn erst einmal die westdeutsche Wirtschaft angekurbelt werde, vermochte Hoffman und seine Mitarbeiter offenbar ebensowenig zu überzeugen wie die Verantwortlichen bei den Militärregierungen. Die deutschen Planungen für 1949 150 wiesen aus amerikanischer und britischer Sicht erneut ein „europäisches Defizit“ auf, und insofern blieb der Grunddissens der ersten Verhandlungsrunde bestehen. Die verbesserten Möglichkeiten für die deutschen Experten, ihren Standpunkt während der Konzipierung des Programms zu Gehör zu bringen, brachten diese Differenzen eher noch deutlicher zum Vorschein. Zweifel an der Ernsthaftigkeit und Hartnäckigkeit des amerikanisch-britischen Einsatzes für die Bizone ließen sich daraus freilich nicht ableiten, vielmehr hatten die Deutschen, wie Hoffman zu Recht betont hatte, allen Grund, mit ihren alliierten "Interessenvertretern“ zufrieden zu sein. Dies zeigte sich aufs neue anläßlich der Verteidigung des Jahresplans 1949/50 vor dem Programmausschuß der OEEC am 12. November 1948.

Für diese Prüfung, der sich jedes Mitgliedsland unterziehen mußte, wurde eigens eine Arbeitsgruppe gebildet, die sich aus den Vertretern von sechs Delegationen zusammensetzte. Jeweils zwei Delegierte aus verschiedenen Ländern nahmen die einzelnen Programme genauer unter die Lupe. Kurz vor dem „Examen“ besprachen sie ihre Fragen und eventuellen Einwände mit den Experten aus den betreffenden Ländern, die dadurch die Chance erhielten, fundierte Antworten vorzubereiten; in begründeten Fällen konnten die "Prüflinge“ sogar darauf bestehen, daß bestimmte Fragen zurückgezogen wurden. Die beiden Hauptprüfer leiteten auch das anschließende Prüfungsverfahren vor dem Programmausschuß, doch hatten dort alle Delegationen das Recht, Fragen zu stellen.147 Obgleich weder die vorgelegten Programme und Antworten der examinierten Ländervertretungen noch mögliche Auflagen seitens des Programmausschusses verbindlich waren, wurden die Prüfungen ernst genommen, stand doch jedesmal das nationale Prestige auf dem Spiel. Außerdem stellten die Anhörungen eine wertvolle Informationsquelle dar: Helmut Meinhold von der Verwaltung für Wirtschaft beispielsweise erhoffte sich „wichtige Fingerzeige für die Art der Beurteilung der Bizone in Europa“; 148 nicht minder bedeutsam waren aber auch die Erkenntnisse über die wirtschaftspolitischen Ziele und Absichten der Partnerländer, die auf diese Weise gewonnen werden konnten. Ernst van der Beugel, damals Mitglied der niederländischen Delegation, ging sogar noch weiter und sah

${ }^{145}$ Draft History of BICO: ERP, Principal Features of the Bizonal ERP Program 1949/50, IfZA, MF 260, 3/409-1/22.

$1+6$ Prud'homme an Harriman v. 29. 10. 1948, ebenda, 17/24-2/8.

147 Vgl. van der Beugel, Marshall Aid, S. 160.

${ }^{148}$ ERP-Arbeitsausschuß, Mitteilung Nr. 6 v. 24. 11. 1948, PA, Bestand 2/608. 
in diesen „Kreuzverhören “ der OEEC „not a formal but nevertheless an essential and lasting infraction of economic sovereignty. ${ }^{149}$ Selbst wenn dieses Lob wegen der bereits erwähnten Unverbindlichkeit der OEEC-Empfehlungen und der anhaltenden Dominanz nationalegoistischer Interessen überzogen erscheint, ist die integrationspolitische Relevanz der „cross-examinations“ unbestreitbar. Sie zwangen die Regierungen dazu, ihre Politik zumindest pro forma auf übergeordnete europäische Ziele und die Planungen der anderen Partnerländer auszurichten und die eigenen Programme vor einem internationalen Gremium zu rechtfertigen. Von dieser bis zum damaligen Zeitpunkt ungewohnten Praxis gingen zweifelsohne „europäisierende“ Impulse aus, welche die Bereitschaft zur Kooperation und Integration in Westeuropa erhöhten.

Als Hauptprüfer des bizonalen Jahresplans 1949/50 fungierten ein Italiener und ein Niederländer. Für die Bizone sprachen die Amerikaner Barlerin und Tank sowie der Brite Howell; Kurt Häfner und Helmut Meinhold nahmen als Sachverständige ebenfalls an der Sitzung teil, ergriffen selbst aber nicht das Wort. Das Interesse der übrigen Länder war offenbar sehr groß und die Diskussion lebhafter als sonst.

Dem Bericht Meinholds zufolge zeigten sich die beiden Prüfer im Vorgespräch „sehr stark beeindruckt" von der Gründlichkeit des Bizonen-Planes, der „sehr viel mehr Informationen" enthalte und "sehr viel mehrins Einzelne" gehe als die Programme aller anderen Teilnehmerländer. ${ }^{150}$ Auf die Frage des Italieners nach den Finanzierungsmöglichkeiten für das bizonale Programm war - aufgrund noch laufender Verhandlungen mit der Militärregierung -eine befriedigende Antwort dennoch nicht möglich, so daß Meinhold dafür votierte, auf diese Frage zu verzichten. Er konnte Barlerin jedoch nicht überzeugen - mit der Folge, daß die zwangsläufig unbefriedigende Auskunft, wie der Deutsche mit vorwurfsvollem Unterton rückblickend feststellte, im Programmausschuß den Eindruck hervorgerufen habe, daß der bizonale Investitionsplan „finanziell undurchführbar und damit das ganze Programm illusorisch" sei. Ganz gleich, ob dieser Vorwurf berechtigt war oder nicht - diese kleine Episode illustriert ziemlich genau die damalige Rollenverteilung in der bizonalen Vertretung: Die Deutschen waren in die technische Arbeit einbezogen und insofern nicht nur Statisten, aber gegen den erklärten Willen der Delegationsleitung, d. h. „politisch", konnten sie sich nicht durchsetzen.

Das „Kreuzverhör“ begann mit einem kurzen Statement Barlerins, in dem er die Grundzüge des Plans und die spezifischen Probleme der Bizone skizzierte und am Ende betonte, daß Deutschland vor dem Kriege „eine entscheidende Position im internationalen Handel“ innegehabt habe und „die Größe seiner Bevölkerung und die Bevölkerungsdichte ... ein Gleiches für die Zukunft" vorschrieben. Derart eingestimmt, konzentrierte sich der Ausschuß auf vier Fragenkomplexe: Investitionen, Produktion, Verbrauch sowie Zahlungsund Außenhandelsbilanz. Es wurde deutlich, daß die übrigen Teilnehmerländer vor allem befürchteten, ihre jeweiligen nationalen bzw. die "gesamteuropäischen“ Interessen könnten von der Bizone nicht genügend berücksichtigt werden. Der italienische Hauptprüfer beispielsweise zeigte sich von dem vorgesehenen Investitionsvolumen alarmiert und bezweifelte die sorgfältige Abstimmung der bizonalen Vorhaben mit bereits verwirklichten oder geplanten Investitionen in anderen OEEC-Ländern; zu den Ziffern für Fertigwaren-

${ }^{149}$ Van der Beugel, Marshall Aid, S. 147.

150 Bericht über die Prüfung des Programms 1949/50 am 12. 11. 1948, PA, Bestand 2/608; dort auch die folgenden Zitate. 
importe merkte er an, die Bizone habe bei ihren Ansätzen den zwischenzeitlichen Aufbau entsprechender Industrien in den Partnerländern ignoriert und offenbar "nicht in Betracht gezogen, daß der europäische Außenhandel nur auf einer gesunden Gegenseitigkeit beruhen" könne. In diese Kerbe hieb auch der Niederländer mit seinem Einwand, bei der Einfuhr von Industrieausrüstungen würden die Vereinigten Staaten als Bezugsquelle bevorzugt. Sorgen bereiteten ferner der Kohlenverbrauch, der drohende Engpaß auf dem Erzmarkt infolge einer höheren Stahlproduktion, der "befremdliche“ Agrarexport sowie die vorgesehenen Importe bestimmter Agrarprodukte aus überseeischen Gebieten. Barlerin, Tank und Howell versuchten diese Befürchtungen zu zerstreuen, indem sie unter anderem auf den hohen heimischen Bedarf an Maschinen und Nahrungsmitteln hinwiesen und im übrigen versprachen, alle vorgetragenen Beschwerden sorgfältig zu prüfen. Den besorgten Fragen zur bizonalen Exportpolitik begegneten sie mit relativierenden Hinweisen auf "ungewisse Schätzungen“ oder eine möglicherweise unrealistische Orientierung an den „Vorkriegsrelationen". Zweifel an der außenhandelspolitischen Maxime der Bizone ließ Barlerin gleichwohl nicht aufkommen: Deutschland habe „schon immer Rohstoffe und Nahrungsmittel eingeführt und Fertigwaren ausgeführt", und diese Exporte müßten in $\mathrm{Zu}$ kunft sogar noch gesteigert werden. Obwohl manche Delegationen diese Botschaft eher mit gemischten Gefühlen aufgenommen haben dürften, blieb die Atmosphäre im Programmausschuß entspannt. Mit dem Verlauf des Hearings konnten die Vertreter der Bizone nicht nur deshalb recht zufrieden sein. Abgesehen von einigen Detailfragen, die zur Klärung an die zuständigen Unterausschüsse der OEEC verwiesen wurden, war die erste Phase der Planungsarbeiten für das Jahr 1949/50 damit abgeschlossen.

Verglichen mit dem bizonalen Programm war jenes der französischen Zone, wie ein Vertreter des Vereinigten Wirtschaftsgebietes nach der Prüfung treffend konstatierte, "durch eine zurückhaltende, um nicht zu sagen, pessimistische Tendenz gekennzeichnet". ${ }^{151}$ Daran waren allerdings zum geringeren Teil die deutschen Sachverständigen schuld: Ihre Mitspracherechte bei der Formulierung des Anfang November fertiggestellten zweiten Jahresprogramms waren zwar deutlich gestiegen, doch hatte die französische Militärregierung unter Hinweis auf Sicherheitsinteressen Frankreichs oder alliierte Vereinbarungen die deutschen Vorschläge verschiedentlich gerade in den Punkten korrigiert, die hinterher von seiten der OEEC oder der ECA kritisiert wurden. ${ }^{152}$

Ebenso wie ihre Kollegen in der Bizone waren die Autoren des französischen Programms für das Jahr 1949/50 bemüht, Erfolge beim Wiederaufbau vorzuweisen. ${ }^{153}$ Die Steigerungsraten bei der landwirtschaftlichen und industriellen Erzeugung waren mit 12 bzw. 15 Prozent jedoch äußerst vorsichtig kalkuliert, lediglich der geplante Anstieg des Volkseinkommens um 40 Prozent fiel deutlich aus dem Rahmen. Mögliche Einwände gegen die, verglichen mit 1948/49, um rund 12 Prozent höheren Einfuhren versuchten die Autoren mit dem Hinweis abzublocken, daß davon ausschließlich die OEEC-Länder profitieren sollten, deren Anteil an den Gesamteinfuhren damit von 56 auf 59 Pro-

151 Bericht über die Prüfung des Jahresprogramms 1949/50 der französischen Besatzungszone am 26. 11. 1948, BA, Z 19, 8.

$152 \mathrm{Vgl}$. Abschlußbericht über die deutschen ERP-Arbeiten in der französischen Besatzungszone v. 24. 10. 1949, verf. v. Karl Albrecht, S. 6, IWW/WA, NL Baade, III ERP.

153 Vgl. zum folgenden Programme 1949-1950 en Zone Française d' Occupation v. 15. 11. 1948, IfZA, MF 260, 11/115-3/4; Wiederaufbauplan 1949/50 der französischen Besatzungszone Deutschlands, Bericht v. Karl Albrecht v. 11. 11. 1948 u. Bemerkungen des Generalsekretärs über das Programm 1949/50 der Französischen Zone v. 21. 11. 1948, beide BA, Z 19, 8. 
zent stieg oder, in absoluten Zahlen ausgedrückt, von 127 auf 151 Mio. Dollar. Bei den Ausfuhren war eine Zunahme um fast 20 Prozent von 145 auf 173 Mio. Dollar eingeplant; der Anteil der Teilnehmerländer an diesem Export blieb mit 80 Prozent nahezu unverändert, die Quote der „westlichen Hemisphäre“ wuchs um 2 Prozent. Bemerkenswert war, daß sich die Exporte aus einer Vielzahl unterschiedlicher Güter zusammensetzten: Allein 133 von insgesamt 173 Mio. Dollar wurden unter der Rubrik „andere Produkte" nicht näher spezifiziert, die größten Einzelposten aus der restlichen Summe entfielen auf Ausrüstungen mit 17 und Textilien mit 12 Mio. Dollar. In der Waren- und Regionalstruktur der Ausfuhr, so hieß es dazu im Jahresprogramm, nähere sich die Zone Schritt für Schritt den Verhältnissen der Vorkriegszeit und damit der handelspolitischen Normalität. ${ }^{154}$ Dazu bedurfte es allerdings, wie Karl Albrecht vom ERP-Koordinierungsausschuß betonte, spürbarer Erleichterungen für deutsche Exporteure; insbesondere müsse das System der "monopolistischen Staatsausfuhr“ über das Office du Commerce Extérieur (OFICOMEX), die Außenhandelsorganisation der Militärregierung, durch ,individuelle Ausfuhrgeschäfte“ ersetzt werden ${ }^{155}$ - eine Forderung, die mit der Fusion von OFICOMEX und JEIA Ende Oktober 1948 offensichtlich noch nicht gegenstandslos geworden war. Gerade auf dem Gebiet des Außenhandels zeigte sich aber auch die besondere Abhängigkeit des südwestlichen Teils Deutschlands vom Austausch mit den übrigen deutschen Gebieten und mit den Nachbarländern. Die Beziehungen zur Bizone spielten deshalb eine sehr viel größere Rolle als umgekehrt. Die fehlende Wirtschaftseinheit zumindest mit den beiden anderen westlichen Zonen wurde, zusammen mit strukturellen und politischen Faktoren, folglich zu Recht für den Entwicklungsrückstand verantwortlich gemacht. Die ERP-Mittel gegenüber dem Vorjahr zu kürzen, hielten die Autoren des Plans aus diesen Gründen für falsch; die beantragte Summe von 102,6 Mio. Dollar übertraf die Anforderung für 1948/49 sogar noch geringfügig. ${ }^{156} \mathrm{Der}$ prozentuale Anteil der ERP-finanzierten Importe war hingegen leicht - von 39 auf 35 Prozent - gesunken. Selbst wenn die Bilanz, mit Blick auf den US-Kongreß, nahezu zwangsläufig optimistisch ausfallen mußte: Bescheidene Fortschritte waren unverkennbar. Die Versicherung der Autoren - „la Zone Française d' Occupation sera en mesure de fournir en 1949-50 plus de merchandises aux Pays Participants, cooperant ainsi d' une façon plus intense avec les Pays d' Europe “157 - war somit mehr als bloße Rhetorik.

Die Prüfung des Jahresprogramms der französischen Zone stieß bei den übrigen OEEC-Partnern, anders als das Bizonenprogramm, nur auf geringes Interesse. Außer den beiden Hauptprüfern aus den Niederlanden und Norwegen meldete sich nur der Amerikaner Martin Tank von der Delegation der Bizone mehrmals zu Wort - allerdings mit zum Teil recht kritischen Fragen. Im Mittelpunkt des Examens standen das Verhältnis zur Bizone, das Volumen der Investitionen, die Produktionssteigerungen und die Entwicklung der Zahlungsbilanz. ${ }^{158}$ Nachdem der Delegationsleiter der französischen

\footnotetext{
154 Programme 1949-1950, S. 10 (wie Anm. 153).

155 Wiederaufbauplan 1949/50, S. 12 f. (wie Anm. 153).

156 Maurice Halff, der Leiter der Marshallplanbürokratie der Militärregierung, hatte zunächst für eine Summe von 80 Mio. Dollar plädiert, dann aber, vor allem auf Drängen der deutschen Experten, der höheren Ziffer zugestimmt. Niederschrift Ministerbespr. v. 20. 9. 1948, TOP 1, StA Sigm., Film S IV, Wü2/779, S. 72.

157 Programme 1949-50, S. 2 (wie Anm. 153).

158 Vgl. Programmes Committee, 48th Meeting v. 26. 11. 1948, PR/M (48) 48, IfZA, MF 260, 11/115-3/4; Bericht Holthaus über die Prüfung des Jahresprogramms 1949/50 v. 4. 12. 1948, BA, Z 19, 8.
} 
Zone, Larre, schon in seinen einleitenden Bemerkungen unter Hinweis auf die sehr engen wirtschaftlichen Beziehungen zum Vereinigten Wirtschaftsgebiet die Vorlage eines separaten Plans fast bedauert hatte, stand zunächst die Frage nach dem Effekt eines möglichen Zonenzusammenschlusses im Vordergrund. Der Franzose konnte sich aufgrund der aufeinander abgestimmten Ex- und Importpläne höchstens kleinere Korrekturen des Programms vorstellen, eine Reduzierung der ERP-Hilfe und des Defizits erwartete er hingegen nicht. Sehr weit her kann es mit dieser Abstimmung indessen kaum gewesen sein, denn ausgerechnet der Vertreter der Bizone, Tank, bemängelte zu geringe Investitionsraten und Produktionserhöhungen, verglichen mit "seiner“ Zone. Larres Argument, daß die Bizone schon seit zwei Jahren von der GARIOA-Hilfe profitiere und dadurch in die Lage versetzt worden sei, den Kapitalstock zu erneuern und die Industrie anzukurbeln, ein Vergleich der beiden Gebiete deshalb nicht ganz fair sei, ließ Tank nicht gelten, weil diese Hilfe nicht für solche Zwecke bestimmt gewesen sei. Zweifel an der optimalen Nutzung der vorhandenen Ressourcen und Kapazitäten klangen auch in den Fragen der beiden Hauptprüfer an, wenngleich sie ihre Bedenken weniger schroff formulierten. Den beiden Franzosen Larre und Halff gelang es jedenfalls nicht, die Kritik in allen Punkten zu entkräften, zumal sie noch dazu einige Widersprüchlichkeiten und Fehler im Zahlenwerk des Programms eingestehen mußten. Ihre Begründung für die vergleichsweise vorsichtigen Prognosen - allzu ehrgeizige Pläne, insbesondere auf dem Gebiet der Investitionen, könnten inflationäre Tendenzen oder, im Falle des Scheiterns, Frustrationen hervorrufen - vermochte die Mitglieder des OEEC-Programmausschusses keineswegs zu überzeugen und war wohl auch eher vorgeschoben: Im Grunde verfolgte die französische Militärregierung bei ihren Planungen für das Jahr 1949/50 einen restriktiven, in erster Linie auf das Sicherheitsbedürfnis und die wirtschaftlichen Interessen Frankreichs ausgerichteten Kurs, wie er etwa im alliierten Industrieniveauplan vom März 1946 in ähnlicher Weise zum Ausdruck gekommen war. Karl Albrecht befürchtete sogar, daß der Lebensstandard in der Zone nicht einmal das damals anvisierte durchschnittliche europäische Niveau erreichen und die Versorgung mit gewerblichen Gütern höchstens 60 Prozent des Standes von 1936 betragen werde. Alles in allem verlief das Hearing der Delegation der französischen Zone also wenig zufriedenstellend, und die deutschen Sachverständigen, die im Gegensatz zu ihren Kollegen aus der Bizone nicht einmal als Zuhörer daran teilnahmen, dürften ihre Abwesenheit zumindest nachträglich kaum bedauert haben. Die Entwicklung in der französischen Zone und ihr Beitrag zum europäischen Wiederaufbau wurden an dem gemessen, was die Bizone vorzuweisen hatte, und dieser Vergleich mußte zwangsläufig, schon aus strukturellen Gründen, eindeutig zugunsten letzterer ausfallen. Die quasi "naturwüchsige“ Sogwirkung, die vom Vereinigten Wirtschaftsgebiet ausging, wurde vor allem von den ECA-Vertretern in Westdeutschland noch verstärkt, die sich nachdrücklich für eine Fusion oder zumindest Zusammenarbeit der drei Zonen einsetzten. Dementsprechend rückte dieses Problem bei der weiteren Arbeit am Programm 1949/50 mehr und mehr in den Vordergrund.

Wie auch beim Wiederaufbauplan für 1948/49 markierten die Examen nur den Abschluß der ersten Phase der Planungsarbeiten, die ohnehin insofern ,in der Luft hingen“, als die Gesamthöhe der ERP-Hilfe für das zweite Marshallplanjahr noch nicht feststand. Auf der Basis der einzelnen Pläne und der Hearings verfaßte der OEEC-Programmausschuß dennoch einen Bericht, den der Rat Ende Dezember 1948 billigte und an die ECA 
weiterleitete. ${ }^{159}$ Dieser Report bilanzierte die bisherigen Aktivitäten und skizzierte die nächsten Schritte zur Aufstellung eines "konsolidierten Programms“. Besonderes Gewicht sollte bei der Überarbeitung darauf gelegt werden, daß der Anstieg des Verbrauchs begrenzt blieb, hinreichende Anstrengungen unternommen wurden, um Dollars zu verdienen bzw. einzusparen, und die Investitionsvorhaben ohne Inflation oder unverhältnismäßige Zahlungsbilanzdefizite realisiert werden konnten. ${ }^{160}$

$\mathrm{Zu}$ den generellen Mängeln der Pläne, die in diesen Empfehlungen indirekt angesprochen waren, kam im Falle Westdeutschlands noch das Abstimmungsproblem zwischen den Zonen. Karl Bode vom Zweimächtekontrollamt hob diesen Punkt in seinen Direktiven zur Revision des Programms 1949/50 ausdrücklich hervor: Um die vorläufig noch getrennt erarbeiteten Wiederaufbaupläne ,jederzeit“ zu einem einheitlichen „Trizonenprogramm" zusammenfügen zu können, regte er an, eine gemeinsame Arbeitsgruppe mit Sachverständigen aus der französischen Zone zu bilden. Weitere konkrete Vorgaben für die Programmrevision waren die Erhöhung der Exporte um 100 Mio. Dollar und der Produktionsziele auf 90 Prozent des Niveaus von 1936, Pläne zur Förderung des Fremdenverkehrs und des Wohnungsbaus sowie Maßnahmen zur Steigerung der Effizienz von Wirtschaft und Verwaltung - also durchweg Appelle, die eigenen Aktivitäten zu verstärken. Aber für die deutsche Seite wohl am erfreulichsten: diese Korrekturen sollten „selbstverantwortlich“ durchgeführt werden. ${ }^{161}$ Wenngleich dieser Grundsatz in den folgenden Wochen und Monaten nicht immer beachtet wurde, war er ein erstes Indiz für die feste Absicht der Amerikaner, die Verantwortlichkeiten nach und nach in deutsche Hände zu legen. Bis zu diesem Zeitpunkt waren die Experten aus der Bizone und besonders aus der französischen Zone, allen nachträglichen Schönfärbereien zum Trotz, über die Rolle von Zuträgern im Grunde nicht hinausgekommen; die endgültige Entscheidung über die Programme hatten sich die Alliierten vorbehalten. Die Revision des zweiten Jahresprogramms bot den deutschen Experten eine erste Gelegenheit, ihren Sachverstand und ihre Leistungsfähigkeit unter Beweis zu stellen.

Es dauerte jedoch noch bis Anfang März 1949, ehe das Exekutivkomitee der OEEC einen Zeitplan für die weiteren Arbeiten und einen Katalog der dabei zu beachtenden Prinzipien und Formalien aufgestellt hatte. Einer der Gründe für diese Verzögerung dürfte die Washington-Reise der Vorsitzenden des Exekutivausschusses und des Rates der OEEC, Edmund Hall-Patch und Baron Jean Charles Snoy, sowie des Generalsekretärs Marjolin in der ersten Januarhälfte gewesen sein. ${ }^{162}$ Ein Ergebnis der Visite waren nämlich erhöhte Anstrengungen der Verantwortlichen in Paris, ihre Organisation als erfolgreich und zielstrebig zu präsentieren. Diesem Zweck diente insbesondere das „Aktionsprogramm" für 1949, das Marjolin am 12. Februar vorstellte und das die Prioritäten für das neue, zweite Jahr fixierte: „The principal aim ... should be to hasten the progress of Europe towards its 1952-53 objectives, and, more particularly, to lessen the dependence of participating countries on American aid." Um das Dollardefizit zu verringern,

159 Vgl. Bizonal Delegation an BICO/ERP Sec. v. 31. 12. 1948, IfZA, MF 260, 11/102-1/18-22.

$160 \mathrm{Vgl}$. Memorandum on the 1949/50 Programme and on the Long Term Programme mit Begleitschreiben des ERP Sekretariats v. 5. 1. 1949, ebenda; ERP-Arbeitsausschuß, Marshallplan-Mitteilungen Nr. 2 v. 18. 1. 1949 (Auszüge aus dem Bericht des Programmausschusses über das Programm 1949/50 in dt. Übersetzung), BA, Z 14, 124.

161 Bode an Schalfejew v. 21. 1. 1949, BA Z 14, 124. Vgl. auch Niederschrift Sitzung ERP-Ausschuß v. 20. 4. 1949, ebenda, Z 14, 9.

162 Vgl. van der Beugel, Marshall Aid, S. 160 f. 
war es vor allem notwendig, die Ausfuhren in den Dollarraum zu steigern und Modernisierungsinvestitionen vorzunehmen - allerdings nicht auf Kosten stabiler Währungen: 1949 wurde nämlich zum Jahr der finanziellen Stabilisierung in Europa auserkoren. ${ }^{163}$ Die Formulierung dieses Aktionsplans und anderer einschlägiger Richtlinien beanspruchte die Aufmerksamkeit und Arbeitskraft der Pariser Bürokratie mehrere Wochen, so daß sich die Inangriffnahme der Programmrevision zunächst verzögerte. Der schließlich verabschiedete Zeitplan sah vor, daß die überarbeiteten Programme bis zum 15. Mai vorliegen sollten. Auf der Basis einer gründlichen Auswertung dieses Materials sollte die OEEC spätestens bis zum 30. Juni ihren Vorschlag zur Vergabe der ERP-Hilfe präsentieren. ${ }^{164}$ Außerdem wurden die Mitgliedsländer durch Beschluß der sogenannten Konsultativgruppe der Außenminister vom 8. März aufgefordert, entsprechend dem Aktionsplan Berichte über die innere finanzielle Stabilität sowie über besondere Maßnahmen zur Steigerung der Exporte in den Dollarraum vorzubereiten. ${ }^{165} \mathrm{Da}$ alle diese Aufgaben gleichzeitig erledigt werden mußten, bedeutete eine zusätzliche Belastung der nationalen Planungszentren mit dem Risiko weiterer Verzögerungen. Die bizonalen Behörden reichten ihren Vorschlag am 1. April 1949 bei den zuständigen amerikanisch-britischen Stellen ein. Von dem eingeplanten Zahlungsbilanzdefizit in Höhe von 976 Mio. sollten 446 Mio. Dollar durch ERP-Mittel gedeckt werden; nach Abzug von 50 Mio. Dollar, die im Rahmen des OEEC-Clearing als Ziehungsrechte vorgesehen waren, hätte sich die Nettohilfe auf 396 Mio. Dollar belaufen. Die alliierten Planer waren mit diesen Ansätzen jedoch nicht einverstanden und plädierten ihrerseits für eine Herabsetzung des Gesamtdefizits auf 876 Mio. und der Nettohilfe auf 300 Mio. Dollar; die Summe der zu gewährenden Ziehungsrechte veranschlagten sie auf 100 Mio. Dollar. ${ }^{166}$ Im großen und ganzen akzeptierten die Spitzen der Militärregierungen in Berlin den entsprechend revidierten Programmentwurf; kleinere Änderungswünsche zielten hauptsächlich auf einen möglichst effektiven Einsatz vorhandener Ressourcen. ${ }^{167}$ Nachdem auch die Bizonale Delegation nichts zu beanstanden hatte, wurde die überarbeitete Fassung des 1949/ 50-Programms mit einer geringfügig auf 302,5 Mio. Dollar erhöhten ERP-Anforderung am 23. Mai bei der OEEC eingereicht. ${ }^{168}$ Der bizonale ERP-Ausschuß diskutierte und billigte das Programm nachträglich. ${ }^{169}$ Die angestrebte Koordination mit den Planungsarbeiten in der französischen Zone gelang jedoch nicht in dem insbesondere von amerikanischer Seite gewünschten Ausmaß. Zwar war bereits im Januar 1949 eine amerikanisch-britisch-französische Arbeitsgruppe gebildet worden, doch konnte sie keine nennenswerten Erfolge erzielen. Aus amerikanischer Sicht lag dies zum einen an den gerin-

163 Action Programme for OEEC in 1949, C (49) 7, IfZA, MF 260, 11/100-1/7-10. Einen ersten Vorstoß in Sachen „innere finanzielle Stabilität“ hatte Marjolin allerdings bereits im November 1948 unternommen. Vgl. Marjolin an Trier v. 9. 11. 1948, ebenda, 11/102-1718-22.

164 Vgl. Bizonal Delegation, Wochenbericht v. 28. 2.-5. 3. 1949, BA Z 14, 47; Programmes Committee, Plan of Work v. 8. 3. 1949, IfZA, MF 260, 11/100-1/7-10; Memorandum White v. 10. 3. 1949, ebenda, 11/ 102-1/18-22.

165 Vgl. Bizonal Delegation, Wochenbericht v. 7.-12. 3. 1949, BA Z 14, 47, Bizonal Delegation an OMGUS v. 9. 3. 1949, IfZA, MF 260, 11/102-1/18-22.

166 Vgl. BICO an OMGUS v. 6. 4. 1949, Telegramm No. 378 an BISEC/Economic Advisers (o. D.), Record Sheet Barlerin v. 9. 4. 1949, alle IfZA, MF 260, 11/102-1/18-22.

$167 \mathrm{Vgl}$. Economic Advisers an Joint Chairmen/BICO v. 20.4. 1949, ebenda.

168 Record Sheet Barlerin v. 17.5. 1949 u. Bizonal Delegation an BICO/ERP Sec. v. 25. 5. 1949, beide ebenda.

169 Vgl. Protokoll Sitzung ERP-Ausschuß v. 9.6. 1949, BA, Z 14, 9. 
gen Kompetenzen des Gremiums, dessen einzige Aufgabe die Wirtschaftsberater Weir und Wilkinson darin sahen, Programme zu koordinieren, ohne diese zu ändern - ein wahrlich schwieriger Auftrag; zum anderen klappte auch die Zusammenarbeit im und mit dem deutschen Pendant nicht wie erhofft: „In fact, it appears that the French Zone Germans ... never had enough freedom of action to make the work of the Commitee successful." ${ }^{170}$ Die ERP-Beamten des Zweimächtekontrollamtes fanden sich deshalb, nicht zuletzt in der Erwartung, daß bald eine westdeutsche Regierung gebildet werden würde, mit der Präsentation getrennter Programme für das Jahr 1949/50 ab, um weitere Zeitverluste in Paris zu vermeiden. Falls möglich, sollte während oder nach den Diskussionen in der OEEC-Zentrale versucht werden, einen koordinierten Vorschlag zustande zu bringen; um dieses Ziel zu erreichen, war man durchaus zu kleineren Zugeständnissen bereit. ${ }^{171}$ Angesichts der wirtschaftlichen Probleme der französischen Zone und um eine Gleichbehandlung mit der Bizone sicherzustellen, hatte die ECA im übrigen schon im Februar erwogen, die ERP-Mittel auf 115 Mio. Dollar zu erhöhen. Norman H. Collison, der ECA-Repräsentant für die Bizone, rechnete dennoch mit "schwierigen organisatorischen Problemen und delikaten politischen Fragen“, die es im Zuge des Zonenzusammenschlusses zu lösen galt. ${ }^{172}$ Für die deutschen Politiker und ERP-Fachleute in der französischen Zone dürfte außerdem noch die Sorge, gegenüber die Bizone nicht ins Hintertreffen zu geraten, eine fusionshemmende Rolle gespielt haben. ${ }^{173}$ Dennoch gelang es hin und wieder, unterhalb der politischen Ebene zu einer praktischen Zusammenarbeit zu kommen: So wurden beispielsweise die Berichte zur inneren finanziellen Stabilität zwar separat vorgelegt, im Exekutivkomitee der OEEC aber gemeinsam diskutiert. 174

Die Prüfung der revidierten Jahrespläne begann Mitte Juni 1949. In der eigens eingesetzten Arbeitsgruppe des OEEC-Programmausschusses war dieses $\mathrm{Mal}$ auch die $\mathrm{Bi}$ zone vertreten. ${ }^{775}$ Es zeigte sich jedoch bald, daß der Ausschuß mit dem Auftrag, obendrein noch einen Vorschlag zur Verteilung der ERP-Hilfe zu entwickeln, überfordert war - vor allem, als die britische Delegation einen Zusatzantrag in Höhe von 500 Mio. Dollar präsentierte und viele Anzeichen darauf hindeuteten, daß der Kongreß gegenüber dem ersten Marshallplanjahr den Gesamtbetrag deutlich kürzen würde. Während einer inoffiziellen Besprechung einigten sich die Delegationsleiter, den Rat der OEEC auf der Basis des Ausschußberichts über die Höhe der ERP-Quoten entscheiden zu lassen. ${ }^{176}$ Als der Bericht der Arbeitsgruppe jedoch auf den massiven Protest Großbritanniens, Frankreichs, Italiens und der Niederlande stieß, beauftragte der Rat seinen Vorsitzenden, den Belgier Snoy, und Generalsekretär Marjolin, einen Vorschlag auszuarbeiten. Diese Empfehlung lag am 27. August 1949 vor. Da Snoy und Marjolin einen etwas höheren Gesamtbetrag zugrunde legten, konnten die Quoten einiger Mitgliedsländer angehoben werden. Die Bizone gehörte jedoch nicht dazu, sie sollte, wie von der Arbeits-

\footnotetext{
170 Vermerk „Tripartite Working Party on Programme Revision“ v. 26. 4. 1949, IfZA, MF 260, 11/102-1/ 18-22.

171 BICO an OMGUS \& BERCOMB v. 4. 5. 1949, ebenda.

172 Bericht Collisson v. 12. 2. 1949 (dt. Übers.) mit Begleitschreiben Albrecht v. 30. 3. 1949, BA, Z 14, 156.

${ }_{173}$ Niederschrift Sitzung Koordinierungsausschuß frz. Zone v. 13./14. 1. 1949, ebenda.

174 Bericht über die Verhandlungen zur Sicherheit der inneren Finanzstabilität am 21. 6. 1949, Verf. Karl Albrecht, ebenda.

175 Vgl. Bizonal Delegation, Wochenbericht v. 13.-18. 6. 1949, BA, Z 14, 47.

176 Vgl. Bizonal Delegation, Wochenbericht v. 25.-30. 7. 1949, ebenda; Hogan, Marshall Plan, S. 244.
} 
gruppe vorgeschlagen, 212 Mio. Dollar erhalten; für die französische Zone war hingegen ein niedrigerer Betrag eingeplant: statt 101 nur noch 86,5 Mio. Dollar. ${ }^{177}$ Auf deutscher Seite stießen diese Zahlen verständlicherweise auf Kritik: Günter Keiser beispielsweise bezeichnete die Abstriche am Bizonenprogramm größtenteils als ungerechtfertigt. Große Hoffnungen, den deutschen Bedenken in Paris Gehör zu verschaffen, hegte er gleichwohl nicht, zumal die alliierten ERP-Verantwortlichen die Position der OEEC unterstützten. ${ }^{178}$

Erwartungsgemäß folgte der Rat am 31. August 1949 nach intensiven und schwierigen Verhandlungen dem Snoy-Marjolin-Entwurf. ${ }^{179}$ Das Gesamtvolumen der beantragten Mittel war gegenüber 1948/49 um 20 Prozent kleiner, die Kürzungen sollten jedoch nicht linear erfolgen. Unter den "großen“ Empfängern traf es die Westzonen, für die erstmals ein Betrag ausgewiesen war, am härtesten:

Tabelle 6: Zuteilungen und Verluste an Dollarhilfe und Auslandshilfe (ohne GARIOA)

\begin{tabular}{|c|c|c|c|c|c|c|}
\hline \multirow{3}{*}{ Empfänger } & \multicolumn{3}{|c|}{$\begin{array}{l}\text { Dollarhilfe } \\
\text { in Mio. Dollar }\end{array}$} & \multicolumn{3}{|c|}{$\begin{array}{l}\text { Auslandshilfe } \\
\text { in Mio. Dollar }\end{array}$} \\
\hline & \multirow[t]{2}{*}{$1948 / 49$} & \multirow[t]{2}{*}{$1949 / 50$} & \multirow{2}{*}{$\begin{array}{l}\text { Rückgang } \\
\text { in \% }\end{array}$} & $(+/-$ Ziehun & srechte & Rückgang \\
\hline & & & & $1948 / 49$ & $1949 / 50$ & in $\%$ \\
\hline Westdeutschland & 510 & 348 & 32 & $501(-9)$ & $185(-163)$ & 63 \\
\hline Frankreich & 981 & 704 & 28 & $1304(+323)$ & $928(+224)$ & 28 \\
\hline Großbritannien & 1239 & 962 & 28 & $949(-290)$ & $893(-69)$ & 6 \\
\hline Italien & 555 & 407 & 24 & $535(-20)$ & $382(-25)$ & 29 \\
\hline
\end{tabular}

Quelle: Die Aufteilung der Dollarhilfe und der innereuropäischen Hilfe für das Jahr 1949/50, Vermerk Wegmann v. 5. 9. 1949, PA, Bestand 2/603.

Selbst wenn man berücksichtigt, daß die in Form von Ziehungsrechten geleistete westdeutsche Wirtschaftshilfe für Europa am Ende statt 163 „nur“ rd. 50 Mio. Dollar ausmachte, mußte Westdeutschland, vom Sonderfall Belgien abgesehen, eine 32prozentige Senkung der Auslandshilfe und damit den tiefsten Schnitt aller Mitgliedsländer hinnehmen. Zusätzliche Lasten erwuchsen aus den Hilfsmaßnahmen für Westberlin, die auf etwa 450 Mio. Dollar veranschlagt wurden. Diese düstere Bilanz hellte sich zwar dadurch etwas auf, daß die Westzonen nach wie vor in den Genuß der GARIO-Hilfe kamen - für das Jahr 1949/50 waren 426 Mio. Dollar eingeplant -, doch war dieser Posten für die Einfuhr von Nahrungsmitteln reserviert und deshalb nicht in dem Maße disponi-

177 Vgl. Bizonal Delegation, Wochenberichte v. 15.-20. und v. 22.-27. 8. 1949, BA, Z 14, 47; der abschließende Bericht des Ratsvorsitzenden und des Generalsekretärs über die Verteilung der ERP-Hilfe v. 31. 8. 1949, ebenda, Z 14, 48; allgemein: Marjolin, Travail, S. 221-223.

178 Protokoll Sitzung ERP-Ausschuß v. 4. 8. 1949, BA, Z 14, 9. Differenzen mit Snoy und Marjolin sowie mit dem OEEC-Council gab es auch in der Frage der Auswirkungen der GARIOA-Kürzungen auf den ECA-Anteil der Bizone. Das Ergebnis längerer Verhandlungen war eher mager: Materiell blieben die deutschen Wünsche nämlich unberücksichtigt, doch hoffte von Mangoldt, daß die ECA bei der endgültigen Entscheidung die deutschen Vorbehalte in Rechnung stellen würde. Mangoldt an Martini v. 1.9. 1949, BA, Z 14, 48 .

179 Vgl. Bizonal Delegation, Wochenbericht v. 29. 8.-2. 9. 1949, BA, Z 14, 47; Hardach, Marshall-Plan, S. $231 \mathrm{f}$. 
bel wie die ERP-Hilfe. ${ }^{180}$ Von einer Bevorzugung Westdeutschlands konnte jedenfalls keine Rede mehr sein; die Amerikaner, die für ihre Intervention zugunsten der Deutschen beim Quotenkompromiß für das erste Marshallplanjahr heftige Kritik geerntet hatten, hielten sich dieses Mal zurück. Entsprechend groß war auf deutscher Seite die Enttäuschung. Herbert Martini vom bizonalen Marshallplanbüro beklagte „das groteske Bild, daß die Bizone mit den stärksten Kriegszerstörungen durch Kürzungen und Ziehungsrechte um nahezu die gesamte ERP-Quote gebracht" werde, während Großbritannien und Frankreich „sehr hohe Quoten“ bekämen, „obwohl diese beiden Länder eine bereits seit Jahren wieder florierende Wirtschaft ohne allzu große Kriegszerstörungen" vorzuweisen hätten. ${ }^{181}$

Jenseits solcher eher auf den kurzfristigen eigenen Vorteil bedachten Einwände provozierten die ernüchternden Erfahrungen mit dem Programm 1949/50 aber auch grundsätzliche Kritik an der Konzeption des Marshallplans und der Arbeit der OEEC. Bernhard Wegmann etwa, der Hauptreferent für ERP-Angelegenheiten beim Länderrat, sah in der Vergabepraxis eine Abkehr von dem Hauptgedanken des Marshallplans, der Dekkung der Dollarlücke in der Zahlungsbilanz; der Marshallplan verkümmere somit zu einer "reinen zeitweiligen Nothilfe“. Er rechnete deshalb damit, „daß die Frage des Wiederaufbaus der europäischen Wirtschaft aus den Händen sowohl der Economic Cooperation Administration wie auch der Organisation für wirtschaftliche Zusammenarbeit erneut in die Hand der Staatsregierungen zurückgelegt" werden würde. ${ }^{182} \mathrm{Ganz}$ so pessimistisch beurteilte der deutsche "Chefdelegierte" in Paris, von Mangoldt, die Zukunft der Organisation im Oktober 1949 zwar nicht, doch war er, wie viele seiner ausländischen Kollegen, überzeugt, daß "die allzu große Konzentration auf Programmierung die OEEC in eine Sackgasse“ führe. Die im Laufe des Sommers 1949 laut gewordenen Vorwürfe an die Adresse der OEEC - Mangel an konstruktiven Ideen und Dynamik - hielt er für berechtigt, und sie wurden ja dadurch noch bestätigt, daß die zweite Revision des Programms 1949/50 vier Monate in Anspruch nahm und trotzdem nicht zu eindeutigen Ergebnissen kam. Die Schuld an der Krise, die durch die weitverbreitete Unzufriedenheit und Kritik aus den Mitgliedsländern ausgelöst worden war, gab von Mangoldt allerdings nicht allein der OEEC; vielmehr machte er die ECA dafür mitverantwortlich, die "bisher zu großen Wert auf Programmarbeiten und Statistiken gelegt" und auf dieser Grundlage auch noch einen einstimmigen Beschluß der Mitgliedsländer über die „Division of Aid“ erwartet habe. Die zwangsläufige Folge dieses ganzen Verfahrens erblickte von Mangoldt darin, daß jedes Land bei der Verteidigung seines Programms „einseitig nationalwirtschaftliche Gesichtspunkte überstark betont" habe. Die Ansicht vieler Kritiker, eine „übergeordnete politische Instanz" an der Spitze der OEEC könne hier Abhilfe schaffen, teilte er allerdings nicht: Man könne „sehr wohl der Auffassung sein, daß auf wirtschaftlichem Gebiet eine Lösung der europäischen Frage leichter zu erreichen sein" werde, „wenn man politischen Gesichtspunkten möglichst wenig Einfluß zukommen“ lasse und „den Ausgleich und die Forderung der wirtschaftlichen Interessen der

180 Vgl. Die Aufteilung der Dollarhilfe und der innereuropäischen Hilfe für das Jahr 1949/50, Vermerk Wegmann v. 5. 9. 1949, PA, Bestand 2/603; Vermerk Mangoldt v. 12. 10. 1949 betr. gegenwärtiger Stand der Arbeiten der OEEC, BA, Z 14, 46; Abelshauser, Funktion, S. $95 \mathrm{f}$.

181 Martini an Mangoldt v. 12. 8. 1949, BA, Z 14, 46.

${ }^{182}$ Die Aufteilung der Dollarhilfe, S. 6 (wie Anm. 180). 
Länder mit Hilfe des common sense" anstrebe. ${ }^{183}$ Trotz aller Unzufriedenheit mit der Arbeit der OEEC war sich von Mangoldt also bewußt, daß eine stärkere „Politisierung“ der Organisation den deutschen Interessen kaum dienlich sein konnte, waren doch das Wirtschaftspotential und der Vorrang wirtschaftlicher Gesichtspunkte in den Diskussionen und Auseinandersetzungen in Paris vorerst die einzigen Trümpfe der erst wenige Wochen amtierenden, politisch einflußlosen Bundesregierung. Obgleich in erster Linie von den Erfahrungen des Praktikers vor Ort geprägt, spiegelte dieses Votum für den „Primat der Wirtschaft" zugleich die damals in Westdeutschland dominierende Konzeption für die europäische Zusammenarbeit wider, die im wirtschaftlichen Bereich den erfolgversprechendsten Ansatzpunkt für einen raschen Wiederaufbau und eine schrittweise Verbesserung der deutschen Mitsprachemöglichkeiten sah.

Aus diesem Grund hätten von Mangoldt und seine Mitarbeiter in Paris und die zuständigen Stellen in Frankfurt und Baden-Baden bzw. später in Bonn die Planungs- und Bewilligungsprozedur vermutlich ein drittes Mal, wenn auch widerwillig, mitgemacht, wäre nicht die ECA selbst zu der Einsicht gelangt, daß eine weitere Zerreißprobe dieser Art höchstwahrscheinlich das Ende der OEEC bedeutet hätte. Die ECA entschied sich deshalb in Absprache mit dem OEEC-Rat für ein neues, vereinfachtes Verfahren: In den verbleibenden zwei Jahren sollte die Marshallplanbehörde in Washington die Mittel völlig selbständig zuteilen, und zwar entsprechend den Ansätzen im Programm 1949/50. Überdies sollte die Gesamtsumme für das Jahr 1950/51 auf 75, für 1951/52 auf 50 Prozent des jeweiligen Vorjahresvolumens gesenkt werden. Mit der Entscheidung für diesen Automatismus entging die OEEC zwar der Gefahr des Scheiterns, sie verzichtete aber in einem wichtigen Bereich zugleich auf die Möglichkeit zu einer umfassenden Koordinierung der Wiederaufbauaktivitäten in Westeuropa. ${ }^{184}$ Die damit verbundene Bilateralisierung der Marshallhilfe hing allerdings auch mit der Ende 1949/Anfang 1950 verstärkt einsetzenden Militärhilfe zusammen, die direkte Verhandlungen zwischen den USA und den jeweiligen Empfängerländern erforderte: „Collective aid recommendations by the OEEC thus became impractical and, in fact, unnecessary. “ 185 Dennoch wurden die Pläne für das Jahr 1949/50 nicht zur bloßen Makulatur, denn die ECA kündigte für Ende 1949 eine Überprüfung der Quoten im Lichte der tatsächlichen Fortschritte in den einzelnen Ländern an, und die selbstgesetzten Ziele sollten dabei als Maßstab dienen. Aus deutscher Sicht schließlich brachte das zweite Marshallplanjahr einen Zuwachs an Kooperationserfahrung und vor allem an Mitsprachemöglichkeiten und Verantwortlichkeiten. Schon aus diesem Grund fiel die Bilanz verständlicherweise nicht so düster aus, wie es bei einigen anderen Mitgliedsländern der Fall war.

\section{Long-Term Program für das Jahr 1952/53}

Die Arbeiten an den langfristigen Programmen hatten gleichzeitig mit den Vorbereitungen für die Pläne 1949/50 im Sommer 1948 begonnen. Diese Parallelität war schon deswegen sinnvoll, weil letztere ausdrücklich als integrale Bestandteile der "Vierjahres-

\footnotetext{
${ }^{183}$ Vermerk v. Mangoldt betr. "Gegenwärtiger Stand der Arbeiten der OEEC“ v. 12. 10. 1949, S. 1-3, BA, Z 14, 46.

184 Vgl. van der Beugel, Marshall Aid, S. 163-166; Milward, Reconstruction, S. 204-207; Marjolin, Travail, S. 223.

${ }^{185}$ Vgl. dazu Wexler, Marshall Plan, S. 68-69; das Zitat S. 68.
} 
pläne“ konzipiert werden sollten. Die OEEC bezeichnete das Langzeitprogramm als „Brennpunkt der vereinten Unternehmungen der Teilnehmerstaaten“ mit dem Zweck, die Aktivitäten der Länder mit denen der OEEC insgesamt zu koordinieren, „um sobald wie möglich ein wirtschaftliches Gleichgewicht Europas ohne finanzielle Unterstützung von außen zu erreichen"; es sollte sehr breit angelegt sein und vor allem die beabsichtigte Wirtschaftspolitik festschreiben. ${ }^{186}$ Aus der Sicht der Partner machte dies gerade im Falle der Bizone den besonderen Wert des Programms aus: Erstmals waren die deutschen Wirtschaftspolitiker und -planer aufgefordert, nicht nur über die nächsten Schritte, sondern über die mittel- und längerfristigen Ziele Auskunft zu geben und damit zugleich die in der Wirtschaft Westeuropas angestrebte Rolle zu definieren. Obwohl die Drei Mächte bei dieser Standortbestimmung zunächst noch ein gewichtiges Wort mitzureden hatten, waren sich die Deutschen bewußt, daß dem Programm, verglichen mit den Jahresplänen, deshalb größere Bedeutung zukam. ${ }^{187}$

Erste einschlägige Überlegungen präsentierte das Exekutivkomitee der OEEC bereits Anfang Juli 1948. Ausgehend von den außenwirtschafts- und beschäftigungspolitischen Zielen des Wiederaufbauprogramms befaßte sich der Bericht mit den Problemen des wirtschaftlichen Gleichgewichts mit dem „Rest der Welt“, des Handels- und Zahlungsverkehrs innerhalb Europas sowie der internen Finanz- und Wirtschaftspolitik der einzelnen Teilnehmerländer. ${ }^{188}$ ECA-Administrator Hoffman griff diese Initiative in einer Rede vor dem OEEC-Rat am 25. Juli auf und bewies damit zum ersten Mal jene Art von Pragmatismus, die für die amerikanische Politik gegenüber der OEEC charakteristisch werden sollte: vorzugsweise solche Vorschläge zu unterbreiten, die in der Organisation bereits Unterstützung fanden. Er ermunterte also die Mitgliedsländer dazu, zunächst einzeln, dann gemeinsam ein Programm zu entwickeln, das den erfolgreichen Abschluß der wirtschaftlichen Rekonstruktion bis zum Sommer 1952 gewährleisten sollte. Ihm schwebte freilich ein flexibles Aktionsprogramm vor, kein rigider und bombastischer „Fünfjahresplan“, welcher das Wirtschaftsleben der einzelnen Länder über Gebühr reglementieren würde. Mit seinem Vorschlag verband er die Hoffnung auf eine gemeinsame Nutzung der nationalen Kapazitäten und Ressourcen; nur auf diese Weise, versuchte Hoffman seine Zuhörer zu überzeugen, seien optimale Ergebnisse zu erzielen. ${ }^{189}$ Obwohl manche Regierungen Notwendigkeit und Nützlichkeit eines solchen Vorhabens aus den unterschiedlichsten Gründen skeptisch beurteilten, verabschiedete der Rat am 4. August 1948 ein Memorandum über Sinn und Zweck des „Long Term"-Programms und die erwünschten Daten und Informationen: „In the first place each country is asked to return a general statement showing the main lines on which it intends to proceed in order to attain viability in 1952/53, and indicating also how it expects its own economy to fit into the pattern of a viable European economy. "Dieses ausformulierte Programm sollte durch statistisches Material ergänzt werden. Da die ECA den Gesamtplan

186 OEEC-Generalsekretariat, Bericht über die Arbeit der OEEC seit ihrem Beginn, 7. 10. 1949 (dt. Übers.), S. 10, BA Z 14, 106, Bl. 187-200. Vgl. allgemein van der Beugel, Marshall Aid, S. 157, 166-172.

${ }^{187}$ Helmut Meinhold, Wer bekommt Kredit und Waren aus dem Marshallplan?, in: Wirtschaftsverwaltung 2 (1949), S. 151-156, hier S. 154.

188 OEEC-Executive Committee, Problems to be studied in the context of the Long-Term Programme, CE(48) 39 (Rev.) v. 3. 7. 1948, IfZA, MF 260, 11/94-2/13.

189 Statement Hoffman v. 25. 7. 1948, ebenda, 11/90-/22. Die These van der Beugels, Marshall Aid, S. 166, der Long-Term Plan sei von Hoffman initiiert worden, ist also nur teilweise richtig: Der Amerikaner gab mit seiner Rede lediglich den letzten Anstoß. 
bis zum 15. November erwartete, setzte der OEEC-Rat als Abgabetermin für die Einzelpläne den 1. Oktober 1948 fest. ${ }^{190}$

Die spezifischen Probleme, die dieser Ratsbeschluß für die zuständigen Beamten der verschiedenen Behörden in der Bizone mit sich brachte, verdeutlichte Ludwig Erhard, der Direktor der Verwaltung für Wirtschaft, gegenüber Vertretern des Zweimächtekontrollamtes: Die deutschen Experten sollten einen volkswirtschaftlichen Plan aufstellen, obwohl sie auf die wichtigen wirtschaftspolitischen Entscheidungen noch keinen nennenswerten Einfluß hatten; überdies hielt er es, anders als bei den übrigen Teilnehmerländern, für „nahezu unmöglich, eine ausgeglichene Handelsbilanz bis 1952 zu erreichen“. Diese ungünstigen Voraussetzungen erschwerten verständlicherweise die Präsentation verläßlicher statistischer Daten, wenn die Beamten „ehrliche Arbeit“ leisten wollten. ${ }^{191}$ Mit anderen Worten: ohne gehörige Schönfärberei schien die Aufgabe, für den Zeitpunkt des Auslaufens des Marshallplans drastische Produktionssteigerungen und eine ausgeglichene Zahlungsbilanz vorweisen zu können, gar nicht zu meistern zu sein. Mit ihrer Vorgabe, bis 1952/53 unbedingt die „viability“ der einzelnen Volkswirtschaften zu erreichen, forderte die ECA Manipulationen der Planziffern deshalb geradezu heraus. ${ }^{192}$ Für die übrigen OEEC-Länder war die Verläßlichkeit der Zahlen und die Stimmigkeit der Produktions- und Außenhandelspläne der Bizone jedoch ohnehin von geringerem Interesse als die darin zum Ausdruck kommenden Absichten, die einen ersten halbwegs authentischen Eindruck davon vermittelten, wie sich die „neuen“ Deutschen ihre wirtschaftliche Zukunft vorstellten.

Die Arbeiten am Langzeitprogramm folgten dem bei der Formulierung des Wiederaufbauplans 1948/49 erprobten Verfahren: Die deutschen Behörden erhielten den Auftrag, Stellungnahmen zu den verschiedenen Komplexen und flankierendes statistisches Material vorzubereiten; gleichzeitig machten sich auch die zuständigen Abteilungen der Militärregierung ans Werk. Letztere entwarfen dann auch - „unter weitgehender Benutzung der Unterlagen der deutschen Sachverständigen“, wie Helmut Meinhold stolz resümierte - das Programm. ${ }^{193}$ Als Orientierungspunkte dienten, neben den Vorgaben der OEEC, spezielle Instruktionen des Zweimächtekontrollamtes. So sollten beispielsweise für das Jahr 1952 eine Bevölkerungszahl von rd. 46 Millionen und eine um 10 Prozent höhere Industrieproduktion als 1936 zugrundegelegt werden; nicht ganz unproblematisch war die Auflage, eine ausreichende Versorgung mit wichtigen Rohstoffen aus dem Ausland zu unterstellen. Den meisten Zündstoff barg jedoch, wie sich bald zeigen sollte, eine andere Arbeitshypothese in sich, nämlich: „Exports will be maximised. “194 Und bemerkenswerterweise beherzigten die amerikanischen und britischen Planer diese $\mathrm{Ma}$ -

190 Long-Term Programme, verabschiedet vom Rat am 4. 8. 1948, IfZA, MF 260, 11/90-2/2. Zur britischen Kritik am Zeitplan und generell an der zu starken Beanspruchung der OEEC und der Mitgliedsländer durch permanente Programmplanung sowie zur Reaktion der ECA vgl. Harriman an US-Botschaft London v. 4. 7. 48 u. Hoffman an Botschaften in Europa v. 13. 7. 1948, beide in: FRUS 1948, III, S. 464465 und $467-469$.

191 Vermerk Bespr. BICO - Vertreter bizonaler Verwaltungen, Wirtschafts- und Länderrat v. 13. 8. 1948, BA, Z 13, 2, Bl. 8-9.

192 Marshallplan-Berater Schniewind zitierte in seinem „Allgemeinen Bericht“ für 1948 v. 7.1. 1949 einen Amerikaner mit den Worten, „man könne sich beim Studium des Long-Term Program nicht des Eindrucks erwehren, daß man das Pferd vom Schwanz her aufgezäumt habe: es gehe von der Lösung - der Viability im Jahre 1953 - aus und beweise dann ihre Möglichkeit“. BA, NL Pünder, 704.

193 Meinhold, Kredit, S. 155 (wie Anm. 187). Vgl. auch Hardach, Marshall Plan, S. 458-460.

${ }^{194} \mathrm{BICO}$ an Commerce \& Industry Group v. 11. 8. 1948, IfZA, MF 260, 11/133-1/8. 
xime sogar noch konsequenter als ihre Kollegen aus den bizonalen Behörden. Trotz grundsätzlicher Zustimmung zu dem alliierten Entwurf, der einen Tag vor der Genehmigung durch die Militärgouverneure zur „Durchsicht" vorgelegt wurde, warnten die deutschen Experten vor zu optimistischen Schätzungen. So erschienen ihnen insbesondere die Exportziele als „eindeutig fiktiv und überhöht“; statt der vorgesehenen Ausfuhren im Wert von 2,8 Mrd. Dollar hielten sie ein Volumen von höchstens 2,4 Mrd. für realistisch. Auch die Aussichten, im eingeplanten Umfang Dollar- durch Nichtdollareinfuhren ersetzen zu können, beurteilten sie eher skeptisch. Folglich hatten die deutschen Sachverständigen ein Zahlungsbilanzdefizit von 568 Mio. errechnet, während die alliierten Experten nur auf 72,3 Mio. Dollar kamen. Helmut Meinhold, der den Vertretern des Zweimächteamtes die deutschen Einwände vortrug, obwohl aus Zeitmangel nennenswerte Textänderungen gar nicht mehr möglich waren, plädierte deshalb dafür, den provisorischen Charakter der Prognosen und Planziffern stärker zu betonen. Seine Gesprächspartner verteidigten jedoch ihre optimistischen Kalkulationen - unter anderem mit dem Hinweis, daß ja auch die vorsichtigen deutschen Ansätze für das Jahr 1948/49 infolge der Währungsreform bereits als überholt gelten müßten. Die offensive Ausrichtung des alliierten Entwurfs blieb also, ungeachtet mancher Bedenken Meinholds und seiner Kollegen, im wesentlichen erhalten. ${ }^{195}$

Das im Oktober 1948 bei der OEEC eingereichte Dokument enthielt auf 46 Seiten das wirtschaftspolitische Programm der Bizone und die einzelnen Ziele in den Bereichen Produktion, Investitionen, Konsum und Außenhandel. Die Autoren erinnerten ausdrücklich an die frühere „bedeutende Rolle“ Deutschlands als „Mittelpunkt der europäischen Industrie" und ließen damit von vornherein keinen Zweifel, welchen Platz der westliche Teil auch künftig beanspruchte: „Wenn Deutschland nicht wieder in dem ihm entsprechenden Ausmaß herstellen und verbrauchen" könne, bleibe „wenig Aussicht, den durchschnittlichen westeuropäischen Lebensstandard wieder auf das Niveau der Vorkriegszeit zurückzuführen." ${ }^{196}$ Unter ökonomischen Gesichtspunkten betrachtet, war diese Feststellung sicherlich richtig; dennoch hatte sie für manche der übrigen OEEC-Länder einen bedrohlichen Beiklang, zumal gleichzeitig eine Steigerung des damaligen Exportvolumens um das Vierfache angekündigt wurde: Für das Jahr 1952/53 plante die Bizone demnach Exporte im Wert von 2,8 Mrd. Dollar, davon sollten auf die Warengruppe Maschinen und Optik 35, auf Bergbau 15 und auf Metall und Metallwaren sowie auf Chemikalien jeweils 14 Prozent entfallen. Verglichen mit 1936 bedeutete dies bei Maschinen einen Anstieg um 14, bei Metall einen Rückgang um 18 Prozentpunkte; die Schätzungen für die übrigen Warengruppen entsprachen in etwa dem früheren $\mathrm{Ni}$ veau. Angesichts des Gesamtvolumens mochte es für die OEEC-Partner zumindest eine gewisse Beruhigung sein, daß die Bizone nicht nur für die Inthronisation multilateraler Handels- und Zahlungsprinzipien in einem möglichst großen Gebiet votierte, sondern auch ihre Abhängigkeit von einer solchen Entwicklung eingestand: „Die Zusammenarbeit und die Schaffung einer wirtschaftlichen Einheit werden somit von den bizonalen Behörden als eine bleibende Notwendigkeit und nicht als ein bloßer Notbehelf auf

195 Vermerk Meinhold v. 30. 9. 1948 u. ders. Bericht über die Wirkungen des Bizonen-Außenhandelsprogrammes 1952/53, beide BA, Z 14, 124.

196 Das langfristige Programm der Bizone, Mitteilung Nr. 7 des ERP-Arbeitsausschusses v. 29. 11. 1948, S. 1, PA, 2/608; die gedruckte Fassung, ebenda, 2/606. 
kurze Sicht betrachtet, um eine schnellere Wiedergesundung zu sichern." ${ }^{197}$ Die Ernsthaftigkeit dieser Zusicherung wurde durch das - entgegen den Wünschen der ECA eingeplante Zahlungsbilanzdefizit von 72 Mio. Dollar noch unterstrichen.

Um die ambitionierten Exportziele realisieren zu können, bedurfte es beträchtlicher binnenwirtschaftlicher Anstrengungen. So sollten die Industrieproduktion auf 100 und das Bruttosozialprodukt auf 105 Prozent des Standes von 1936 gebracht werden. Die hierfür erforderlichen Investitionen übertrafen 1952/53 das Niveau des Jahres 1936 (vgl. nachstehende Tabelle), sollten aber dennoch nicht auf Kosten der Stabilität der neuen Währung getätigt werden, vielmehr versprachen die bizonalen Behörden, alle Inflationstendenzen entschlossen zu bekämpfen. Ein Hindernis für die eingeplante allgemeine Steigerung der Produktion war nach wie vor die auf 10,7 Mio. Tonnen pro Jahr begrenzte Rohstahlerzeugung; die Verfasser des Programms forderten zwar nicht ausdrücklich eine Erhöhung dieser Obergrenze, deuteten aber mit dem Hinweis, daß die bislang zulässige Höchstproduktion etwa um 25 Prozent unter dem Niveau von 1936 lag, zumindest an, welche Größenordnung ihnen vorschwebte. Schon um die vorgesehenen Ziele in der Sparte Maschinenbau zu erreichen, mußte mehr Stahl produziert werden. Alles in allem war deutlich das Bemühen zu spüren, nach Möglichkeit zur „Normalität“ der Vorkriegszeit zurückzukehren. Die internationalen Rahmenbedingungen hatten sich freilich gewandelt, und das langfristige Programm erkannte dies auch ausdrücklich an. Wirtschaftliche Zusammenarbeit war das oberste Gebot, mehr als einen „erträglichen Standard wirtschaftlichen Wohlergehens“, der zu „scharfem Rechnen“ zwinge und „keine Spanne für Wohlstand und Macht“ lasse, „mit der man spielen könnte“, beanspruchte die Bizone gar nicht. Obgleich es notwendig sein werde, „zu kämpfen“ und in den „Wettbewerb um Absatzmärkte einzutreten“, hoffe man, hieß es beruhigend, daß "durch Zusammenarbeit und Weitsicht diesem Kampf der Stachel genommen“ und „der Welthandel somit eher ein Austausch zugunsten beider Partner als ein Kampf um wirtschaftliches Überleben“" werde. ${ }^{198}$

Tabelle 7: Brutto- und Nettokapitalanlagen im Vergleich zum Bruttosozialprodukt (in Mrd. Dollar von 1948)

$\begin{array}{lrrrrrr} & 1936 & 1948 & 1949 & 1950 & 1951 & 1952 / 53 \\ \text { Bruttosozialprodukt } & 32,3 & 24,1 & 25,8 & 28,1 & 30,7 & 33,9 \\ \text { Bruttoanlagen } & 6,6 & 4,5 & 4,9 & 5,7 & 6,7 & 7,7 \\ \text { in \% des Bruttosozialprodukts } & 20,5 & 18,7 & 19 & 20,3 & 21,8 & 22,7 \\ \text { Nettoanlagen } & - & 1,5 & 1,6 & 2,1 & 2,9 & 3,7 \\ \text { in \% des Bruttosozialprodukts } & - & 6,2 & 6,2 & 7,5 & 9,5 & 10,9\end{array}$

Quelle: Das langfristige Programm der Bizone (wie Anm. 196). 
Wie berechtigt diese Versuche waren, den Partnern von vornherein die Furcht vor einem wiedererstarkenden Deutschland zu nehmen, zeigte sich spätestens beim obligatorischen Examen durch die OEEC Anfang November 1948. Die Anhörung fand dieses Mal vor dem Exekutivkomitee statt, Prüfer waren, wie beim Jahresplan 1949/50, die Niederlande und Italien. Und ungeachtet der vielen beschwichtigenden Formulierungen und mancher offensichtlich auf deutschen Wunsch eingefügten Hinweise auf die Vorläufigkeit bestimmter Prognosen und Plandaten löste das bizonale Programm beträchtliche Unruhe aus.

Neben der Sorge, ob die bizonalen Planungen, beispielsweise bei den Investitionen oder der Kohlenförderung und -ausfuhr, genügend auf die Bedürfnisse und Vorhaben der übrigen OEEC-Länder abgestimmt waren, beherrschte erwartungsgemäß das Exportprogramm die Diskussion im Exekutivkomitee. ${ }^{199}$ Dieses Programm wirkte, nach den Worten Meinholds, „geradezu sensationell“. Das Erstaunen darüber, daß Westdeutschland ,in einem derartigen Ausmaß wieder wirtschaftlich aktiv zu werden plant, war allgemein". ${ }^{200}$ Sowohl der niederländische Prüfer als auch die Delegierten Frankreichs und Großbritanniens zeigten sich von der Höhe der Ausfuhr überrascht und bezweifelten, daß diese Exporte überhaupt Abnehmer fänden, zumal in manchen Ländern mittlerweile entsprechende eigene Industrien im Aufbau begriffen seien. Mit der Bemerkung, „die Länder, die am meisten unter der deutschen Besatzung gelitten hätten, sollten also den größten Teil des Dollardefizits der Bizone decken", verdeutlichte der Niederländer überdies die "moralische“ Dimension des Problems, ohne allerdings daraus direkte Forderungen abzuleiten. ${ }^{201}$ Die amerikanischen Sprecher der Bizone überhörten folglich diese Mahnung und bemühten sich statt dessen, mit dem Hinweis auf deutsche Ausfuhren im Wert von etwa 3,2 Mrd. Dollar im Jahre 1936 - also unter autarkistischen und protektionistischen handelspolitischen Vorzeichen - die Wogen zu glätten. Das neue Exportziel war mithin, gemessen an den Zahlen der Vorkriegszeit, keineswegs besonders hoch und kaum geeignet, Erschütterungen hervorzurufen, wenn der Welthandel, wie erhofft, expandierte. ${ }^{202} \mathrm{Zwar}$ ließen sich die Kritiker durch diese Hinweise nicht überzeugen, doch bekannten sich alle zur vollständigen Einbeziehung Westdeutschlands in den westeuropäischen Wiederaufbau. Dies schloß, freilich im Rahmen der Bestimmungen des Industrieniveauplanes, einen möglichst hohen Lebensstandard ein: Das Entstehen eines politischen Unruheherdes sollte ebenso verhindert werden wie ein „internationales Lohndumping". 203

Trotz des in solchen Äußerungen und in einigen anderen Fragen spürbaren Mißtrauens wertete Günter Keiser von der Verwaltung für Wirtschaft die zweitägige Prüfung zu Recht als „atmosphärischen Dammbruch“, hatte doch auch der Vorsitzende des Exeku-

199 Vgl. dazu Aktennotiz v. Mangoldt über die Befragung der bizonalen Delegation v. 7./8. 11. 1948, Bericht Keiser über Reise nach Paris vom 5.-7. 11. 1948, Bericht Meinhold über die Wirkungen des Bizonen-Außenhandelsprogrammes 1952/53 in Paris, o. D., Bericht Keiser über Bespr. des Long-Term Planes der Bizone, o. D., alle BA, Z 14, 124.

200 Bericht Meinhold über die Wirkungen (wie Anm. 199).

201 Bericht Keiser über Bespr. des Long-Term Planes, S. 3 (wie Anm. 199). In seinem Bericht über die Paris-Reise (ebenda) führte Keiser dazu aus: „Eine grundsätzliche Kritik an dem Lebensanspruch, den die Bizone mit diesem Programm angemeldet hat, knüpfte nur an die Tatsache an, daß das Programm der Bizone einen Ausfuhrüberschuß nach Europa vorsah, um ihr Dollardefizit zu decken, worin man eine Art Zumutung für diejenigen Länder sah, die unter der deutschen Besatzung zu leiden gehabt haben.“

202 Bericht Keiser über Bespr. des Long-Term Planes, S. 6 (wie Anm. 199).

${ }^{203}$ Aktennotiz v. Mangoldt v. 7./8. 11. 1948 (wie Anm. 199). 
tivkomitees, der Brite Sir Edmund Hall-Patch, von einem „bedeutsamen Schritt“ gesprochen. Das Hauptverdienst dafür kam nach Keiser den - ausschließlich - amerikanischen Sprechern für die Bizone zu; insbesondere Karl Bode bescheinigte er eine „im besten Sinne fair(e) “ Interessenvertretung. Verbindlich im Ton, aber in essentiellen Fragen unnachgiebig, hatten er und die anderen Amerikaner das bizonale Programm verteidigt. Die Rolle der deutschen Sachverständigen hatte lediglich darin bestanden, für diesen „Kampf ... die Waffen zu liefern“. Zweifellos bedeutete es aber für die zukünftige Arbeit ein „außergewöhnliches Aktivum“, daß sich die Militärregierung durch diesen offiziell vorgelegten Plan in einer Reihe wichtiger Fragen weitgehend im Sinne der deutschen Vorstellungen festgelegt hatte. ${ }^{204}$

Ob der vom Zweimächteamt, insbesondere von den Amerikanern, eingeschlagene Weg allerdings tatsächlich der richtige war, darüber waren sich die deutschen Experten zunächst nicht einig. Keiser gehörte zu denjenigen, die für die forschere Gangart der Militärregierung eintraten. Er rechtfertigte etwa die hohe Exportziffer wegen ihrer „außerordentlichen, sozusagen erzieherischen Wirkung " auf die OEEC-Partner, denen damit die Notwendigkeit vor Augen geführt worden sei, „die Bizone als einen äußerst gewichtigen Konkurrenten“ auf den Weltmärkten anzuerkennen. ${ }^{205}$ Dieser Personenkreis, zu dem auch Meinhold zählte, plädierte dafür, „die in Paris unter Führung der Militärregierung begonnene Politik, die Umwelt an das zur Lebensfähigkeit Westdeutschlands erforderliche Ausmaß des Außenhandels zu gewöhnen“, fortzusetzen, schon weil man überzeugt war, daß die „prononzierte Betonung des deutschen Wiederaufstiegs“ zu den Hauptanliegen der amerikanischen Außenpolitik zählte und es deshalb wenig ratsam erschien, „sich dieser großen Entwicklung durch Verringerung einzelner Exportzahlen in Paris entgegenzustemmen“. Andere Stimmen, die überwiegend aus dem Kreis der deutschen Sachverständigen in den verschiedenen Ausschüssen der OEEC kamen, rieten zu einem vorsichtigeren Vorgehen und lehnten die öffentliche Verkündung von „überhöhten“ und damit „unnötig erschreckenden Zielen“ ab. Angesichts nach wie vor kursierender Forderungen nach einer „Übernahme der früher von Deutschland versorgten Märkte durch die ausländische Konkurrenz" oder einer Öffnung Westdeutschlands für ausländische Fertigwaren warnten diese in Paris agierenden Fachleute vor möglichen negativen Auswirkungen der hohen deutschen Zahlen. Die Konkurrenten könnten nämlich, und erste Anzeichen glaubten einige Beobachter sogar schon zu erkennen, wirtschaftliche Gegenmaßnahmen in die Wege leiten, solange „die deutsche Industrie noch nicht zu tatkräftiger Abwehr" in der Lage sei; auch politische Druckmittel - Demontage, Verlangsamung des Wiederaufbaus - stünden zur Verfügung und würden teilweise schon angewandt. Die Taktik der Praktiker vor Ort war es deshalb, „die erforderlichen Größenordnungen aus der wirtschaftlichen Notwendigkeit heraus selber und mit geringeren Widerständen wachsen zu lassen“, d. h., die Diskussion von der politischen auf die wirtschaftliche Ebene zu verlagern und dadurch Zeit zu gewinnen, bis die westdeutsche Wirtschaft kräftig genug war, den befürchteten Gegenmaßnahmen standhalten zu können. ${ }^{206}$

\footnotetext{
204 Bericht Keiser über Reise nach Paris (wie Anm. 199).

205 Ebenda.

206 Bericht Meinhold über die Wirkungen des Bizonen-Außenhandelsprogramms (wie Anm. 199).
} 
Gedanken über die richtige Taktik, freilich in umgekehrter Richtung, machte man sich allerdings auch auf der Gegenseite. Hier standen sich ebenfalls zwei Konzepte gegenüber: eine „sanfte“, auf die zähmende Kraft des Integrationsprozesses vertrauende und eine "harte“, Restriktionen und Kontrollen favorisierende Politik. Beim Examen in Paris hatte erstere dominiert, aber gegen diesen Kurs gab es in den einzelnen Ländern teilweise massiven Widerstand. So nahm beispielsweise der Präsident des Board of Trade in Großbritannien das bizonale Langzeitprogramm zum Anlaß, vor einem Frontalangriff auf die britischen Exportinteressen zu warnen. Er hatte dabei vor allem die geplanten Fertigwarenausfuhren nach Nord- und Südamerika und in die nicht der OEEC angehörenden Sterlingländer im Blick. An die Möglichkeiten und die Verpflichtung erinnernd, als Besatzungsmacht auch die Interessen der heimischen Industrie zu schützen, schlug er vor, "to prescribe to the Bizone, while there is still time, an alternative programme designed to develop its economy on a more self-sufficient pattern of agriculture and a more modest and realistic programme for the export of manufactures“ ${ }^{207}$ In die gleiche Kerbe hieb der Spitzenverband der Unternehmerschaft in Großbritannien, die „Federation of British Industries“. Angesichts eigener Pläne, die Ausfuhren gegenüber 1938 um 50 Prozent zu steigern, mußte selbst ein um „lediglich“ 30 Prozent höheres deutsches Exportvolumen äußerst bedrohlich erscheinen, zumal dieses Niveau innerhalb von vier Jahren praktisch vom Nullpunkt aus erreicht werden sollte: „Clearly, if the above export programme is allowed to proceed and the control of Bizone's economy handed over to the German government, a period of destructive competition with other exporting manufacturing countries is likely to ensue in overseas markets. “ Überdies fürchtete der Verband einen Rückfall in alte Gewohnheiten: „At the same time Germany would be likely to embark on ,unfair practises" of the kind of which she became such a master in pre-war days." Immerhin verstand sich die Spitzenvertretung, trotz solcher düsteren Prognosen, zu der Versicherung, Deutschland solle keinesfalls die Rückkehr in den Kreis der großen Exportnationen versperrt werden, und dies war vermutlich kein Lippenbekenntnis, mußte doch auch die britische Industrie an einer Wiederherstellung bewährter und für beide Seiten vorteilhaften Handelsbeziehungen interessiert sein. Worum es nicht nur der britischen Industrie letztlich ging, war: Vorkehrungen zu treffen, daß diese Rückkehr in geordneten Bahnen verlief und in einem Tempo, das Störungen im Prozeß des Wiederaufbaus in Europa ausschloß. ${ }^{208}$ Bemerkenswerterweise schloß sich das Foreign Office solchen Beschwerden und Forderungen nicht an, sondern bemühte sich im Gegenteil, einige einseitige oder gar unzutreffende Behauptungen zu korrigieren. So stellte ein Mitarbeiter des Außenministeriums fest, daß die für 1952/53 eingeplanten Ausfuhren keineswegs eine noch nie dagewesene Höhe erreichen, sondern selbst im günstigsten Fall unter dem Niveau des Spitzenjahres 1929 bleiben würden. Das änderte zwar nichts daran, daß Westdeutschland auch im Foreign Office als „formidable competitor“ eingeschätzt wurde, aber von einem Einsatz der Großbritannien als Besatzungsmacht zur Verfügung stehenden Druckmittel rieten die mit einem solchen Ansinnen konfrontier-

${ }^{207}$ Cabinet, Economic Policy Committec, Long-Term Programme of the Bizone of Germany, Memorandum by the President of the Board of Trade v. 23. 11. 1948, PRO, FO 371/70737. Einem Vermerk v. 26. 11. 1948 zufolge, ebenda, wurde das Memorandum zurückgezogen; seine Bedeutung als eine Art "Stimmungsbarometer" wird dadurch freilich nicht gemindert.

${ }^{208}$ Federation of British Industries, The European Recovery Programme of Western Germany, 31. 1. 1949, PRO, FO 371/76844. 
ten Beamten schon wegen der zu erwartenden negativen Reaktion der Amerikaner ab. Das Problem, die eigene Rekonstruktionspolitik mit dem Erfordernis in Einklang zu bringen, Westdeutschland von ausländischer Hilfe unabhängig zu machen, ließ sich auf diese Weise nicht lösen. Nach Frankreich und Großbritannien gebührte der Bizone aus der Sicht des Foreign Office eine herausragende Rolle beim europäischen Wiederaufbau; übrig blieb die schwache Hoffnung, daß sich die bizonalen Planungen tatsächlich als überzogen und zu ehrgeizig erweisen würden. ${ }^{209}$

Zweifellos verdiente die Haltung des Foreign Office ebenfalls das Prädikat „fair“ aber es war eher eine Fairneß aus Schwäche und nicht, wie im Falle der Vereinigten Staaten bzw. der amerikanischen Militärregierung, aus Stärke. Die Amerikaner gaben in der bizonalen ERP-Politik eindeutig den Ton an, und insofern war es aus deutscher Sicht nur konsequent, ihren offensiven Kurs innerhalb der OEEC zu unterstützen, obgleich manche deutschen Sachverständigen eine vorsichtigere Gangart vorgezogen hätten. Die maßgeblichen Personen in der Verwaltung für Wirtschaft und im Marshallplanbüro waren im Gefühl der - zumindest auf längere Sicht gesehen - wirtschaftlichen Stärke Westdeutschlands und der Rückendeckung durch die Vereinigten Staaten weniger zimperlich und hielten ein allzu behutsames Agieren für unnötig. Freilich waren dies nur taktische Differenzen, die ohnehin so lange keine praktische Auswirkungen hatten, wie die Amerikaner in der Pariser Delegation und in der bizonalen ERP-Politik das Heft in der Hand behielten. Die Diskussion um das Long-Term Program hatte jedenfalls den deutschen Politikern und Wirtschaftsplanern einen Vorgeschmack auf die Probleme gegeben, mit denen sie nach der Überleitung der Verantwortlichkeiten konfrontiert werden würden; das Programm hatte aber umgekehrt auch den übrigen OEEC-Ländern auf drastische Weise demonstriert, wie sich Amerikaner und Deutsche die künftige Rolle Westdeutschlands im europäischen Wirtschaftsleben vorstellten.

Eine ähnlich große Resonanz war dem langfristigen Programm für die französische Zone verständlicherweise nicht beschieden. Auf sich selbst gestellt, war die Zone wirtschaftlich doch zu unbedeutend, um mit ihren Planungen bei den übrigen OEEC-Mitgliedern überdurchschnittliche Aufmerksamkeit hervorrufen zu können. Die deutschen Experten, die einen ersten Entwurf zu erstellen hatten, waren sogar gehalten, ihre Planungsarbeiten von vornherein möglichst eng mit der Bizone abzustimmen, also ihrerseits auf die Bedürfnisse und Möglichkeiten des potenteren Partners Rücksicht zu nehmen. Die zweite Vorgabe der Militärregierung an den Koordinierungsausschuß in Baden-Baden lautete, das Long-Term Program so zuzuschneiden, daß die Zone mit Ablauf der Marshallhilfe aus eigenen Kräften wieder lebensfähig zu sein versprach. Initiative und Verantwortung für das Programm sollten weitgehend auf deutscher Seite liegen. Die drei Länderregierungen und der Koordinierungsausschuß sahen sich jedoch im August 1948, als dieser Auftrag erging, dazu außerstande, solange das Verhältnis zwischen der Militärregierung und den Landesregierungen nicht geklärt war. Dennoch gestaltete sich die praktische Zusammenarbeit mit den französischen Dienststellen, wie Albrecht rückblickend einräumte, „durchaus vertrauensvoll“, weil diese den deutschen Argumenten bei der Regierung in Paris hin und wieder doch Gehör und Anerkennung verschafften. Begünstigt wurde die gedeihliche Zusammenarbeit vor allem dadurch, daß beide Seiten

209 Vermerk Mc Farlanc v. 26. 11. 1948 u. Vermerk Nicholls für Sir William Strang v. 6. 12. 1948, bcide PRO, FO $371 / 70737$. 
übereinstimmend der Auffassung waren, daß es "nicht möglich sein würde, die französische Besatzungszone bis 1952 vollkommen selbsttragend zu machen, sofern nicht sehr weitgehende Änderungen in der politischen Gesamtsituation eintreten würden“..210

Trotz dieses Vorbehalts waren die Autoren des Programms bemüht, den Erwartungen auf seiten der ECA und der OEEC gerecht zu werden und "optimistische" Daten zu präsentieren. ${ }^{211}$ So sollte das Volkseinkommen ungefähr das Niveau des Jahres $1936 \mathrm{er}$ reichen, die Versorgung mit Nahrungsmitteln 90 und mit industriellen Verbrauchsgütern 80 Prozent des Vorkriegsstands; verglichen mit der Bizone lag das veranschlagte Pro-Kopf-Einkommen allerdings um 27 Prozent niedriger. Für Investitionen waren 900 Mio. DM eingeplant, davon 30 Prozent für das Verkehrs- und Transportwesen. Die Industrieproduktion, 1948 noch 35 Prozent hinter dem Stand von 1936 zurück, sollte die Vorkriegsmarke 1952/53 um 3 Prozent übertreffen, die landwirtschaftliche Produktion in etwa gleichziehen. Wegen des hohen Importbedarfs errechneten die Autoren, obgleich das Exportvolumen um 3 Prozent gesteigert werden sollte, ein Zahlungsbilanzdefizit von 36 Mio. Dollar. Die vorgesehenen Einfuhren bestanden zu zwei Dritteln aus Rohstoffen und Fertigwaren und zu einem Drittel aus Nahrungsmitteln, die Ausfuhren in erster Linie aus Erzeugnissen der chemischen und der Eisen- und Stahlindustrie, Präzisionsmaschinen sowie Artikeln der Uhren- und Holzindustrie. Diese Lieferungen stellten aus Sicht der Verantwortlichen in der französischen Zone zugleich eine substantielle Hilfe für die europäische Wirtschaft dar. Das Gesamtvolumen der geplanten Ausfuhren belief sich auf 250 Mio. Dollar. Obwohl die Planungen alles in allem recht bescheiden und insbesondere in der zentralen Frage der Zahlungsbilanz erstaunlich ehrlich waren, erschienen sie den Experten der OEEC und des Zweimächtekontrollamtes in manchen Punkten als zu optimistisch: „It would seem that Z.F.O.A., economically inter-locked with the Bizone, is really too small a unit to plan for viability with any real hope of success", lautete, entgegen den französischen Wünschen, das Fazit. ${ }^{212}$ Den langfristigen Planungen der französischen Zone hafteten deshalb von Anfang an - und in weitaus stärkerem Maße als den Programmen der anderen OEEC-Mitglieder - wirklichkeitsfremde, "theoretische“ Züge an. Wichtiger als die Fernziele waren für Albrecht und seine Mitarbeiter denn auch die Zugeständnisse, zu denen sich die französische Militärregierung im Laufe der Arbeiten am Long-Term Program durchrang: keine weiteren Entnahmen von Lebensmitteln oder industriellen Rohstoffen zugunsten der Besatzungsmacht, keine weiteren Strom-Zwangsexporte, erhebliche Abstriche am Demontageprogramm, Lockerung des Verbots der Aluminiumproduktion und Wiederaufbau einer bescheidenen Handelsflotte.

Während die deutschen Wirtschaftspolitiker und -planer in der französischen Zone mit "ihrem“ Vierjahresprogramm wegen seiner „Nebenwirkungen“ mithin durchaus zufrieden waren, konnte davon bei ihren Kollegen in der Bizone nicht die Rede sein. Aufgrund von Differenzen in einer Reihe von Fragen - Exportvolumen, Zahlungsbi-

${ }^{210}$ Karl Albrecht, Abschlußbericht über die deutschen ERP-Arbeiten in der französischen Besatzungszone v. 4. 10. 1949, IWW/WA, Baade-NL, III ERP. Vgl. auch Niederschrift 72. Sitzung Staatsministerium Württemberg-Hohenzollern v. 20. 9. 1948, StA Sigm., Film S IV, Wü2/779, S. 72.

211 Vgl. Programme à long terme en Zone Française d' Occupation mit Begleitschreiben v. 13. 11. 1948, Comments by Secretary General on the Long-Term Programme of the French Zone v. 15.11. 1948, Questions for Investigations on French zone Long-Term-Programme, o. D., alle in IfZA, MF 260, 11/ 115-3/4; außerdem Albrecht, Abschlußbericht (wie Anm. 210).

${ }^{212}$ Questions for Investigations (wie Anm. 211). 
lanzdefizit, Stahlproduktion, Arbeitskräfteüberschuß, Investitionsbedarf, Finanzpolitik - sahen sich die bizonalen ERP-Experten außerstande, das Programm als eine deutschalliierte Gemeinschaftsarbeit anzuerkennen. Darum sperrten sie sich, als das Zweimächteamt für das Frühjahr 1949 eine Veröffentlichung in deutscher Übersetzung vorbereitete und, zum Zeichen deutschen Einverständnisses, die Unterschriften Pünders und Erhards erbat. ${ }^{213} \mathrm{Zwar}$ sollte, schon weil die endgültige Fassung noch nicht vorlag, eine öffentliche und offizielle Distanzierung durch den Verwaltungsrat vermieden werden, um bei den Amerikanern keine Verstimmung hervorzurufen ${ }^{214}$; die anschließenden Verhandlungen über die strittigen Punkte des Vierjahresplans brachten aber offenbar nicht die erwünschten Ergebnisse, denn das Anfang März 1949 schließlich in deutscher Sprache publizierte langfristige Programm ermangelte der beiden Unterschriften und damit der ausdrücklichen Billigung der deutschen Stellen.215

Die Überarbeitung der nationalen Pläne war unterdesssen ins Stocken geraten, weil die OEEC erst die Revision der Programme für 1949/50 abschließen wollte - sollten diese doch als Grundlage für die „division of aid“ dienen. Ohnehin war das ehrgeizige Ziel, die einzelnen, inhaltlich und formal sehr unterschiedlichen Länderentwürfe zu einem einzigen, kohärenten Gesamtplan zu verschmelzen, bereits aufgegeben worden. Statt dessen hatte die OEEC Ende 1948 einen ERP-Zwischenbericht veröffentlicht, dessen zweiter Teil aus den vollständig abgedruckten Plänen der Mitgliedsländer bestand. ${ }^{216}$ Damit hatte sich die Arbeit der nationalen Planungsstäbe zumindest erst einmal gelohnt, ehe im Mai 1949 die Examen der revidierten Fassungen stattfanden.

Die Programme der Bizone und der französischen Zone wurden zusammen verhandelt. Von einem einführenden Statement des Amerikaners Tank abgesehen, sprachen ausschließlich Deutsche - von Mangoldt, Keiser und Häfner - für die Bizone, während für die französische Zone nur Franzosen das Wort ergriffen. Beide Programme fielen dieses Mal pessimistischer aus, gegenüber der ursprünglichen Fassung waren einige Schätzungen nach unten korrigiert worden. Insbesondere die Exportziffern waren deutlich gesenkt worden: um 500 Mio. Dollar auf 2,3 Mrd. Dollar bzw. um 24 Mio. auf 228 Mio. Dollar. Obgleich auch die Importziffern reduziert worden waren - für die Bizone von 2,8 auf 2,55 Mrd. Dollar - erhöhten sich die eingeplanten Defizite in der Zahlungsbilanz: Die Bizone veranschlagte insgesamt 320 statt 72 Mio. Dollar, die französische Zone 50 statt 36 Mio. Dollar. Vor dem Hintergrund des Dollarmangels bereitete vor allem der erwartete Anstieg des bizonalen Defizits mit Nordamerika von 278 auf 370 Mio. Dollar Sorgen. Demgegenüber fiel es kaum ins Gewicht, daß die französische Zone nur noch mit einem Defizit von 50 Mio. Dollar rechnete; insgesamt belief sich das für 1952/ 53 prognostizierte westdeutsche Dollardefizit damit nämlich auf 420 Mio. Dollar. Opti-

${ }^{213}$ Keiser an Mangoldt v. 31. 12. 1948 u. Vermerk Meinhold für Erhard v. 4. 1. 1949, beide BA, Z 14, 124. 214 Vermerk Martini für Pünder v. 26. 1. 1949, ebenda.

${ }^{215}$ Das langfristige Programm der Bizone, PA, Bestand 2/606. Im Vorwort heißt es, das Programm sei „in Zusammenarbeit" mit der bizonalen Wirtschaftsverwaltung aufgestellt worden. Dagegen verwahrte sich ein Mitarbeiter Schniewinds ausdrücklich: „Nach dem Vorwort könnte der Eindruck entstehen, daß es sich hierbei nicht - wie es tatsächlich der Fall ist - um die Fassung der Militärregierung handele, sondern um ein mit Zustimmung der deutschen Stellen veröffentlichtes Programm. "Vermerk Rieck v. 3.3. 1949, BA, Z 14, 124.

216 OEEC, Interim Report on the European Recovery Programme, Vols. I und II, Paris 1948; eine Zusammenfassung des $Z$ wischenberichts in deutscher Sprache findet sich in BA, Z 14, 124; vgl. auch van der Beugel, Marshall Aid, S. 166-172. 
mistische Prognosen wagten dagegen zumindest die bizonalen Experten für die Entwicklung der Produktion; sie hofften, das Niveau von 1936 nicht nur, wie ursprünglich geplant, um 10, sondern sogar um 20 Prozent übertreffen zu können. ${ }^{217}$

Nachdem beim ersten Examen im November 1948 vor allem die Exportpläne der Bizone beträchtliche Unruhe verursacht hatten, provozierten dieses Mal das Dollardefizit und die bizonalen Produktionsziffern kritische Fragen der OEEC-Partner. Um das ursprüngliche Ziel des Marshallplans - die Unabhängigkeit von spezieller Auslandshilfe wenigstens annähernd zu erreichen, hatte der Programmausschuß der OEEC beispielsweise vorgeschlagen, die preisbewußte Einfuhrpolitik zugunsten dollarsparender Importe aus den OEEC-Ländern aufzugeben und die vorhandenen Mittel und Ressourcen verstärkt für Investitionen und zur Verringerung des außenwirtschaftlichen Ungleichgewichts einzusetzen anstatt zur Erhöhung des Verbrauchs. Auf einen entsprechenden Einwand schienen die deutschen Experten nur gewartet zu haben, denn Günther Keiser verteidigte mit einem vehementen Plädoyer den Standpunkt der Bizone: Vorrangiges Ziel der Investitionspolitik sei es, die zerstörten Städte und die Produktionsanlagen wieder aufzubauen und der Bevölkerung einen Lebensstandard zu garantieren, der nicht allzu weit unter dem der Nachbarländer liege. Es sei kaum möglich, diese Ziele zu realisieren und gleichzeitig das Dollardefizit zu verringern; Vorrang gebührte aber, daran ließ Keiser keinen Zweifel, der Rekonstruktionspolitik. Wegen der ungünstigen Ausgangsbedingungen und der schweren Lasten infolge des Krieges sei - das von deutscher Seite erwünschte Konsumniveau vorausgesetzt - mit einer ausgeglichenen Dollarbilanz ohnehin frühestens $1955 \mathrm{zu}$ rechnen. Mit diesem Statement, welches die deutschen Schwierigkeiten in den Vordergrund rückte und keine Bereitschaft erkennen ließ, die Ratschläge der OEEC-Partner anzunehmen, sorgte Keiser im Programmausschuß für enorme Irritationen. „In general, the atmosphere of the Committee became somewhat cold“, konstatierte ein Mitglied der britischen Delegation. ${ }^{218}$ Der Sprecher der französischen Vertretung behielt sich eine Stellungnahme vor und wollte erst neue Instruktionen seiner Regierung abwarten. Diese zeigte sich allerdings weniger über das westdeutsche Zahlungsbilanzdefizit besorgt als über die geplante Steigerung der Produktion. Maurice Halff von der Marshall-Abteilung in Baden-Baden machte den Wirtschaftsberater des Militärgouverneurs unmittelbar nach der Prüfung des bizonalen Programms auf das Problem aufmerksam und identifizierte auch gleich den mutmaßlichen „Drahtzieher": die ECA. Die Einwände einzelner Delegationen während des Examens hatten seiner Meinung nach nämlich nicht ausgereicht, den übrigen Teilnehmerstaaten die Gefahren zu verdeutlichen, die von den „übersteigerten“ Produktionszielen der Bizone drohten. ${ }^{219}$

$\mathrm{Daß}$ die Irritationen, die Keiser mit seiner Erklärung ausgelöst hatte, nicht ganz unberechtigt waren, erhellt aus einer Reihe interner Stellungnahmen Karl Albrechts zu den Beschwerden aus OEEC-Kreisen, die für die Einstellung der maßgeblichen deutschen

217 OEEC, Programmes Committee, Review of Long-Term Programmes - Western Germany v. 3. 6. 1949, BA, Z 14, 124.

${ }^{218}$ U. K. Delegation an Foreign Office v. 11. 5. 1949, PRO, FO 371/76844. Dort drei weitere Telegramme gleichen Datums mit Berichten über das Examen der Langzeitprogramme.

219 Halff an Conseiller Economique et Financier v. 9. 5. 1949, AO, Aff EcoFin, Carton 2, Dossier 3000 AII, Marshall Plan. Die Datierung scheint allerdings falsch zu sein, denn in dem Vermerk werden Einzelheiten über die Prüfung vom 10. Mai berichtet. - Halff machte übrigens die bizonalen Besatzungsbehörden auch dafür verantwortlich, daß kein gemeinsames revidiertes Long-Term-Programm präsentiert werden konnte. 
ERP-Fachleute und Wirtschaftspolitiker durchaus repräsentativ waren. Das begann schon bei der Neigung, kritische Einwände abzublocken oder die Schuld für bestimmte Fehlentwicklungen oder Mängel bei anderen, bevorzugt bei den Besatzungsmächten, zu suchen. So forderte Albrecht beispielsweise die Aufhebung der alliierten Restriktionen oder wenigstens eine Förderung bestimmter Industriezweige als Ausgleich für die $\mathrm{Be}-$ schränkung anderer; außerdem mahnte er eine größere Aufnahmebereitschaft des Auslands auch für „less and non essential goods“ aus den Westzonen an. Hinzu kam eine mehr und mehr ins Prinzipielle gehende Kritik an der Konzeption des Marshallplans. Die „derzeitige Methodik der amerikanischen Auslandshilfe“, so Albrecht, stehe "grundsätzlich in Widerspruch zu ihren eigenen Zielen“. Sie verleite zu „überhöhtem Konsum und zu Fehlinvestitionen“, sei „mehr Subvention als Sanierung“ und begünstige „die bilaterale Beschränkung anstelle einer multilateralen Expansion“. Sein Gegenvorschlag: Die Dollarbeträge der amerikanischen Auslandshilfe sollten „ausschließlich zur Währungs- und Finanzsanierung etwa mit Hilfe der Weltbank“ reserviert werden, d. h., die einzelnen Länder sollten zur Überbrückung des Zahlungsbilanzdefizits Dollaranleihen erhalten - allerdings nur unter gewissen Voraussetzungen: Sie sollten sich verpflichten, die Konvertibilität ihrer Währungen herbeizuführen, auf „künstliche Manipulierung “ der Wechselkurse zu verzichten, für einen „ausgeglichenen Staatshaushalt“ Sorge zu tragen, auf dem Gebiet der Investitionen zusammenzuarbeiten und „künstliche Hemmnisse für den Warenverkehr wie Prohibitivzölle, Ein- und Ausfuhrzölle und Kontingente“ zu beseitigen. ${ }^{220}$ Mit diesen Schlußfolgerungen aus den bis dahin gewonnenen Erfahrungen mit dem Marshallplan glaubte er sich überdies, und wohl nicht ganz zu Unrecht, im Einklang mit „den Erkenntnissen sehr maßgebender amerikanischer Kreise und vermutlich auch der Auffassung von McCloy“, dem neuen ECA-Repräsentanten in Europa und späteren Hohen Kommissar der Vereinigten Staaten in der Bundesrepublik. Schon aus diesem Grund erhoffte sich Albrecht eine Stärkung der Position Westdeutschlands in der Pariser Organisation, wenn die Deutschen diese Auffassung offiziell und „in geeigneter Form“ bei der ECA-Mission und gegebenenfalls auch bei der OEEC vertreten würden. ${ }^{221}$

Über „Konstruktionsmängel“ des Marshallplans klagte im Zusammenhang mit dem Programm 1952/53 auch Albrechts Kollege Keiser, und sogar öffentlich: Er monierte ebenfalls eine falsche Verwendung der ERP-Mittel, wollte aber im Unterschied zu Albrecht nicht die Zahlungsbilanz, sondern den Kapitalbedarf der einzelnen Länder als Richtschnur nehmen; auf diese Weise wäre Westdeutschland voraussichtlich in den Genuß höherer Marshallplanhilfe gekommen. Insofern traf sich Keisers Kritik im Kern mit dem Vorschlag seines Kollegen - beide wollten die vermeintliche Benachteiligung Westdeutschlands korrigieren. Die bei Albrecht anklingenden Befürchtungen vor einem Überhandnehmen planwirtschaftlicher Methoden beim europäischen Wiederaufbau teilte Keiser, mittlerweile Sozialdemokrat, allerdings nicht; was in Paris versucht wurde, war für ihn „vielleicht Planung, aber niemals Planwirtschaft“. Man habe, mokierte er sich sogar, „den Long-Term-Plan der einzelnen Länder als einen Wandschirm angesehen, auf dem sich die einzelnen Probleme wie Schattenrisse“ abzeichneten; bestimmte

220 „Bemerkungen zur OEEC-Kritik an den westdeutschen Long-Term-Plänen“ v. 13. 6. 1949, Verf. Karl Albrecht, BA, Z 14, 124. Vgl. auch Albrecht an v. Mangoldt v. 13.6.1949 u. Vermerk Albrecht v. 11.6. 1949 , ebenda.

221 Albrecht an Martini v. 4. 7. 1949, ebenda. 
Elemente und Daten der Pläne seien nach Belieben als Argumente in den OEEC-internen Diskussionen eingesetzt worden, aber „mehr als ein gutes Lehrstück für alle Beteiligten" sei die "Long-Term-Planung" bisher nicht gewesen.222 Den Vorwurf der Planwirtschaft wies übrigens auch Helmut Meinhold zurück. Er sah in dem Programm keinen "Generalwirtschaftsplan, sondern ein statistisch beschriebenes Wirtschaftsziel“. Die eigentliche Verpflichtung bestand für ihn darin, daß die Teilnehmerländer die in ihren Programmen skizzierte und an den Plandaten orientierte Wirtschaftspolitik auch tatsächlich betrieben.223

Diese Stimmen lassen erkennen, daß die teilweise hohen Erwartungen, mit denen die Deutschen an die Formulierung des „Vierjahresplans" herangegangen waren, längst einer pragmatischeren Sicht Platz gemacht hatten - eine Tendenz, die sich gleichzeitig im nachlassenden Planungseifer der OEEC manifestierte. Andere Aufgaben und Zielsetzungen erhielten Priorität, nachdem sich der ursprüngliche Gedanke eines ausgefeilten westeuropäischen Wiederaufbauplans als illusorisch erwiesen hatte. Die Mühen waren gerade für die Deutschen gewiß nicht sinnlos gewesen, die dabei gesammelten Erfahrungen und Erkenntnisse sicherlich von Nutzen für die weitere Arbeit im Rahmen der OEEC und zu Hause. Aber von den Long-Term-Programmen als einem „Symbol abendländischen Geistes, achtung- und furchtgebietend zugleich" zu sprechen, wie Otto Schniewind es getan hatte ${ }^{224}$, mutet höchst peinlich an - wenn man nicht unterstellen möchte, er habe damit den Niedergang, die „Materialisierung“ des „abendländischen Geistes" zum Ausdruck bringen und indirekt kritisieren wollen.

Der eigentliche Wert der Planungsarbeiten bestand aus Sicht der deutschen ERP-Experten darin, einen Überblick über die eigenen Ressourcen und Möglichkeiten zu gewinnen und die Potentiale und Zielsetzungen der anderen OEEC-Länder kennenzulernen. $\mathrm{Da}$ die verhältnismäßig starke Konzentration der Pariser Organisation auf „Programmierung" - Jahrespläne für 1948/49 und 1949/50 und Langzeitplan - auch auf deutscher Seite auf Ablehnung stieß, änderte daran nichts. Im Laufe der Vorbereitung, Formulierung und Verteidigung der Programme hatten die drei Militärregierungen die Mitspracherechte der Frankfurter und Baden-Badener Stellen Schritt für Schritt erweitert; bei der Prüfung des revidierten „Vierjahresplans" kamen von Mangoldt, Keiser und Häfner sogar zu ihrem ersten Auftritt als alleinige Sprecher der Bizone. Selbst wenn diese Premiere zumindest aus britischer Sicht, wie erwähnt, etwas unglücklich verlaufen war - eine gute Gelegenheit, sich mit dem neuen Stil multilateraler Außenwirtschaftspolitik vertraut zu machen und den diplomatischen Umgang mit einstigen Kriegsgegnern einzuüben, war es allemal gewesen. Nicht zu vergessen schließlich, daß die im Zuge der Planungsarbeiten intensivierte Kooperation mit amerikanischen Stellen wichtige Auf-

222 Günter Keiser, Konstruktionsmängel des Marshallplans, in: Wirtschaftszeitung v. 5. 11. 1949 (dort das erste Zitat); ders., Das Long-Term-Programm und die amerikanische Politik, Ref. auf der 3. Mitgliederversammlung der „Arbeitsgemeinschaft deutscher wirtschaftswissenschaftlicher Forschungsinstitute" vom 1.-2.9. 1949 in München, IWW/WA, Baade-NL, III ERP.

${ }^{223}$ Helmut Meinhold, Lenkung der Marktwirtschaft im Long-Term-Programm, in: Wirtschaftsverwaltung 2(1949), S. 348-349. Dieser Beitrag war Teil einer in den Heften 9 bis 15 dieser Zeitschriften geführten Debatte über verschiedene Aspekte und Implikationen des Long-Term-Programms, an der sich u. a. der Generalsekretär des Länderrats, Heinrich Troeger, und Leonhard Miksch von der Verwaltung für Wirtschaft beteiligten. Vgl. dazu Troeger, Interregnum, S. 110 u. 159 (Anm. 10).

${ }^{224}$ Otto Schniewind, Allgemeiner Bericht über den Marshall-Plan für 1948 v. 7. 1. 1949, BA, NL Pünder/ 704. 
schlüsse über die längerfristigen Ziele der Vereinigten Staaten in Westdeutschland und Westeuropa brachte. Auf diese Weise war eine „vorauseilende“ Anpassung der eigenen an die amerikanische Politik möglich, und wie wertvoll der Beistand der westlichen Führungsmacht war, um westdeutsche Interessen in der OEEC durchsetzen zu können, dies hatten die Verhandlungen in Paris mehrmals in aller Deutlichkeit gezeigt. Allerdings gelang diese Adaption nicht so problemlos, wie es das Image eines Juniorpartners der USA, das Westdeutschland nach und nach aufbauen konnte, vermuten ließe.

\section{b) Liberalisierung und Multilateralisierung des Handels- und Zablungsverkebrs}

Wie mühsam dieser Anpassungsprozeß mitunter sein konnte, dafür lieferte das Tauziehen um die Handelsliberalisierung den schlagenden Beweis - und dies, obgleich sich Ludwig Erhard und seine Mitstreiter im nachhinein als Schrittmacher der Liberalisierung feierten und feiern ließen. ${ }^{225}$

Der Abbau der innereuropäischen Handelsschranken gehörte von Anfang an zu den „essentials“ der amerikanischen ERP-Politik. ${ }^{226}$ Nachdem der Versuch, liberale Handelsprinzipien weltweit durchzusetzen, mit dem Scheitern des Projekts einer „International Trade Organisation“ (ITO) zunächst einmal mißglückt war, sollten wenigstens in Westeuropa Fortschritte erzielt werden. Dort war zwar grundsätzlich die Bereitschaft vorhanden, über neue, flexiblere Handelsmethoden und Zahlungssysteme nachzudenken, aber in der Praxis dominierten bilaterale Konzepte und Vereinbarungen. Dies hing zum einen damit zusammen, daß die Handelspolitiker vielerorts glaubten, mit den vertrauten und bewährten Praktiken die Interessen ihrer Länder am wirkungsvollsten wahrnehmen zu können; zum anderen war die reale wirtschaftliche Bedeutung der bilateralen Verrechnungsabkommen nicht von der Hand zu weisen, denn fast ein Viertel des Handels zwischen den späteren OEEC-Ländern, die Kolonien ausgenommen, wurde Ende 1947 auf dieser Basis abgewickelt. Allerdings drohte dieses System allmählich an seine Grenzen zu geraten; Stagnationstendenzen im innereuropäischen Handel waren dafür ein untrügliches Zeichen. Denn bevor die Schuldnerländer nach Überschreitung ihrer Kreditlinien Gefahr liefen, die neuen Schulden in Gold oder konvertiblen Währungen bezahlen zu müssen, griffen sie lieber zu dem bequemeren Mittel der Kürzung oder des völligen Stopps der Importe. ${ }^{227}$ Deshalb hatte es gehörigen amerikanischen Drucks bedurft, ehe sich die Teilnehmer an der CEEC-Schlußkonferenz vom September 1947 zu einem vorsichtigen Bekenntnis zu den Grundsätzen eines freien, multilateralen Warenverkehrs durchringen konnten. Entsprechende Bestimmungen wurden dann auch in die OEEC-Konvention vom 16. April 1948 aufgenommen. Allerdings dauerte es noch bis Ende Mai 1949, ehe erste konkrete britische und französische Vorschläge für den Abbau der mengenmäßigen Beschränkungen - dies vor allem meinte der Terminus „Libera-

225 Deutschlands Rückkehr zum Weltmarkt, hrsg. v. Ludwig Erhard, Düsseldorf 1954, bes. S. 15; vgl. auch Hentschel, Ludwig Erhard, bes. S. 107-111.

226 Vgl. zum folgenden Werner Bührer, Erzwungene oder freiwillige Liberalisierung? Die USA, die OEEC und die westdeutsche Außenhandelspolitik 1949-1952, in: Herbst/Bührer/Sowade (Hrsg.), Marshallplan, S. 139-162; Buchheim, Wiedereingliederung, bes. S. 99-133. Aus zeitgenössischer amerikanischer Sicht Herbert G. Schmidt, The Liberalization of West German Foreign Trade 1949-1951, hrsg. v. Office of the U.S. High Commissioner for Germany, Frankfurt a. M. 1952.

227 Vgl. Wexler, Marshall Plan, bes. S. 121-124; Buchheim, Wiedereingliederung, S. 111-119. 
lisierung" im damaligen OEEC-Sprachgebrauch - vorlagen. Am 4. Juli verabschiedete der Rat der Organisation endlich einen Beschluß, in dem sich die Teilnehmerländer verpflichteten, „die mengenmäßigen Beschränkungen bei der Einfuhr untereinander allmählich abzubauen, damit bis 1951 der intereuropäische Handel möglichst weitgehend liberalisiert" sei; erwartet wurde zunächst ein einseitiger Abbau der Handelsschranken. Bis zum 1. Oktober 1949 sollte jedes Land über die entsprechenden Schritte berichten, damit die OEEC nachprüfen konnte, ob auch wirklich alle Möglichkeiten ausgeschöpft worden waren. ${ }^{228} \mathrm{Am} 13$. August präzisierte der Rat diesen Beschluß und forderte dazu auf, zwei Arten von Liberalisierungslisten vorzulegen: Einmal einen Katalog derjenigen Waren, die unbeschränkt bzw. aufgrund „automatisch“ erteilter Einfuhrlizenzen eingeführt werden konnten; zum anderen eine sogenannte Verhandlungsliste mit Gütern, die nur für den Fall entsprechender Gegenleistungen potentieller Handelspartner von Einfuhrbeschränkungen befreit werden sollten.

Nach diesem Vorstoß der OEEC mit konkreten Aufträgen und festen zeitlichen Vorgaben reichten wohlfeile Lippenbekenntnisse zum Freihandel nicht länger aus. Dies galt in besonderem Maße für die westdeutschen Wirtschaftspolitiker, die sich überdies, im Zuge der Überleitung der ERP-Verantwortlichkeiten, immer weniger hinter dem „breiten Rücken“ der Amerikaner verstecken konnten. Schon weil die deutschen Verantwortlichen somit gezwungen waren, selber „Farbe zu bekennen“, wurde ihre Stellungnahme mit Spannung erwartet. Die Wichtigkeit Westdeutschlands für den europäischen Handelsverkehr tat ein übriges, einer solchen ersten eigenverantwortlichen Präsentation der handelspolitischen Grundsätze und Ziele die kritische Aufmerksamkeit der Öffentlichkeit in Westeuropa sowie der Experten von OEEC und ECA zu sichern.

Bis zu diesem Zeitpunkt hatten sich die einschlägigen Überlegungen und Vorschläge aus Industrie, Handel und zuständigen Verwaltungen überwiegend auf traditionellen Bahnen bewegt. Freilich hatte es sich zumeist um reine Gedankenspielereien gehandelt, denn der Außenhandel der westlichen Besatzungszonen war zunächst ausschließlich von alliierten Stellen abgewickelt worden. ${ }^{229}$ Erst im Laufe des Jahres 1947 hatte die anglo-amerikanische Joint Export Import Agency deutschen Exporteuren größere Mitsprachemöglichkeiten eingeräumt, ohne allerdings schon auf die letztendliche Entscheidungsgewalt zu verzichten. So war es nicht ganz unverständlich, daß politische und wirtschaftliche Kreise in den Westzonen mit dem Begriff „Liberalisierung“ zuerst und vorrangig größere eigene Mitspracherechte und den zügigen Abbau der alliierten Restriktionen meinten. Dagegen stießen die amerikanischen Initiativen zugunsten eines freien, multilateralen Welthandels anfangs eher auf Skepsis. Zwar lobte beispielsweise Ludwig Erhard im Frühjahr 1948 den multilateralen Warenaustausch als die „reifere Form außenhandelspolitischer Betätigung" gegenüber den damals verbreiteten zweiseitigen Handels- und Clearingabkommen, aber wegen der vielfältigen Störungen politischer und wirtschaftlicher Art war er davon überzeugt, daß man sich in den Westzonen solcher "Zwischenlösungen“ bedienen müsse, „ehe das Ideal Verwirklichung finden“

${ }^{228}$ Eine deutsche Übersetzung des Beschlusses C (49) 88 (Final) v. 4. 7. 1949 findet sich in BA, B 146, 324.

229 Vgl. hierzu insbesondere Friedrich Jerchow, Deutschland in der Weltwirtschaft 1944-1947, Düsseldorf 1978; Hanno Sowade, Wegbereiter des Wiederaufstiegs, München 1992; aus zeitgenössischer Sicht Evamaria Lierke, Der Wiederaufbau des Außenhandels in der Bizone, Diss. Bonn o. J. (1951). 
könne. ${ }^{230}$ Deshalb verwundert es nicht, daß die bizonalen Instanzen in ihren Stellungnahmen und Programmen die Liberalisierungsproblematik allenfalls am Rande behandelten - und weniger aus eigenem Antrieb, als um den Erwartungen der ECA zu entsprechen. Der Langzeitplan beispielsweise kam mit wenigen Zeilen aus.

Den Ratsbeschluß vom 4. Juli kommentierte Hans Karl von Mangoldt, der deutsche "Chefdelegierte“ der bizonalen Vertretung in Paris, denn auch eher zurückhaltend.231 Fortschritte beim Abbau von Handelshemmnissen waren schließlich auch auf dem Wege zweiseitiger Vereinbarungen möglich, wie die Deutschen mit den wenig später unterzeichneten Abkommen mit der Schweiz und den Niederlanden glaubten nachweisen zu können. Gegenüber der Schweiz verpflichtete sich die westdeutsche Seite dazu, im Rahmen von jeweils für vier Wochen gültigen Gesamtquoten die Einfuhr von Industriegütern keinerlei Restriktionen zu unterwerfen; die Einfuhr aus den Niederlanden wurde, von einigen Agrarerzeugnissen abgesehen, sogar noch großzügiger - und vor allem zunächst erst einmal einseitig - liberalisiert. ${ }^{232}$ Aber nicht der bilaterale, sondern der multilaterale Abbau von Handelsbarrieren war das eigentliche Anliegen der ECA und, gemessen an ihren Beschlüssen und Verlautbarungen, der OEEC. Es erscheint angesichts der späteren Selbststilisierung als Wegbereiter des Freihandels doch bemerkenswert, daß sich Erhard, Pünder und die anderen „Handelspolitiker“ so passiv verhielten, obgleich sie sich vergleichsweise „gefahrlos“ als Pioniere der Handelsliberalisierung hätten profilieren können: Wegen der anfangs fehlenden politischen Kompetenz mußten und konnten sie ihren Worten gar keine Taten folgen lassen.

In Kreisen der ECA und des State Departments war man jedenfalls zutiefst beunruhigt, daß ausgerechnet die Politiker und Behördenvertreter des Landes, dem die Planer in Washington eine Schlüsselrolle bei der Rückkehr zum freien Welthandel zugedacht hatten, hinter den Erwartungen zurückbleiben und damit das gesamte Projekt gefährden könnten. Zusätzlich alarmiert durch die wachsende Kritik einiger OEEC-Länder insbesondere an der bizonalen Handelspolitik, bemühte sich vor allem die ECA im Sommer 1949 um eine Kurskorrektur, solange dies dank der Kompetenzen der Militärregierung noch vergleichsweise problemlos möglich schien. Allerdings mußten dafür erst einmal Clay und sein Stab gewonnen werden, hatten sie doch die bisherige Politik durch die Joint Export Import Agency und auf anderen Ebenen maßgeblich bestimmt, wie die ECA-Angehörigen fairerweise einräumten. Im wesentlichen waren es zwei „Anklagepunkte“, mit denen sich die alliierten und deutschen Instanzen der Bizone konfrontiert sahen: „In the first place, it is contended that German trade policy is unduly restrictive and that it hampers the effort to restore and strengthen intra-european trade. Secondly, it is argued that the drawing rights extended by the Bizone to other participants have been grossly inadequate. "233 Die ECA-Mitarbeiter teilten diese Kritik. Das bei den Wirtschaftsexperten der amerikanischen Militärregierung und ihren deutschen Kollegen aus den bizonalen Wirtschafts- und ERP-Bürokratien gleichermaßen beliebte Argument, Westdeutschland sei zu schwach für eine andere Politik, ließen sie nicht länger gelten. Insbesondere die Unterscheidung zwischen „essentials“ und „non-essentials“ und die

\footnotetext{
${ }^{230}$ Ansprache Ludwig Erhards, abgedruckt in: Außenhandel 1 (1948), Heft 1, S. 4-7.

${ }^{231}$ Bericht über Council-Sitzungen v. 11. 7. 1949, BA, Z 14, 48.

232 Vgl. Buchheim, Wiedereingliederung, S. $119 \mathrm{f}$.

233 Vgl. z. B. Bissell an Hoffman v. 3. 8. 1949, NA, RG 469, ECA, Assistant Administrator for Programs, Subject Files, 1948-50, Box 18.
} 
Weigerung, die Einfuhr von Gütern der zweiten Kategorie aus den Exporterlösen zu finanzieren, hielten sie mittlerweile für überholt. Westdeutschland war ihrer Meinung nach in besonderem Maße verpflichtet, den größtmöglichen Beitrag zum Wiederaufbau in Europa zu leisten: „It would not be unfair to add that Germany should be especially aware of this responsibility, not merely because of the events of the past, but because of the importance of Germany's full acceptance on an equal basis into the European community of nations." Großzügigere Ziehungsrechte waren aus Sicht der ECA also keineswegs ein "Geschenk“ Westdeutschlands an die OEEC-Partner, sondern allenfalls "a partial repayment to the common fund of the resources made available by American aid. “234

Aber nicht nur Landsleute wie Lawrence Wilkinson, den Wirtschaftsexperten der Militärregierung, oder John McCloy, den designierten Hohen Kommissar und ECA-Repräsentanten in Westdeutschland, versuchten die ECA-Beamten davon zu überzeugen, daß ein Kurswechsel notwendig sei; auch den deutschen Verantwortlichen redeten sie ins Gewissen. So ließ Hector Prud'homme, Missionschef in der französischen Zone, Karl Albrecht im August 1949 vertraulich wissen, man erwarte, daß sich Westdeutschland bei den im Herbst anstehenden OEEC-Verhandlungen über den Abbau der Importbeschränkungen im innereuropäischen Handel zum „Vorkämpfer einer wahrhaft europäischen Wirtschaft" machen werde. Da die bizonalen Stellen in ihren einschlägigen Erklärungen und Memoranden von dieser Linie noch weit entfernt waren, befürchtete man bei der ECA, sie könnten sich auch künftig „mit kleinlichen Vorschlägen“ begnügen. 235

Offensichtlich blieben solche Ermahnungen und Appelle nicht folgenlos. Am Ende seiner bereits erwähnten Rede auf einer Tagung der wirtschaftswissenschaftlichen Forschungsinstitute Anfang September 1949 rief Günter Keiser, nachdem er zuvor die deutsche Passivität mit den gewohnten Argumenten zu rechtfertigen versucht hatte, doch zu dem erwarteten mutigen Schritt auf. Die Deutschen könnten, so beschwor er seine Zuhörer, „nur dadurch ernst genommen werden und etwas erreichen“, wenn sie "mit ganz klaren und entschlossenen Taten“ vorangingen und, "unter Umständen mit ganz großem Risiko“, die „Türen“ aufmachten: „Nur wenn der Damm bricht, dringt die Flut durch, und ich glaube, wir sind die einzigen, die den Damm einreißen könnten!" ${ }^{236}$ Offizielle Verlautbarungen fielen jedoch nach wie vor bedeutend vorsichtiger aus. In einer Erklärung vom 6. September zur Liberalisierung der "unsichtbaren Einfuhren“ - dazu zählten beispielsweise der Reiseverkehr, Transportkosten, Gebühren für Patente, Urheberrechte und Warenzeichen sowie Provisionen für Auslandsvertreter - plädierte der Marshallplan-Berater zwar dafür, „einseitig oder im Wege von vertraglichen Bindungen einschränkende Maßnahmen aufzugeben“; 237 ein Beamter vom ERP-Sekretariat des Zweimächtebüros empfand diese Erklärung jedoch eher als eine „Beschwerdeschrift über die Maßnahmen der Alliierten“ denn als ein Zeugnis deutscher Bereitschaft zum Abbau der Handelsbarrieren. ${ }^{238}$ Von einer Schrittmacherrolle der Deutschen war also in

\footnotetext{
${ }^{234}$ Staff Memorandum: German Foreign Trade Policy, o. D. (Begleitschreiben v. 28. 7. 1949), ebenda. 235 Vermerk Martini v. 08. 1949, BA, Z 14, 5.

${ }^{236}$ Günter Keiser, Das Long-Term-Programm und die amerikanische Politik, IW/WAA, Baade-NL, III, ERP.

${ }^{237}$ Martini an Bizonale Delegation v. 6. 9. 1949, BA, Z 14, 165 b.

238 Vermerk Rieck v. 21. 9. 1949, ebenda.
} 
den ersten anderthalb Jahren ihrer OEEC-Zugehörigkeit nichts zu merken, im Gegenteil: Sie blieben, ebenso wie ihre alliierten Vertreter in Paris, mit ihren Ansichten und Angeboten zur Liberalisierung hinter Ländern wie Belgien, Frankreich oder Großbritannien eher zurück. Ähnlich abwartend agierten die westdeutschen Wirtschaftspolitiker und -fachleute auch in der Frage der Multilateralisierung des Zahlungsverkehrs.

Als Folge der bis in die dreißiger Jahre zurückreichenden wirtschaftlichen Verzerrungen in Westeuropa waren überall, von der Schweiz und Portugal abgesehen, "weiche“, nicht oder höchstens sehr begrenzt konvertible Währungen entstanden. Die einzelnen Länder versuchten, dieses Problem durch strenge Devisenbewirtschaftung und zweiseitige Zahlungsabkommen zu entschärfen. Während die Hartwährungsländer auf diese Weise diskriminiert werden konnten - und auch sollten -, erlaubte der Bilateralismus die Fortsetzung des Handels zwischen den Weichwährungsländern. Nicht verhindern konnte dieses System jedoch, daß aus den einzelnen Ländern rasch entweder chronische Schuldner oder chronische Gläubiger wurden. ${ }^{239}$ Einen ersten Versuch, den westeuropäischen Zahlungsverkehr aus den Fesseln des Bilateralismus zu befreien, hatte Belgien, unterstützt von den Niederlanden und Luxemburg, bereits im Sommer 1947 unternommen. Der Grundgedanke dieses Vorschlages, den erforderlichen multilateralen Mechanismus mit dem Marshallplan zu kombinieren, konnte im ersten multilateralen Verrechnungsabkommen zwischen den Beneluxländern, Frankreich und Italien vom 18. November 1947 - die Bizone schloß sich wenig später an - allerdings noch nicht verwirklicht werden; mehr noch, die amerikanische Regierung lehnte es zunächst ausdrücklich ab, ERP-Mittel für Clearingzwecke freizugeben. ${ }^{240}$ Das Volumen der Transaktionen blieb denn auch sehr gering, das technische Verfahren erwies sich aber offensichtlich als brauchbar. Die Unterscheidung zwischen - automatischen - Verrechnungen „erster Kategorie" und solchen „Zweiter Kategorie“, welche der Zustimmung der betroffenen Länder bedurften, wurde im intereuropäischen Zahlungs- und Verrechnungsabkommen vom 16. Oktober 1948 nämlich beibehalten. Obgleich alle OEEC-Länder dieses Abkommen unterzeichneten, kam der erste Verrechnungsmodus nur für solche Länder in Betracht, die zugleich Gläubiger und Schuldner waren: Es mußte ein geschlossener Kreis von Kredit- und Debetbeziehungen bestehen, damit die jeweiligen Schuldsalden um den kleinsten Saldo zwischen zwei Teilnehmern am Verrechnungskreis gekürzt werden konnten. Der wichtigste Fortschritt gegenüber dem Abkommen von 1947 bestand in der nun doch realisierten Koppelung mit der Marshallhilfe. Die Gläubigerländer unter den OEEC-Mitgliedern verpflichteten sich, den jeweiligen Schuldnerländern in Höhe des Aktivsaldos "Ziehungsrechte" auf die eigene Währung einzuräumen. Entsprechend der Höhe dieser Ziehungsrechte wandelte die ECA die ERP-Mittel in „bedingte“ Hilfe für die Gläubigerländer um, die aber nur in dem Umfang gewährt werden sollte, in dem die Ziehungsrechte tatsächlich in Anspruch genommen wurden. Dieses System, von Zeitgenossen auch „kleiner Marshallplan“ genannt, ermöglichte es den Schuldnerländern somit, durch Einfuhrüberschüsse entstandene Zahlungsbilanzdefizite auszugleichen, und

\footnotetext{
239 Vgl. dazu Hans Möller, Das intereuropäische Zahlungs- und Verrechnungsabkommen vom 16. Oktober 1948, in: Europa-Archiv 4 (1949), S. 1781-1794; Wexler, Marshall Plan, S. 121-124; Buchheim, Wiedereingliederung, S. 111-117.

240 Wexler, Marshall Plan, S. 127.
} 
wirkte sich insgesamt positiv auf den innereuropäischen Handelsverkehr aus. ${ }^{241}$ Allerdings tendierte es dazu, den Güteraustausch in "weniger produktive Richtungen“ zu lenken, wie beispielsweise von deutscher und britischer Seite moniert wurde, da für die Einfuhrentscheidung nicht länger Preis- und Dringlichkeitsgesichtspunkte allein ausschlaggebend waren, sondern auch der „Zwang", die Margen tatsächlich auszunutzen.242 Weil die Gewährung von Ziehungsrechten weniger Nettohilfe und Gegenwertmittel bedeutete, waren die Überschußländer verständlicherweise bemüht, die Ausfuhr zu reduzieren und den Import zu erhöhen. Wegen dieser Implikationen empfanden die Verantwortlichen in der Bizone, die zu der Gruppe der "Nettogläubiger“ zählte, nicht nur Genugtuung über die Exportkraft der westdeutschen Wirtschaft. Hans Möller, damals Abteilungsleiter bei der Bank deutscher Länder und 1950 einer der "Chefökonomen“ der deutschen OEEC-Vertretung, wertete das Zahlungsabkommen zwar als einen "großen Fortschritt“, zumal die Schuldnerländer ihre Debetsalden nun mit Hilfe der Ziehungsrechte ausgleichen konnten und der handelshemmende Effekt der offiziell weiter gültigen Dollarklausel damit vermindert wurde. Allerdings bedauerte er zugleich, daß die Bizone für den Ausfuhrüberschuß in Höhe von $10 \mathrm{Mio}$. Dollar gegenüber den westeuropäischen Ländern insgesamt "keine Gegenleistung" erhalte. ${ }^{243}$ Auch im ERP-Ausschuß des bizonalen Verwaltungsrats gingen die Ansichten auseinander: Während manche die "drawing rights" als ein "Instrument zur Wiedereroberung des europäischen Marktes“ begriffen und deshalb in hohen Überschüssen gegenüber Westeuropa keinen Nachteil zu erblicken vermochten, dämpfte Günter Keiser allzu optimistische Erwartungen mit dem Hinweis, daß sich die Zahlungsbilanzprobleme gegenüber dem Dollarraum dadurch kaum verringerten. Überdies resultierten die Überschüsse hauptsächlich aus Kohlenexporten. ${ }^{244}$ Für die Bundesrepublik kam es aber in erster Linie darauf an, die früheren Fertigwarenmärkte zurückzuerobern.

Die anfangs eher verhaltene Kritik am „kleinen Marshallplan“ wuchs jedoch rasch, als die Bizone im zweiten ERP-Jahr erneut als Überschußland eingestuft wurde und damit mehr Ziehungsrechte gewähren mußte, als sie von den Partnern eingeräumt bekam. Wie im Zusammenhang mit der Revision des Programms 1949/50 bereits erwähnt, lagen die Erwartungen der OEEC deutlich höher als die Offerten von deutscher Seite. Während die Bizone zunächst „drawing rights“ in Höhe von 98 Mio. Dollar angeboten und nach zähen Verhandlungen immerhin ein Volumen von 140 Mio. akzeptiert hatte, forderten die Pariser Stellen 240 Mio. Dollar. Da Militärregierung und ECA ebenfalls zu erkennen gaben, daß sie die bizonalen Angebote für unzureichend hielten, rechneten Keiser und seine Mitarbeiter mit massivem Druck auf die Pariser Delegation. ${ }^{245}$ Ihre Lage wurde dadurch noch erschwert, daß die Bizone die ihr für das Jahr 1948/49 zustehenden Ziehungsrechte nur zu einem geringen Prozentsatz - im Juni 1949 waren es gerade 20 Prozent - ausgenutzt hatte. Auch wenn die deutschen Experten versuchten, diese Tatsache als "temporäre Erscheinung“ hinzustellen, litt darunter ihre Glaubwürdigkeit: Der im-

${ }^{2+1}$ Vgl. Abelshauser, Marshallplan, bes. S. $215 \mathrm{f}$. Zum Verrechnungsmechanismus vgl. Möller, Zahlungsund Verrechnungsabkommen, bes. S. 1787-1790.

${ }^{242} \mathrm{Vgl}$. Möller, Zahlungs- und Verrechnungsabkommen, S. $1791 \mathrm{f}$.

243 Ebenda, S. 1793.

${ }^{244}$ Niederschrift Sitzung ERP-Ausschuß v. 20.4. 1949, BA, Z 14, 9.

${ }^{245}$ Protokoll Sitzung ERP-Ausschuß v. 24. 8. 1949, ebenda. 
mer wieder beschworene „Notstand“ schien doch nicht so drückend zu sein, wenn die Deutschen die vorhandenen Möglichkeiten nicht einmal voll ausschöpften.246

Obwohl sich die Bizone schließlich lediglich verpflichten mußte, Ziehungsrechte in Höhe von 163 Mio. Dollar einzuräumen - von diesem Betrag wurden am Ende nur etwa 50 Mio. Dollar auch tatsächlich in Anspruch genommen -, dominierten auf deutscher Seite nun die kritischen Stimmen. Die unmittelbaren Nachteile, welche der „kleine Marshallplan" der Bizone bescherte, wogen aus der Sicht der Behörden und wirtschaftlicher Kreise offenbar schwerer als die erhofften langfristigen Vorteile: „Die Planung der Ziehungsrechte“, so konstatierte der ERP-Experte des Länderrats, „stimmte also nicht mit der tatsächlichen Entwicklung der Nachfrage überein. “247 Auch Günter Keiser rügte, daß der amerikanische „Dollar- und Drawing Right-Segen mehr oder weniger schematisch" entsprechend den momentanen Zahlungsbilanzdefiziten verteilt werde und somit „in gewissem Sinn ungesunde Ungleichgewichtigkeiten“ konserviere und „die wirtschaftspolitische Untüchtigkeit" prämiere.248 Allerdings ging keiner der Kritiker so weit, den Mechanismus grundsätzlich abzulehnen. Ihnen kam es vielmehr darauf an, durch eine Modifikation der Zuteilungskriterien zu erreichen, daß die Marshallhilfe für Westdeutschland nicht noch weiter gekürzt wurde. Diese Sorge war auch einer der Gründe für die eher verhaltene Aufnahme des amerikanischen Vorschlags vom Frühjahr 1949, die Ziehungsrechte transferierbar und in Dollar konvertierbar zu machen - eine Maßnahme, die einen wirklich entscheidenden Schritt zur Multilateralisierung des Zahlungsverkehrs bedeutet hätte. Freilich hätte eine solche Regelung wahrscheinlich einen Rückgang des innereuropäischen Warenaustauschs und eine Verlagerung des Handels in den Dollarraum mit seinen attraktiven Angeboten zur Folge gehabt - eine Perspektive, die zumindest den Defizitländern kaum willkommen sein konnte. Aber auch in den Überschußländern gab es Kreise, die den außereuropäischen Wettbewerb zum damaligen Zeitpunkt scheuten und um die Gold- und Dollarreserven bangten. Da die Amerikaner überdies ankündigten, mit dem Prinzip, „bedingte“ Hilfe nur in Höhe der tatsächlich ausgenutzten Ziehungsrechte zu gewähren, nunmehr Ernst machen zu wollen, fürchteten die Gläubigerländer zudem weitere Einbußen bei der Dollarhilfe. Zwar führte Großbritannien den Widerstand gegen die amerikanischen Pläne an, aber zweifelsohne waren die Verantwortlichen in Westdeutschland nicht weniger erleichtert, als die ECA den Gedanken der Konvertibilität ganz fallen ließ und sich damit zufrieden gab, daß 25 Prozent der insgesamt gewählten Ziehungsrechte übertragbar blieben. ${ }^{249}$

Auch auf diesem zweiten zentralen Schauplatz der Auseinandersetzung um die künftige Organisation der internationalen Wirtschafts- und Handelsbeziehungen waren die westdeutschen Wirtschaftspolitiker somit weit davon entfernt, eine Vorreiterrolle zu spielen. Ihre ersten Vorschläge und Aktivitäten ließen jenen Wagemut, dessen sie sich

\footnotetext{
${ }^{246}$ Protokoll Sitzung ERP-Ausschuß v.9. 6. 1949, ebenda. Vgl. auch Bernhard Wegmann, Die Grundlinien des gesamten Marshallplan-Systems, Ausarbeitung v. 3. 9. 1949, PA, 2/603. Als Grund für die geringe Ausnutzung der Ziehungsrechte führte er an, „daß unsere Importeure, die schließlich die Lieferungen des Auslandes in DM zu bezahlen haben, dort vielfach nicht die geeigneten preiswerten Waren fanden, die in der Doppelzone absetzbar" seien.

247 Wegmann, Grundlinien, S. 5 (wie Anm. 246).

${ }^{248}$ Günter Keiser, Konstruktionsmängel des Marshallplans, Artikel für die „Wirtschaftszeitung“ v. 5. 11. 1949, IWW/WA, Baade-NL, III ERP.

${ }^{249}$ Bernhard Wegmann, Ansätze zur Revision des Kleinen Marshallplans, Ausarbeitung v. 6. 9. 1949, PA, 2/603. Vgl. auch Wexler, Marshall Plan, bes. S. 142-148.
} 
später gerne rühmten, gänzlich vermissen. Ängstlich darauf bedacht, gegenüber den anderen OEEC-Ländern nicht ins Hintertreffen zu geraten, konzentrierten sich Erhard, Pünder, Schniewind und ihre Mitarbeiter auf eine an kurzfristigen Zielen orientierte Interessenpolitik. Die vertrauten Instrumente und Praktiken schienen am besten geeignet, diese Ziele zu erreichen. Um diese defensive Einstellung allmählich und punktuell aufzugeben, bedurfte es schon massiver amerikanischer Appelle. Hilfreich war sicherlich auch, daß sich die Exportindustrie zum entschiedenen Anwalt einer liberalen, multilateral organisierten Außenhandelspolitik machte und manchen zögernden Ministerialbeamten davon zu überzeugen vermochte, daß der langfristige, standortpolitische Nutzen einer Überschußposition die kurzfristigen Nachteile des einseitigen Ressourcentransfers in die europäischen Defizitländer bei weitem aufwog. ${ }^{250}$ Der Übergang zu einer aktiveren, offensiveren Liberalisierungspolitik war damit bereits vorgezeichnet. Allerdings legten die deutschen Verantwortlichen nun erst recht besonderen Wert darauf, Richtung und Tempo nicht von außen, von der OEEC, vorgeschrieben zu bekommen, sondern nach Möglichkeit selbst zu bestimmen.

\section{c) Versuche zur "Politisierung “ der OEEC}

Schon aus diesem Grund war man auf deutscher Seite an einer Stärkung der Pariser Organisation nicht interessiert; überdies waren die Westzonen in den maßgeblichen Gremien, deren Kompetenzen im Zuge einer solchen Reform vermutlich erweitert worden wären - Exekutivausschuß und Generalsekretariat - gar nicht vertreten. Und selbst für den Fall, daß dieser Nachteil durch die Aufnahme deutscher Repräsentanten bald hätte ausgeglichen werden können, war es doch mehr als fraglich, ob eine stärker politische Ausrichtung der OEEC für die in dieser Hinsicht „ohnmächtigen “ Westdeutschen überhaupt von Vorteil gewesen wäre. Aber auch die meisten anderen Mitgliedsländer waren, wenngleich aus anderen Motiven, dagegen, die OEEC mit mehr Macht auszustatten. Genau diese Absicht verfolgte jedoch die ECA schon seit dem Sommer 1948, nachdem Hoffman und Harriman Gelegenheit gehabt hatten, erste Eindrücke von der Arbeitsweise und dem tatsächlichen Einfluß der Organisation auf die Politik der Nationalstaaten zu sammeln. 251

Diese Eindrücke waren aus amerikanischer Sicht wenig ermutigend. Großbritannien agierte von Anfang an in einer Weise, die den Plänen der ECA klar zuwiderlief, und ob die als aufgeschlossen eingeschätzten Regierungen in Paris, Brüssel und Rom im „Ernstfall" wirklich im Sinne der amerikanischen Vorstellungen handeln würden, darüber war sich Harriman keineswegs sicher. Um hier Abhilfe zu schaffen, sollte der Hebel bei der OEEC selber angesetzt werden: „I have now come to the conviction that the OEEC must be led by a man of international political position as a type of director general, to be responsible for initiation of cooperative measures, presentation of controversial problems to Council... and for the implementation of policy decisions taken ", schrieb der US-Sonderbeauftragte Ende Juli 1948 an Außenminister Marshall. ${ }^{252}$ Mit dem belgischen Ministerpräsidenten und Außenminister Paul-Henri Spaak, damals Vorsitzender

250 Vgl. Abelshauser, Marshallplan, S. 224

251 Vgl. Milward, Reconstruction, S. 182-185.

252 Harriman an Marshall v. 31. 7. 1948, FRUS 1948, III, S. 472-473, hier S. 473. 
des Rats der OEEC, glaubten Harriman und sein Chef auch schon die geeignete Persönlichkeit gefunden zu haben. Gegen den Belgier und die ihm zugedachte Aufgabe regte sich erwartungsgemäß insbesondere britische Opposition, die trotz heftiger amerikanischer Pressionen nicht nachließ. Zwar machte Spaak innenpolitische Gründe verantwortlich, als er im Oktober 1948 sein Desinteresse andeutete; der hartnäckige Widerstand aus London dürfte aber mindestens ebenso wichtig gewesen sein. Dennoch gaben die Amerikaner die Suche nach einem Politiker vom Kaliber Spaaks keineswegs auf; Spaak blieb sogar ihr Wunschkandidat. ${ }^{253}$

Daneben hielten sie aber noch nach anderen Wegen Ausschau, die Arbeit der OEEC in ihrem Sinne zu lenken. So zogen amerikanische Diplomaten beispielsweise die Möglichkeit in Betracht, über die einzelnen Mitgliedsländer, also gewissermaßen „von unten“, den Kurs der Pariser Organisation zu beeinflussen. Die drei wichtigsten Länder schieden nach Ansicht Wayne G. Jacksons von der Europaabteilung des State Departments allerdings vorerst aus: Großbritannien schien sich nicht zwischen Kontinent und Commonwealth entscheiden zu können. Frankreichs Fähigkeit, eine Führungsrolle zu übernehmen, zog er in Zweifel, weil sich das Land in einem Zustand offensichtlicher Demoralisation befinde. Und auch der dritte Kandidat kam nicht in Frage: „In spite of the important position which Germany has had and will again have in Europe, there are obvious reasons why the germans themselves can do nothing now. “ Daß die Besatzungsbehörden hier einsprangen, hielt Jackson für unwahrscheinlich: Zum einen blickten sie kaum über den westdeutschen „Tellerrand“ hinaus, zum anderen konnte man solche Schrittmacherdienste von ihnen realistischerweise wohl gar nicht erwarten. Als „Komplizen“ blieben also nur kleinere Länder wie Belgien oder Italien übrig - und die vage Hoffnung, Großbritannien doch noch für die amerikanischen Pläne zu gewinnen. Auf jeden Fall wollten ECA und State Department rasch diesen aus ihrer Sicht unbefriedigenden Zustand überwinden, „where we are very much on the sidelines and are not even coaching the players." 254

Die Bemühungen der ECA um eine „Politisierung“ der OEEC begannen im Frühjahr 1949 Früchte zu tragen. Mit der Bildung einer „Groupe Consultatif“ war im Februar immerhin ein erster Schritt in Richtung der erwünschten politischen „Härtung“ der Organisation getan, denn dieses Gremium, das sich regelmäßig versammeln sollte, um den Kurs der Organisation festzulegen, setzte sich aus den Ministern der sieben im Exekutivkomitee vertretenen Länder, dem irischen Außenminister, der bereits einen Vorschlag zur Verbesserung der Arbeit der OEEC präsentiert hatte, und dem Ratsvorsitzenden Spaak zusammen. ${ }^{255}$ Dieser Erfolg stellte Hoffman und Harriman jedoch keineswegs zufrieden, sondern spornte sie im Gegenteil dazu an, die widerstrebenden Europäer doch noch von der Notwendigkeit eines „politischen Direktors“ zu überzeugen.

Bis zu diesem Zeitpunkt hatten die amerikanischen Bestrebungen auf deutscher Seite keine erkennbaren Reaktionen provoziert. Weder in den wöchentlichen Berichten von

${ }^{253}$ US-Botschafter in Belgien an Marshall v. 11. 10. 1948 u. Acting Secretary of State an Botschaft in Belgien v. 13. 10. 1948, beide ebenda, S. 490-492; Vermerk über Gespräch Alphand-Harriman v. 8. 1. 1949, HAEC, MAEF/DECE, 341.

254 Jackson an Hickerson v. 18. 10. 1948, NA, RG 59, Lot files 55 D 105, Files of Miriam Camp, Box 2.

255 Vgl. Vermerk Schniewind v. 2. 3. 1949, BA, Z 14, 106, Bl. 184; Telegramm des französischen Außenministers v. 7. 2. 1949, HAEC, MAEF/DECE, Serie 04, 341, Bl. 110-114; McBride an Osterog, Februar 1949, ebenda, Bl. 128-132; Milward, Reconstruction, S. 192. 
Mangoldts oder anderer deutscher Delegationsangehöriger noch in einschlägigen Stellungnahmen und Vermerken Pünders und Schniewinds fanden sich Hinweise auf entsprechende Diskussionen oder gar auf Versuche, in dieser Frage eigene Standpunkte zu formulieren. Verständlicherweise hatten die deutschen ERP-Spezialisten zunächst dringendere Probleme zu lösen, als sich über eine Stärkung der OEEC Gedanken zu machen, auf die sie damals ohnehin keinen Einfluß ausüben konnten. Erst als sich die Chance abzeichnete, daß Westdeutschland Mitglied des Exekutivausschusses werden konnte, schwand die Gleichgültigkeit.

Anfang März 1949 berichtete von Mangoldt von der für den 1. April geplanten Neuwahl für dieses wichtige Gremium und erwähnte dabei inoffizielle Überlegungen in OEEC-Kreisen, daß „Deutschland“ dort vertreten sein müsse. Ob man sich in Frankfurt und Baden-Baden schon so früh berechtigte Hoffnungen machen konnte, ließ er allerdings offen. Auf jeden Fall empfahl er, dieser Angelegenheit besondere Aufmerksamkeit zu schenken und die Frage einer möglichen Mitgliedschaft „bei sich bietender günstiger Gelegenheit in lockerer Form auch mit der Militärregierung " zu besprechen, zumal ein solcher Sitz anfangs „selbstverständlich“ von alliierten Vertretern eingenommen werden würde. Angesichts dieser Perspektiven wuchs das Interesse an den Politisierungsversuchen der ECA und den Implikationen für die Westzonen merklich. Der deutsche "Chefdelegierte“ wertete diese Bemühungen, insbesondere die frisch aus der Taufe gehobene "Groupe Consultatif“, als einen Versuch, der OEEC einen neuen, über den Marshallplan weit hinausweisenden Impuls zu geben. Eine Prognose zu den Erfolgsaussichten dieses Versuchs wagte er nicht, zumal er weitere Anhaltspunkte für eine Politisierung der OEEC nicht zu entdecken vermochte. Zweifellos konnten die Deutschen unter den damaligen Bedingungen nur davon profitieren, wenn die anstehenden Aufgaben vorrangig unter wirtschaftlichen Gesichtspunkten beurteilt und ohnehin nicht auszuschließende politische Überlegungen tunlichst auf ein Minimum beschränkt wurden. ${ }^{256}$ Insofern war es nur konsequent, wenn von Mangoldt in einem weiteren Bericht den exklusiven Charakter der Beratungen der Konsultativgruppe beanstandete. ${ }^{257}$ Vorsorglich regte er an, für die Ende Juni 1949 auf Ministerebene stattfindende Council-Sitzung, an der für die Bizone Sir Cecil Weir und Lawrence Wilkinson teilnehmen sollten, „jemand Maßgebliches (sic!) des gleichen Niveaus von deutscher Seite zur Mitteilnahme zur Verfügung" zu halten.258

Von der Position, die wirtschaftspolitische Aufgabenstellung der OEEC beizubehalten, aber zugleich für „politische“ Eventualitäten die nötigen organisatorisch-personellen Vorkehrungen zu treffen, gingen die deutschen Verantwortlichen zunächst nicht ab. Die Initiative des irischen Außenministers McBride zur politischen Aktivierung der Pariser Organisation vom Sommer 1949, um nur ein Beispiel zu nennen, wurde kommentarlos zur Kenntnis genommen. ${ }^{259}$ Dies war um so leichter möglich, als die OEEC mit der Liberalisierung des Handels und der Multilateralisierung des Zahlungsverkehrs neue

256 Vermerk Schniewind v. 2. 3. 1949, BA, Z 14, 106, B1. 184

${ }^{257}$ Bizonale Delegation, Wochenbericht v. 7.-12. 3. 1949, BA, Z 14, 47. Allerdings bestand für Nicht-Mitglieder des Exekutivkomitees, vorbehaltlich der Zustimmung dieses Gremiums, die Möglichkeit, zu Sitzungen, in denen "matters directly affecting their interests“ behandelt wurden, „Beobachter“ zu entsenden; CE/M (49) 29 v. 12. 7. 1949, HAEC, OEEC, 117.

${ }^{258}$ v. Mangoldt an Martini v. 9.6. 1949, BA, Z 14, 48.

259 v. Mangoldt an Martini v. 30.7. 1949, ebenda. 
Ziele formulierte, mit denen sich die deutschen "Wirtschaftspolitiker" wesentlich leichter identifizieren konnten. Die Skepsis gegenüber einer Politisierung der OEEC nahm denn auch keineswegs ab. In seiner bereits erwähnten Zwischenbilanz vom Oktober 1949 hielt von Mangoldt ausdrücklich daran fest, daß die Lösung der europäischen Probleme auf wirtschaftlichem Gebiet und mit wirtschaftlichen Mitteln eher möglich sei als durch eine übergeordnete politische Instanz. ${ }^{260}$ Und gewiß war dies nicht nur die Privatmeinung eines Mannes aus der Wirtschaft, von dem zu erwarten war, daß er schon aufgrund seiner Herkunft stärker in wirtschaftlichen Kategorien dachte. Vielmehr hatte sich offensichtlich auf deutscher Seite die Erkenntnis durchgesetzt, daß den eigenen Interessen zumindest vorläufig mit einer "Ökonomisierung" der OEEC mehr gedient war als mit ihrer „Politisierung“. Ob die Deutschen damit lediglich aus der Not eine Tugend machten oder ob diese Konzeption auch auf längere Sicht als das bessere Rezept galt, mußte sich spätestens dann zeigen, wenn der deutsche Einfluß in der OEEC durch die direkte Mitgliedschaft auch politisch größer wurde.

\section{d) Rekrutierung deutscher Mitarbeiter für den OEEC-Apparat}

Obgleich die OEEC als eine "nicht-nationale" Institution konzipiert worden war und ehemalige Akteure rückblickend das „entnationalisierte“, europäische Selbstverständnis der Pariser „Equipe“, den Vorrang europäischer vor nationalen Loyalitäten hervorhoben, dürften zumindest einzelne Regierungen mit dem Anspruch auf bestimmte Positionen auch die Hoffnung verbunden haben, die Politik der Organisation beeinflussen zu können. ${ }^{261}$ Ein solches Kalkül war den deutschen Marshallplan-Experten ebenfalls nicht fremd. Allerdings war ihnen klar, daß es einige Zeit dauern würde, bis sie in der Lage sein würden, bedeutendere Posten zu besetzen.

Erste Überlegungen hatte der Direktor des Statistischen Amtes der Bizone, Gerhard Fürst, bereits im August 1948 zu Papier gebracht. Die Notwendigkeit, einen Deutschen im internationalen Sekretariat zu plazieren, begründete Fürst mit der Rolle dieses Gremiums bei der Aufstellung eines europäischen Wirtschaftsprogramms: Selbst wenn das Sekretariat nur die Aufgabe hatte, die verschiedenen nationalen Pläne zu einem integrierten Gesamtplan „zusammenzubauen“ - wie es dann ja ansatzweise auch geschah -, konnte es wichtige Akzente setzen. Ein gewisser Einfluß auf das OEEC-Sekretariat war für die Vertretung deutscher Interessen also wichtig. Für diese Aufgabe gab Fürst einem Volkswirt und Statistiker den Vorzug vor einem Wirtschaftspolitiker. Freilich war er sich bewußt, daß die Deutschen, wie auch schon im Genfer Sekretariat nach der Aufnahme in den Völkerbund Mitte der zwanziger Jahre, keine „Schlüsselstellung mit politischem Einfluß" erhoffen durften, sondern zunächst mit technischen Posten Vorlieb nehmen mußten. Eine der Lehren, die Fürst aus der damaligen, von ihm als fehlerhaft eingestuften deutschen Personalpolitik zog, lautete deshalb, daß sich „auf dem sehr schwierigen

260 Vermerk v. Mangoldt v. 12. 10. 1949, BA, Z 14, 46.

261 Zum Selbstverständnis der Führungsmannschaft heißt es in den Erinnerungen des damaligen Generalsekretärs Marjolin, Travail, S. 194: „Notre dévouement à la cause européenne était sans limites; il venait avant nos loyautés nationales. Ou plutôt, nous étions convaincus que la meilleure fạcon de servir nos pays respectifs était de faire en sorte que la grande entreprise, à laquelle nous étions attachés, réussît, même si quelques intérêts nationaux secondaires devaient être sacrifiés chemin faisant." Vgl. auch van der Beugel, Marshall Aid, bes. S. $146 \mathrm{f}$. 
Nachkriegsterrain... sachlich nicht voll qualifizierte Herren, die, schon weil sie Deutsche sind, an die Wand gedrängt werden sollen, besonders schwer durchsetzen“ könnten. ${ }^{262}$ Dieser Ansicht war auch die Leitung der Bizonalen Delegation, die ausdrücklich dazu aufforderte, "die qualitativen Anforderungen möglichst hoch zu schrauben“. Nur Mitarbeiter von „besonderem Format" könnten sich deshalb innerhalb des Generalsekretariats eine gute Position verschaffen - andernfalls würden sie der Delegation auch keine "wichtigen Stützpunkte" sein können. ${ }^{263}$ Noch entscheidender als die fachliche Qualifikation war jedoch, zumal aus der Sicht der zuständigen Stellen der Militärregierungen und der OEEC, die politische Vergangenheit der Kandidaten.

Dies wurde deutlich, als Ende 1948, offenbar auf Initiative des Leiters der Bizonalen Delegation, in OEEC-Kreisen über die Aufnahme deutscher Mitarbeiter in das internationale Sekretariat diskutiert wurde. Sowohl auf seiten Marjolins und seiner Berater als auch unter den Delegationschefs herrschte Konsens, daß es einer äußerst sorgfältigen politischen Überprüfung möglicher Bewerber bedurfte; insbesondere sollte sichergestellt werden, daß ehemalige Angehörige deutscher Besatzungsbehörden keine Chance erhielten. Vorgesehen waren vorerst allerdings höchstens zwei untergeordnete Positionen bis zum Rang eines Sekretärs mit einem Jahresgrundgehalt zwischen 600000 und 110000 Franc, und zwar lediglich in solchen Abteilungen, die nicht mit praktischen $\mathrm{Pla}$ nungen betraut waren. ${ }^{264}$ Obwohl sich die Personalabteilung der OEEC und die Delegationen der hauptsächlich betroffenen, vormals von Deutschland besetzten Länder mit einem solchen schrittweisen Vorgehen einverstanden erklärten und die vorhandenen $\mathrm{Va}$ kanzen bereits sondiert wurden, kam die Angelegenheit nicht recht voran. Die enormen fachlichen und die politischen Anforderungen ließen, zusammen mit den formalen Kriterien für eine Anstellung bei der OEEC - Hochschulbildung, 25 Jahre Mindest-, 50 Jahre Höchstalter, Beherrschung der französischen und englischen Sprache -, die Zahl aussichtsreicher Bewerber offensichtlich stark zusammenschrumpfen. ${ }^{265}$ Und in Zweifelsfällen entschied die in die Überprüfung der Kandidaten eingeschaltete „Bipartite Vetting Party" eher zu deren Ungunsten. So wurde beispielsweise eine für das Dokumentationszentrum des Sekretariats vorgesehene Assistentin abgelehnt, obwohl der Chefdelegierte der Bizonalen Delegation, der Amerikaner Malcolm White, wegen der großen Schwierigkeiten, geeignete Deutsche für die Arbeit in Paris zu finden, für eine Einstellung votiert hatte. Freilich war auch der Amerikaner sich des Risikos bewußt: „Ill-advised appointments at this stage can do irreparable harm to the introduction of Germans into the work of the OEEC. “266

Schwierigkeiten dieser Art existierten für die anderen Teilnehmerländer nicht, und dennoch war die Zusammensetzung des Sekretariats anfangs, so Robert Marjolin rückblickend, "principalement anglo-français“ und spiegelte damit auch die Kräfteverhält-

262 Gerhard Fürst, Gedanken zur Organisation der deutschen Mitarbeit im ERP, Ausarbeitung v. 5. 8. 1948, BA, Z 14, 106, Bl. 165-169.

263 Vermerk v. Mangoldt v. 28. 12. 1948, BA, Z 14, 107.

${ }^{26,}$ UK-Delegation an Foreign Office v. 24. 11., Handley-Derry an White v. 27. 11. und Foreign Office an UK-Delegation v. 8. 12. 1948, alle IfZA, MF 260, 11/100-2/2.

265 Der erste Leiter der Bizonalen Delegation, der Amerikaner Robert Trier, hatte die Parole ausgegeben, bei der Auswahl „allerstrengste Maßstäbe“ anzulegen: Diese „erste Gelegenheit, in das Licht der internationalen Öffentlichkeit“ zu treten, müsse „Deutschland - wenn überhaupt - so benutzen, daß es ein Erfolg“ werde. Wenn das nicht gewährleistet sei, solle „lieber kein Vertreter benannt werden“. Vermerk Martini o. D. (Nov. 1948), BA, Z 14, 4.

266 White an Joint Deputy Chairmen/BICO v. 12. 3. 1949, IfZA, MF 260, 11/100-2/2. 
nisse in der OEEC wider. ${ }^{267}$ Von den Direktoren bzw. Leitern der sechs Abteilungen waren drei Engländer und zwei Franzosen. ${ }^{268}$ Wenn es also schon den übrigen Mitgliedsländern nur schwer möglich war, solche einflußreichen Posten zu besetzen, brauchten sich die deutschen Verantwortlichen erst gar keine Hoffnungen zu machen zumal weder die amerikanisch-britische noch die französische Militärregierung entsprechende Ambitionen unterstützt hätten. Aber um den Kurs der Organisation wenigstens punktuell beeinflussen zu können, beispielsweise durch die Festlegung der Tagesordnung von Ausschußsitzungen, durch Analysen oder zusammenfassende Berichte, waren Positionen auf dieser Ebene erforderlich.

Doch bis dahin war es für die Deutschen noch ein weiter Weg. Im Mai 1949 bat der Generalsekretär um die Nominierung von fünf oder sechs Personen - wiederum nur für Sekretärsstellen. Als zusätzliche Qualifikation verlangte er Kenntnisse und Erfahrungen in Wirtschafts- und Finanzfragen sowie die Fähigkeit, sich problemlos in internationalen Gremien zurechtzufinden. Das Zweimächteamt hatte sogar schon zwei Kandidaten parat und verlangte von den zuständigen bizonalen Stellen weitere Vorschläge; die letzte Entscheidung lag allerdings bei Marjolin. ${ }^{269}$ Zwei Monate später, Mitte Juli, lag die erbetene Bewerberliste jedoch noch immer nicht vor. ${ }^{270}$ Möglicherweise zögerte man auf deutscher Seite aber auch aus Rücksicht auf die in naher Zukunft zu erwartende Konstituierung der Bundesregierung, den dann zuständigen Stellen in personalpolitischen Fragen vorzugreifen. Der „Durchbruch“ bei der Einstellung Deutscher in das OEEC-Sekretariat gelang folglich erst nach dem offiziellen Beitritt der Bundesrepublik.

Eine Strategie der „personellen Infiltration“, dies war jedenfalls deutlich geworden, versprach, wenn überhaupt, keine schnellen Erfolge. Abgesehen von den politischen Hindernissen gab es in Westdeutschland dafür einfach zu wenig Anwärter, die politisch unbelastet waren und gleichzeitig über die nötige Kompetenz, Takt und ausreichende Sprachkenntnisse verfügten. Erst allmählich wurden sich deutsche „Wirtschaftsdiplomaten" wie von Mangoldt der verheerenden Folgen der weitgehenden Isolation Deutschlands in den Jahren nach 1933 bewußt: „The old type of serious and conscientious Ger(man) civil servant with experience of conditions abroad, knowledge of languages and familiarity with international committee work, was now practically non-existent in Germany", so faßte der britische Delegationsleiter Sir Edmund Hall-Patch seinen Eindruck nach einem Gespräch mit dem Deutschen zusammen. Dies war im übrigen auch einer der Gründe dafür, daß bevorzugt in Bank- und Industriekreisen nach geeigneten Kandidaten Ausschau gehalten wurde. ${ }^{271}$ Auf Rekrutierungsprobleme dieser Art stießen Pünder, Schniewind und von Mangoldt aber nicht nur bei der Besetzung von Stellen im Generalsekretariat; noch mehr machte ihnen die dünne Personaldecke im Zuge der Übernahme der alliierten Verantwortlichkeiten zu schaffen.

\footnotetext{
267 Marjolin, Travail, S. 194.

${ }_{268} \mathrm{Vgl}$. Organization of International Secretariat, Aufstellung v. 7. 4. 1949, BA, Z 14, 106.

269 BICO an Vorsitzenden des bizonalen Verwaltungsrates v. 9. 5. 1949, IfZA, MF 260, 11/100-2/2. In dt. Übers. findet sich das Schreiben, allerdings auf den 2. 5. datiert, in BA, Z 13, 11, Bd. 2. Dort als Anhang auch Lebensläufe der beiden Kandidaten.

270 Bespr. mit BICO-Vorsitzenden v. 12. 7. 1949, BA, Z 3, Anh. 2, Bl. 113. Carl Krautwig von der Direktorialkanzlei versprach die Übersendung der Liste für den nächsten Tag. Ob diese Zusage eingehalten wurde, ließ sich nicht ermitteln.

271 Hall-Patch an Harriman v. 24. 11. 1949, PRO, FO 371/76940.
} 


\section{Die Überleitung der Verantwortlichkeiten}

Bereits im Frühjahr 1949 mehrten sich die Anzeichen, daß die Alliierten gewillt waren, die Vertretung deutscher Interessen bei der OEEC Schritt für Schritt in deutsche Hände zu legen. Den Grundsatz, von dem sich die Besatzungsbehörden dabei leiten ließen, brachten Mitarbeiter des Zweimächteamtes mit der Formel „smooth transition“ recht präzise auf den Begriff. Die Initiative ging eindeutig von den Amerikanern aus. Ihre britischen Kollegen zogen zwar mit, achteten aber darauf, daß die Regierungen der kleineren Länder ihre Standpunkte zu Gehör bringen konnten. Nur die französischen Verantwortlichen benötigten etwas mehr Zeit, doch konnten und wollten sie die von den USA in Gang gesetzte Entwicklung ebenfalls nicht blockieren. Auch im Generalsekretariat der OEEC begann man sich schon Gedanken über eine „volle Mitgliedschaft" Westdeutschlands zu machen. ${ }^{272}$ So erhielten die deutschen ERP-Politiker und -Beamten in einem Prozeß, der sich etwa über ein dreiviertel Jahr hinzog, nach und nach all jene Kompetenzen, die erforderlich waren, um die Aufgaben in Paris und gegenüber der ECA wahrnehmen zu können. 1949 wurde damit zum Geburtsjahr der ersten offiziellen westdeutschen Auslandsvertretung nach dem Zweiten Weltkrieg.

Zumindest die deutschen Repräsentanten vor Ort, in Paris, betrachteten diese Entwicklung mit durchaus gemischten Gefühlen. Sie waren sich sehr wohl bewußt, daß ihnen die Durchsetzungsfähigkeit eines Robert Trier - dem ersten Delegationsleiter attestierte ein Mitarbeiter des Foreign Office eine „eiserne Faust“ ${ }^{\text {“273 }}$ - fehlte und vermutlich auch noch einige Zeit fehlen würde. Zwar waren die alliierten Sprecher in der Routinearbeit der OEEC wenig in Erscheinung getreten, aber in "kritischen " Situationen, etwa bei der Verteidigung der Programme oder der Verteilung der ERP-Mittel, war ihr Einsatz stets ausschlaggebend gewesen. Obwohl kaum zu erwarten war, daß die Regierung der Vereinigten Staaten ihre "schützende Hand" nach der deutschen Amtsübernahme abrupt zurückziehen würde, ließ sich nicht genau abschätzen, wie die OEEC auf die neue Lage reagieren und welche Auswirkungen der offizielle Rückzug der Amerikaner auf das "standing" der deutschen Delegation haben würde. Aber auch für die Westmächte bedeutete der Wechsel ein Wagnis, und über manche Implikationen mußten sich die Verantwortlichen selbst erst einmal Klarheit verschaffen.

Dies galt besonders für eine eventuelle Aufnahme der Westzonen in das Exekutivkomitee der OEEC, die angesichts der im Frühjahr 1949 anstehenden Neuwahlen akut wurde. Zwar hatten die Besatzungsmächte im ersten Jahr keinen Sitz in diesem Gremium beansprucht - die Amerikaner, um nicht der internen Einflußnahme auf die Politik der OEEC bezichtigt zu werden, Briten und Franzosen, um den Schwierigkeiten einer Doppelmitgliedschaft in diesem Lenkungsorgan aus dem Weg zu gehen -, doch unter der Perspektive der direkten und gleichberechtigten Mitgliedschaft Westdeutschlands stellte sich diese Frage neu. Gewiß wurde der deutsche Anspruch auf einen Platz im Exekutivkomitee von keiner Seite prinzipiell bestritten. Aufgrund der großen Bedeutung des Landes war beispielsweise für den britischen Militärgouverneur Robertson dieser Sitz eine Selbstverständlichkeit; er plädierte sogar dafür, daß von Anfang an ein

272 BICO an Schniewind v. 19. 7. 1949, IfZA, MF 260, 11/100-2/4-5; Elkin an Marjolin v. 13. 3. 1949, HAEC, OEEC, 402.

${ }^{273}$ Minute Titchener betr. Reputation der Bizonalen Delegation, PRO, FO 371/76937. 
Deutscher die Aufgabe übernehmen sollte. Anders verhielt es sich mit der entsprechend dem Exekutivausschuß zusammengesetzten Konsultativgruppe auf Ministerebene: „Once we allow a German to sit as a member of that Committee I should imagine that allied control, not merely of foreign trade but even of foreign affairs, will evaporate rapidly. “ Deshalb votierte er in diesem Fall für eine Vertretung durch einen der Militärgouverneure. ${ }^{274}$

Der ranghöchste deutsche Delegierte, von Mangoldt, wäre mit einer solchen Konstruktion, ja selbst mit einer alliierten Repräsentation auch im Exekutivkomitee durchaus einverstanden gewesen: „Von unserem deutschen Standpunkt aus wäre es natürlich sehr zu begrüßen, wenn wir in das Executive Committee eintreten würden, solange noch die Militärregierung unsere hiesige Vertretung selbst durchführt", berichtete er an seine Stammbehörde in Frankfurt. Er war überzeugt, daß dadurch die Arbeit des künftigen deutschen Vertreters wesentlich erleichtert werden würde. ${ }^{275}$ Den deutschen ERP-Fachleuten in der französischen Zone waren solche Überlegungen ebenfalls nicht fremd. Karl Albrecht beispielsweise gab grundsätzlich zu bedenken, ob nicht „aus taktischen Gründen die offizielle Vertretung durch die Militärbefehlshaber vorteilhafter" sei. ${ }^{276}$ Ermuntert durch den Eifer der Amerikaner, die ERP-Zuständigkeiten abzugeben, sondierte von Mangoldt zur gleichen Zeit bereits behutsam die Ansichten anderer OEEC-Länder zu einer ausschließlich mit Deutschen besetzten Mission. Ihn interessierte vor allem die Frage, ob eine solche Mission „als politisch oder wirtschaftlich angesehen“ werden würde. Seine Gesprächspartner neigten offenbar mehr der zweiten Auffassung zu; gegen eine rasche Überleitung der Kompetenzen erhoben sie keine Einwände, hielten es aber für denkbar, daß übergangsweise alliierte „liaison-officers“ in der Delegation vertreten sein würden. Der deutsche „Chefdelegierte“ riet gegenüber seinen Vorgesetzten davon ab, die Entwicklung „über Gebühr zu beschleunigen“, weil die internationale Situation für die Deutschen „Zweifellos noch keine leichte“ sei. ${ }^{277}$

Daß aus der deutschen Mitgliedschaft im Exekutivkomitee im Frühjahr 1949 noch nichts wurde, dürfte bei den deutschen Verantwortlichen also nicht nur Enttäuschung, sondern insgeheim wohl auch Erleichterung hervorgerufen haben. Da noch keine deutsche Regierung existierte und bei unterschiedlicher Vertretung im Exekutivausschuß und in der Konsultativgruppe Komplikationen zu befürchten waren, sprach sich das Foreign Office nämlich dafür aus, die Angelegenheit um ein Jahr zu vertagen. Dann, so die Hoffnung der britischen Außenpolitiker, würde die internationale Akzeptanz der neuen Regierung bereits so hoch sein, daß sie ohne Schwierigkeiten in beiden Gremien Mitglied werden könnte. ${ }^{278}$

Unterhalb dieser Ebene gingen die Vorbereitungen für den geplanten Wechsel jedoch weiter. Die deutschen Delegationsmitglieder und die jeweils zu den Sitzungen der OEEC-Ausschüsse anreisenden Experten erhielten im Laufe des Frühjahrs und Sommers 1949 Schritt für Schritt jene Kompetenzen, die bis dahin alliierten Vertretern vorbehalten gewesen waren. So sollten beispielsweise Jahres- und Aktionsprogramme sowie Stellungnahmen zu einzelnen Problemen wie der Handelsliberalisierung künftig

\footnotetext{
${ }^{274}$ Robertson an Kirkpatrick v. 23. 2. 1949, PRO, FO 371/76937.

275 v. Mangoldt an Martini v. 7. 3. 1949, BA, Z 14, 48.

${ }^{276}$ Albrecht an Martini v. 30. 3. 1949, BA, Z 14, 106, Bl. 131.

277 Vermerk Schniewind v. 2. 3. 1949, ebenda, Bl. 184.

278 Foreign Office an Robertson v. 16. 3. 1949, PRO, FO 371/76937.
} 
weitgehend selbständig vorbereitet und in den „Examen" auch ohne fremde Hilfe verteidigt werden. ${ }^{279}$ Obwohl die ersten Gehversuche auf der internationalen Bühne den Erwartungen in London, Paris und Washington nicht immer entsprachen, wurde der Kurs der sukzessiven Überleitung der Verantwortlichkeiten nicht mehr grundsätzlich in Frage gestellt, zumal sich die drei Außenminister Anfang April in Washington gerade für eine gleichberechtigte Mitgliedschaft der künftigen Bundesrepublik in der OEEC ausgesprochen hatten. ${ }^{280}$ Für den Fall, daß die wiederholten Appelle, nur erstklassige Leute nach Paris zu entsenden, unbeachtet blieben, vertraute man in den alliierten Stäben auf die heilsame Wirkung peinlicher Auftritte, die möglicherweise sogar eine Kürzung des ERP-Anteils zur Folge haben konnten.

Immerhin registrierte der Wirtschaftsberater des britischen Militärgouverneurs, Sir Cecil Weir, bei den Deutschen ein wachsendes Verantwortungsbewußtsein. Die frühere Neigung, die ERP-Programme auf die leichte Schulter zu nehmen, wich allmählich dem Bemühen, solide und durchdachte Pläne und Stellungnahmen vorzulegen; öfters als zuvor suchten die zuständigen Beamten nun den Rat ihrer alliierten Kollegen. ${ }^{281}$ Vorwürfe wegen fehlender fachlicher Kompetenz waren denn auch die Ausnahme. Hans Karl von Mangoldt, schon Ende Mai als künftiger Delegationsleiter auserkoren, genoß ein ausgesprochen hohes Ansehen. Der britische Sekretär der Bizonalen Delegation, HandleyDerry, charakterisierte ihn als einen gewissenhaften und hart arbeitenden Mann, der seine politischen Überzeugungen niemandem aufdrängte;282 auch Militärgouverneur Robertson attestierte ihm, er sei „ein guter Mann“ ${ }^{283}$ Kaum schlechter schnitt der als Leiter der volkswirtschaftlichen Abteilung vorgesehene vormalige Oberregierungsrat im bayerischen Wirtschaftsministerium und promovierte Volkswirt Otmar Emminger $a b: ~ „ H e$ is probably the most balanced and intelligent of all the Germans in Paris (excepting Dr. von Mangoldt) und appears very capable and a hard worker." ${ }^{284}$ Obgleich die „Noten" für die übrigen deutschen Delegationsmitglieder nicht ganz so gut ausfielen und gelegentlich Kritik an dem einen oder anderen deutschen Sachverständigen in Paris

279 BICO/ERP Branch, ERP Situation Report v. 23. 4 1949, PRO, FO 371/76990; Niederschrift Sitzung ERP-Ausschuß v. 20. 4. 1949, BA, Z 14, 9. Die Vorsitzenden des Zweimächteamtes unterrichteten Pünder von der Neuregelung der Zuständigkeiten am 14. 4. 1949. Vgl. Working Party on Programme Control, Memorandum by the chairman v. 25. 4. 1949, IfZA, MF 260, 11/100-2/4-5. Versuche deutscher Delegierter, in ihrer Muttersprache zu reden, wurden allerdings von seiten der OEEC in Übereinstimmung mit dem amerikanischen Leiter der bizonalen Delegation sofort unterbunden; vgl. Vermerk Lintott v. 6. 5. 1949, HAEC, OEEC, 402.

280 Die Verhandlungen der Außenminister sind dokumentiert in FRUS 1949, III, S. 156-186; vgl. bes. Memorandum Achesons v. 8. 4. 1949, S. 175 f., und die Vereinbarung über die Zuständigkeiten der Drei Mächte nach der Gründung der Bundesrepublik gleichen Datums, S. 178f. Zu den Auswirkungen auf die ERP-Arbeiten und die Überleitung der Zuständigkeiten vgl. BICO an Control Commission for Germany (British Element) v. 20. 4. 1949, IfZA, MF 260, 11/100-2/4-5.

281 Weir an Nicholls v. 3. 5. 1949, PRO, FO 371/76937.

282 Report No. 43, PRO, FO 371/76938

${ }^{283}$ Bespr. Militärgouverneure mit bizonalen Vertretern v. 15. 7. 1949, AVBRD 5, Dok. 65A, S. 901.

${ }^{284}$ Report No. 47, PRO, FO 371/76938. Der Vorname lautet dort fälschlicherweise Otto. Emminger machte später Karriere bei der Bank deutscher Länder bzw. der Deutschen Bundesbank, deren Präsident er von 1977 bis 1979 war. Zu seiner Tätigkeit in Paris vgl. Otmar Emminger, D-Mark, Dollar, Währungskrisen. Erinnerungen eines ehemaligen Bundesbankpräsidenten, Stuttgart 1986, S. $46 \mathrm{ff}$. 
laut wurde, ${ }^{285}$ hielten Pünder und Schniewind an ihrer Personalpolitik fest. Einzig im Falle Werner Dankworts, der bis 1945 Botschaftsrat in Stockholm gewesen und nun als Stellvertreter von Mangoldts vorgesehen war, stießen sie damit auf ernsthaften, politisch motivierten Widerstand. Vermutlich war es jedoch weniger die frühere NSDAP-Mitgliedschaft des Deutschen, die als störend empfunden wurde - Dankwort „was a loyal German to the end but not a rabid Nazi“, bescheinigte ihm ein Angehöriger der britischen Botschaft in Stockholm -, sondern vielmehr seine berufliche Herkunft. Er zählte nämlich zu den wenigen Kandidaten - noch dazu für einen herausgehobenen Posten mit „Wilhelmstraßen-Vergangenheit", während die meisten anderen „Männer der ersten Stunde“ aus Industrie- und Bankkreisen stammten. Am Ende aber akzeptierten die anglo-amerikanischen Besatzungsbehörden diese Ernennung. ${ }^{286}$ Allerdings rieten sie ihren Gesprächspartnern aus der bizonalen Verwaltung, „in den nächsten Monaten“ zu überlegen, „ob man einzelne dieser Posten mit Herren noch größeren Formats besetzen könne, um eine den anderen Delegationen gleichwertige Besetzung in Paris zu haben. “287 $\mathrm{Da}$ die deutschen Behörden gleichzeitig eine Vertretung bei der ECA in Washington aufbauen mußten, die sich um die technische Abwicklung der Marshallplanlieferungen kümmern sollte, waren sie über diesen Rat sicherlich nicht gerade begeistert. ${ }^{288}$

Während die ERP-Verantwortlichen in den Militärregierungen in Personalangelegenheiten nur noch darauf achteten, daß die politischen Voraussetzungen für eine Tätigkeit in Paris erfüllt waren, versuchten sie den organisatorischen "takeover" genauer zu planen. Ein Memorandum vom 25. April 1949 listete die einzelnen erforderlichen Schritte auf. Das reichte von der offiziellen Unterrichtung der OEEC und der ECA über die provisorische Geschäftsordnung für die Übergangszeit bis hin zu Vorschlägen für den Aufbau einer adäquaten deutschen Organisation, deren Finanzierung und die Verfahren zur Bewältigung der Routinearbeiten. Besonderen Wert legten die alliierten Experten auf die Konzentration der ERP-Arbeiten in einem Ministerium und die politische Verantwortlichkeit des betreffenden Ministers. Solange noch keine deutsche Regierung existierte, d. h. solange die Vereinigten Staaten, Großbritannien und Frankreich bei der OEEC-Konvention und bei den bilateralen ERP-Abkommen Signatarmächte blieben, lag die Entscheidungskompetenz freilich noch bei den Militärgouverneuren: „The initial phase will be one of delegation, the Germans acting as the agents of Military Govern-

285 Vgl. die Reports No. 44 (Hans Christian Halter, stellv. Delegationssekretär), No. 45 (Horst-Kraft Robert, volkswirtschaftl. Referent), No. 46 (Otto Nack, Sekretariatsassistent), ebenda. Eine Liste der vorgesehenen Personen für die Pariser Delegation und das Büro in Frankfurt, datiert auf den 9. 3. 1949, in BA, Z 14, 106, Bl. 132. Zur Kritik an den deutschen Sachverständigen vgl. AVBRD 5, Dok. 65A, S. 901. BICO-Mitarbeiter bestätigten gegenüber Schniewind ausdrücklich, daß gegen die ständigen deutschen Mitglieder der Bizonalen Delegation keine Einwände bestünden: „alle seien sehr tüchtig, fleißig und von geschicktem Auftreten“. Vermerk Schniewind v. 28. 7. 1949, BA, Z 14, 75.

286 Zur Kontroverse um die Nominierung Dankworts vgl. mit mehreren Belegen, PRO, FO 371/76937. Das Zitat in Botschaft Stockholm an Foreign Office v. 7. 7. 1949, ebenda. In seinen ungedruckten Erinnerungen erwähnt Dankwort diese Schwierigkeiten nicht. Vgl. Fragmente aus einem Diplomatenleben 1920-1950, Dritter Teil: Aufbau mit dem Marshallplan, Politisches Archiv des Auswärtigen Amtes (künftig: PA AA), NL Dankwort. Werner Dankwort war von 1951 bis 1956 Generalkonsul bzw. Botschafter in Kanada, von 1956 bis 1958 Botschafter in Brasilien und von 1958 bis 1960 ständiger deutscher Beobachter bei den Vereinten Nationen.

287 Vermerk Schniewind v. 28. 7. 1949, BA, Z 14, 75.

${ }^{288} \mathrm{Vgl}$. Bührer, Auftakt, S. 549. Der Aufbau der Mission in Washington ist dokumentiert in BA, Z 14, 92, 93 u. 94. 
ment in this as in other spheres. " 289 Auf deutscher Seite, wo sich Mitglieder des ERPAusschusses ungefähr gleichzeitig ebenfalls darum bemühten, den rechtlichen Status der bizonalen Delegation während der Übergangszeit zu definieren, gelangte man mit der Formel, „daß das Mündel im Auftrag des Vormunds für sich selbst handele“, übrigens zu einer ziemlich ähnlichen Interpretation des Verhältnisses zwischen Besatzungsmächten und deutschen Stellen in Sachen Marshallplan. ${ }^{290}$ Dabei durfte der Spielraum Pünders, Schniewinds, von Mangoldts und der übrigen involvierten Beamten und Experten nach alliierter Auffassung nicht zu sehr eingeengt werden: „The Germans must be clearly made to feel that henceforth they have real responsibility and that they will be judged in Paris both as representatives and as individuals by the quality of the work which they produce and by the spirit in which they submit their case for scrutiny." Getreu der Maxime von der "smooth transition" sollten die Verantwortlichkeiten nach einem vierstufigen Schema übertragen werden: Nach der gemeinsamen Klärung der anstehenden Aufgaben und Probleme absolvierten deutsche Fachbeamte in den alliierten ERP-Abteilungen eine Art „Lehre“, ehe eigene, für eine bestimmte Zeit parallel arbeitende Abteilungen aufgebaut werden konnten. Am Ende dieses Prozesses sollten die Kompetenzen auf die deutsche Seite verlagert und ein ausreichender und regelmäßiger Informationsfluß sichergestellt werden. So hofften die alliierten Experten die Kontinuität der Planungsarbeiten und der Repräsentation bei der OEEC am besten gewährleisten zu können. ${ }^{291}$

$\mathrm{Da}$ in der Bizone bereits eine eingespielte ERP-Apparatur vorhanden war, sah Pünder keine Veranlassung, die Vorschläge des Zweimächteamtes aufzugreifen: „Grundsätzlich" werde die bisherige Organisation beibehalten, beschied er die alliierten Ratgeber, da sie sich bewährt habe und in ihrem Aufbau „ungefähr" der alliierten Organisation sowie der ERP-Verwaltung in Großbritannien entspreche. ${ }^{292}$ Die deutschen MarshallplanFachleute der französischen Zone, die zwar seit Frühjahr 1949 über ein eigenes Büro in Paris verfügten, aber von Anfang an auf eine enge Zusammenarbeit mit ihren Kollegen aus der Bizone Wert gelegt hatten und darin von französischer Seite mittlerweile auch bestärkt wurden, ${ }^{293}$ bereiteten sich auf die Mitarbeit in den bizonalen Instanzen vor und sahen ebenfalls keinen Grund, die organisatorische Struktur des Marshallplan-Apparates zu verändern. Schniewind warnte sogar ausdrücklich davor, den Behördenapparat in der französischen Besatzungszone im Hinblick auf die Übernahme der ERP-Aufgaben zu vergrößern, und bot dem Leiter der Baden-Badener Geschäftsstelle, Sachs, und Albrecht vom Koordinierungsausschuß an, in sein Amt überzuwechseln. ${ }^{294}$ Gehör fanden

289 Working Party on Programme Control, Memorandum by the Chairman v. 25. 4. 1949, IfZA, MF 260, 11/100-2/4-5.

290 Niederschrift Sitzung ERP-Ausschuß v. 20. 4. 1949, BA, Z 14, 9.

291 Vgl. Memorandum v. 25. 4. 1949 (wie Anm. 288) und BICO-Memorandum v. 3. 5. 1949, beide IfZA, MF 260, 11/100-2/4-5.

292 Pünder an BICO v. 20.6. 1949 (Entwurf), BA, Z 14, 99. Das Antwortschreiben in Englisch, datiert auf den 20. 7. (!) 1949, in IfZA, MF 260, 11/100-2/4-5.

${ }^{293}$ Vgl. zur Einrichtung des Büros Compte-Rendu Mitzakis v. 25. 2. 1949 und Fiche pour le Commandant en Chef Français en Allemagne v. 9. 3. 1949, beide AO, AffEcofin, Carton 2, Dossier 3000A: Plan Marshall; Sachs an Rieck v. 25. 3. 1949, Z 14, 156. In der zweiten Aprilhälfte sprachen sich maßgebliche Angehörige der französischen Militärregierung für die Herstellung „ $d$ ' une étroite liaison entre les représentations à l' O.E.C.E. de la Zone française et de la Bizone" aus. Fiche Leroy-Beaulieu v. 23. 4. 1949, AO, EcoIA5d.

${ }^{294}$ Schniewind an Sachs v. 6. 5. 1949, Sachs an Rieck v. 2. 5. 1949, beide in BA, Z 14, 156. 
hingegen in Baden-Baden und in Frankfurt die auf die Spitze dieses Apparates zielenden alliierten Anregungen. Karl Albrecht machte sich beispielsweise bereits „Gedanken über die Zweckmäßigkeit eines besonderen Außenhandelsministeriums "295, bei dem neben dem Konsularwesen, der Handels- und Zollpolitik sowie der Regelung des internationalen Zahlungsverkehrs auch die im Rahmen des Europäischen Wiederaufbauprogramms anfallenden Aufgaben ressortieren sollten. In die gleiche Richtung zielten Überlegungen aus der Umgebung Pünders, ein Ministerium für zwischenstaatliche Angelegenheiten bzw. ausschließlich für den Marshallplan zu bilden. Man dürfe nicht übersehen, hieß es in der Begründung für letzteren Vorschlag, „daß der Marshallplan im Augenblick in politischer und wirtschaftlicher Hinsicht das Gebilde“ sei, von dem „der größte Einfluß auf Existenz und Zielrichtung der westdeutschen Bundesrepublik" ausgehe; deshalb sei es vollauf gerechtfertigt, "mit der Durchführung dieser in ihren Ausstrahlungen so wichtigen Aufgaben einen besonderen Minister zu beauftragen“. ${ }^{296}$

Unterdessen waren, auf der Ebene der direkt involvierten alliierten und deutschen Stellen, die Überleitungsbemühungen fortgesetzt worden. Das Zweimächteamt war mit den dabei in Frankfurt, bei den "Stammbehörden“, erzielten Fortschritten unzufrieden, und diese Unzufriedenheit resultierte nicht zum geringsten Teil daraus, daß die deutsche Seite die alliierten Ratschläge weitgehend ignoriert hatte. Die Vertreter des anglo-amerikanischen ERP-Sekretariats empfahlen deshalb noch einmal dringend, deutsche Beamte etwa zwei Monate lang am Bürobetrieb des Zweimächtekontrollamtes teilnehmen zu lassen, damit sie sich dort mit den Verfahren und Arbeitsweisen vertraut machen konnten. ${ }^{297}$

Schwierigkeiten praktischer Art bereitete aber auch der personelle Wechsel in der Bizonalen Delegation. Als bekannt wurde, daß mit den Amerikanern White und Barlerin sowie dem Engländer Jackson der Leiter, sein Stellvertreter sowie eines der kompetentesten Mitglieder der Delegation etwa gleichzeitig Ende Juli ausscheiden würden, stellte sich mit einem Mal die Frage, ob die Deutschen schon vor der Konstituierung der Bundesregierung und dem offiziellen Beitritt die Pariser Vertretung in eigener Verantwortung übernehmen sollten. Zwar wurden auch Stimmen laut, die für einen raschen, radikalen Schritt plädierten - „the sooner the Bizonal Delegation becomes entirely German the better" 298 - doch überwogen die Stellungnahmen zugunsten der Erhaltung der alliierten Präsenz und Entscheidungskompetenz bis zum offiziellen Beitritt der im Entstehen begriffenen Bundesrepublik. Es waren im wesentlichen zwei Gründe, welche für die Verfechter eines graduellen Übergangs ausschlaggebend waren: Aus der Sicht der Verantwortlichen in den Militärregierungen, aber auch in der OEEC, mußte vermieden werden, daß die Delegation in der Phase des Wechsels ohne klare Direktiven blieb; ein solcher Zustand hätte möglicherweise den Entscheidungsprozeß innerhalb der OEEC in einer kritischen Phase, nämlich der Vergabe der Mittel für das Jahr 1949/50, blokkiert. ${ }^{299}$ Die Deutschen wiederum befürchteten, bei diesem Gerangel um möglichst hohe

\footnotetext{
295 So der Titel seiner Aufzeichnung v. 7. 6. 1949, BA, Z 14, 99.

${ }^{296}$ Aufzeichnung Martini v. 26. 9. 1949, ebenda. Der Vorschlag zur Errichtung eines zwischenstaatlichen Ministeriums stammte von Johannes von Elmenau; Vgl. Vermerk v. 31. 8. 1949, BA, NL Pünder, 718. 297 Vermerk Rieck v. 29.6. 1949, BA, Z 14, 99.

298 Stevens an Weir v. 19. 7. 1949, PRO, FO 371/76937.

${ }^{299}$ Dies beispielsweise die Befürchtung Marjolins, vgl. ebenda.
} 
Quoten ohne alliierten Beistand chancenlos zu sein. ${ }^{300}$ Marjolin schaltete deswegen sogar den designierten US-Hochkommissar und ECA-Missionschef für Westdeutschland, McCloy, ein. Die Spitzen der Militärregierungen in Berlin kamen daraufhin überein, bis zum endgültigen Auszug dafür Sorge tragen zu wollen, daß erfahrene alliierte Beamte in ausreichender Zahl in der Delegation verblieben. ${ }^{301}$ Die deutschen Sorgen zerstreuten Mitarbeiter des Zweimächteamtes mit dem Versprechen, White oder ein anderes einflußreiches Delegationsmitglied würden bis nach Abschluß der Verhandlungen über die Aufteilung der Mittel in Paris bleiben: Bemerkenswerterweise begründeten sie diesen Entschluß nicht nur damit, „daß die Bizone ohne alliierte Unterstützung einen schweren Stand haben würde“, sondern auch mit der ein erstaunliches Maß an Fürsorge verratenden Überlegung, "daß es ein schlechter Start sei, gleich Geld zu verlangen“. ${ }^{302}$

Nachdem dieses Problem somit zu aller Zufriedenheit gelöst war und mit dem Amerikaner Martin Tank, welcher der Bizonalen Delegation fast von Anfang an angehört hatte, und dem Briten Robert Brayne vorsorglich zwei alliierte Beamte bestimmt worden waren, die, falls erforderlich, Leitungsfunktionen übernehmen sollten, ${ }^{303}$ begannen auf deutscher Seite die letzten Vorbereitungen zur Übernahme der Delegationsaufgaben. Ein bereits im Mai erstellter Voranschlag der jährlichen Gehälter und Tagegelder für die Pariser Vertretung war für stattliche 26 Stellen auf rd. 285000 DM gekommen. ${ }^{304}$ Hans Karl von Mangoldt nahm Ende Juli, merklich bescheidener, eine provisorische Geschäftsverteilung für seine beiden Mitarbeiter vor. ${ }^{305}$ Er selbst versuchte offenbar, sich aus der täglichen Routinearbeit herauszuhalten, um genügend Zeit für politisch-diplomatische Aktivitäten zu haben.

Ein weiteres Problem, das noch gelöst werden mußte, war eine angemessene Unterkunft. Die bizonale Delegation war bis dahin in einem Hotel untergebracht, doch lehnte von Mangoldt diese Art der Unterbringung auf die Dauer als ungeeignet und zu kostspielig ab. Schon seit Anfang 1949 waren die Deutschen deshalb auf der Suche nach einem besseren Quartier. Der Rückgriff auf ehemaligen Grundbesitz des Deutschen Reiches, den von Mangoldt zunächst ins Auge gefaßt hatte, erschien ihm dann doch noch verfrüht, den Einzug in die ehemalige deutsche Botschaft hielt er „psychologisch nicht für richtig“. ${ }^{306}$ Die Wahl fiel schließlich auf ein Objekt in der Rue Léonard de Vinci. ${ }^{307}$

Unterdessen war die Einarbeitung der deutschen Mitarbeiter in Paris und Frankfurt offenbar gut vorangekommen, denn nach der Auflösung des Zweimächtekontrollamtes Ende September vereinbarten alliierte und deutsche Stellen eine $Z$ wischenregelung, die bis zur Aufnahme der Bundesrepublik in die OEEC gelten sollte. Darin wurden die deutschen Zuständigkeiten noch einmal erweitert: So sollten beispielsweise an den Aus-

$300 \mathrm{Vgl}$. v. Mangoldt an Martini v. 14. 7. 1949, BA, Z 14, 75.

301 Brit. Militärregierung an Foreign Office v. 22. 7. 1949, PRO, FO 371/76937.

302 Rieck an v. Mangoldt v. 21. 7. 1949, BA, Z 14, 75.

303 Brit. Militärregierung an Foreign Office v. 21. 7. 1949, PRO, FO 371/76937.

304 Aufzeichnung v. 21. 5. 1949, BA, Z 14, 75.

305 Danach war Hans Christian Halter zuständig für die Sitzung der OEEC-Ausschüssc, die Betreuung der angereisten Sachverständigen, den Schriftwechsel mit der OEEC, das deutsche Personal bei der OEEC und die wöchentliche Berichterstattung. Otto Nack oblag die organisatorische Vorbereitung der Ausschußsitzungen, der Schriftverkehr mit dem Zweimächteamt und dem Berater für den Marshallplan sowie die Pressearbeit; v. Mangoldt an Martini v. 26. 7. 1949, ebenda.

306 v. Mangoldt an Martini v. 12. 5. 1949, BA, Z 14, 79.

307 Vermerk Martini v. 22. 6. 1949 u. Martini an Bizonale Delegation v. 16. 9. 1949, ebenda. Die deutsche Vertretung bei der OECD residiert noch heute in diesem Haus. 
schußsitzungen nur noch deutsche Vertreter teilnehmen; Delegation und Stammbehörde sollten direkt, ohne Umweg über eine alliierte Stelle, miteinander verkehren können; offizielle Erklärungen an die Adresse der OEEC bedurften allerdings noch der $\mathrm{Zu}$ stimmung der Alliierten Hohen Kommission. ${ }^{308}$ Die praktische ERP-Arbeit leisteten damit nur noch Deutsche. Um alle diese Aufgaben bewältigen zu können, mußte die Personalausstattung der Pariser Delegation deutlich verbessert werden. Ein neuer Stellenplan vom 4. Oktober 1949 sah 33 Mitarbeiter vor und übertraf damit noch den Voranschlag vom Mai. Die Delegation war auf der Leitungsebene zunächst überwiegend mit Angehörigen der ehemaligen bizonalen Vertretung besetzt. Einzig Theodor Axenfeld wurde von der Delegation der französischen Zone übernommen. ${ }^{309}$

Verglichen mit den Anfängen deutscher Interessenvertretung in Paris im Sommer 1948, als deutsche Experten höchstens am „Katzentisch“ an den Verhandlungen teilnehmen durften, verglichen selbst mit dem Frühjahr 1949, als ihre Kompetenzen allmählich ausgeweitet wurden, hatte die Delegation damit enorm an Bedeutung gewonnen. Dies war zum Teil sicherlich auch das Verdienst Hans Karl von Mangoldts - des ersten mit einer Tätigkeit im Ausland beauftragten Deutschen, wie er sich selber stolz charakterisierte $^{310}$ - und seiner Mitarbeiter. Es ist gewiß müßig, darüber zu spekulieren, was diese außenpolitischen "Pioniere“ des "neuen Deutschland“ alles hätten verkehrt machen müssen, um die „smooth transition“ zu gefährden - daß es eine ganze Reihe von „Fettnäpfchen“ gab, steht jedoch außer Frage. Zumindest das Tempo und die Reibungslosigkeit, mit der die Überleitung vonstatten ging, waren deshalb dem Pariser Team und der Stammbehörde in Frankfurt zu verdanken. Allerdings war die Toleranzbereitschaft der Westmächte, dies sollte bei allem Lob für individuelles Geschick und persönlichen Einsatz nicht übersehen werden, doch in erster Linie davon abhängig, welche Rolle sie Westdeutschland zugestehen wollten.

\footnotetext{
308 Vgl. Aktennotiz v. Mangoldt v. 29. 9. und Sachs v. 30. 9. 1949, BA, Z 14, 99.

${ }^{309}$ Geschäftsverteilung für die Vertretung der Bundesrepublik Deutschland bei der OEEC v. 4. 10. 1949, BA, Z 14, 75. Einer Liste des OEEC-Generalsekretariats v. 3. 11. 1949 zufolge zählte die Delegation, Büropersonal ausgenommen, 10 Personen; vgl. SGD (49) 96, HAEC, OEEC, 402. 310 v. Mangoldt an Pünder v. 11. 8. 1949, BA, NL Pünder, 704.
} 